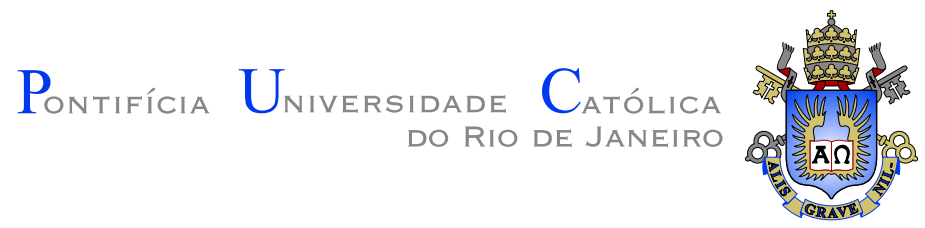

Eric Mauricio González Fontalvo

Avaliação da Pressão Dinâmica no Modelo de Dois Fluidos Unidimensional Aplicado ao Escoamento Anular Vertical

Dissertação de Mestrado

Dissertação apresentada como requisito parcial para obtenção do grau de Mestre pelo Programa de Pós-graduação em Engenharia Mecânica do Centro Técnico Científico da PUC-Rio .

Orientador Prof. Angela Ourivio Nieckele Co-Orientador: Dr. João Neuenschwander Escosteguy Carneiro 

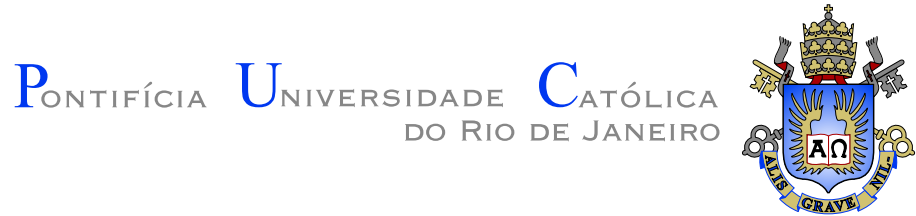

Eric Mauricio González Fontalvo

\section{Avaliação da Pressão Dinâmica no Modelo de Dois Fluidos Unidimensional Aplicado ao Escoamento Anular Vertical}

Dissertação apresentada como requisito parcial para obtenção do grau de Mestre pelo Programa de Pós-graduação em Engenharia Mecânica do Centro Técnico Científico da PUC-Rio . Aprovada pela Comissão Examinadora abaixo assinada.

Prof. Angela Ourivio Nieckele

Orientador

Departamento de Engenharia Mecânica - PUC-Rio

Dr. João Neuenschwander Escosteguy Carneiro

Co-Orientador

SINTEF do Brasil

Prof. Jader R. Barbosa Jr.

UFSC

Dr. Igor Braga

Departamento de Engenharia Mecânica - PUC-Rio

Prof. Márcio da Silveira Carvalho

Coordenador Setorial do Centro Técnico Científico - PUC-Rio 
Todos os direitos reservados. É proibida a reprodução total ou parcial do trabalho sem autorização da universidade, do autor e do orientador.

\section{Eric Mauricio González Fontalvo}

Possui graduação em Engenharia Química pela Universidad Industrial de Santander (2013). Realizou intercâmbio acadêmico na graduação na PUC-Rio durante o segundo período de 2012.

Ficha Catalográfica

Fontalvo, Eric Mauricio González

Avaliação da Pressão Dinâmica no Modelo de Dois Fluidos Unidimensional Aplicado ao Escoamento Anular Vertical / Eric Mauricio González Fontalvo; orientador: Angela Ourivio Nieckele; co-orientador: João Neuenschwander Escosteguy Carneiro. - 2016.

97 f.: il. color. ; $30 \mathrm{~cm}$

Dissertação (mestrado) - Pontifícia Universidade Católica do Rio de Janeiro, Departamento de Engenharia Mecânica, 2016.

Inclui bibliografia.

1. Engenharia Mecânica - Teses . 2. Pressão dinâmica. 3. Modelo de Dois Fluidos 1D. 4. Escoamento Anular Vertical. I. Nieckele, Angela Ourivio. II. Carneiro, João Neuenschwander Escosteguy. III. Pontifícia Universidade Católica do Rio de Janeiro. Departamento de Engenharia Mecânica. IV. Título. 
Dios, gracias a Él todo es posible. Mi familia, papá, mamá y hermanos, siendo siempre mi admiración, respeto y mi apoyo incondicional para cualquier objetivo que me propongo. A Fabio por su incondicional apoyo y respaldo. 


\section{Agradecimentos}

Á Prof. Angela Ourivio Nieckele, primeiramente pela amizade, orientação e o valioso conhecimento transmitido durante todo o desenvolvimento do trabalho; grande admiração em sua disposição de ensinar e exigir o melhor de mim.

Ao meu co-orientador João Neuenschwander Escoteguy Carneiro, pelo valioso tempo dedicado, os conhecimentos prestados e a grande experiência de ter trabalhado em conjunto com você.

Ao Prof. Igor Braga pela grande ajuda no programa de pós-processamento de frequências e velocidade da estrutura.

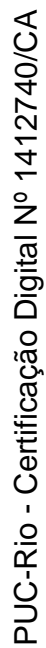

Ao Prof. Jader Barbosa, por ter aceito participar na banca examinadora e acrescentar com recomendações o conteúdo deste trabalho.

Agradecimentos em particular a PUC-Rio e aos órgãos de fomento à pesquisa CNPq, e CAPES. 


\section{Resumo}

Fontalvo, Eric Mauricio González ; Nieckele, Angela Ourivio; Carneiro, João Neuenschwander Escosteguy. Avaliação da Pressão Dinâmica no Modelo de Dois Fluidos Unidimensional Aplicado ao Escoamento Anular Vertical. Rio de Janeiro, 2016. 97p. Dissertação de Mestrado - Departamento de Engenharia Mecânica, Pontifícia Universidade Católica do Rio de Janeiro.

Uma análise numérica de escoamento anular vertical ascendente é realizada utilizando o Modelo de Dois Fluidos unidimensional. Para escoamentos verticais, na ausência de mecanismos estabilizadores, o sistema de equações resultante é incondicionalmente mal posto. Dessa forma, visando tornar o sistema de equações bem posto, adicionou-se às equações de quantidade de movimento um termo de pressão dinâmica. Dois modelos disponíveis na literatura são investigados. O primeiro só considera a pressão dinâmica na equação de quantidade de movimento do líquido, a qual é baseada em uma simples expressão para a velocidade da onda na interface. O segundo modelo inclui uma contribuição da pressão dinâmica em ambas equações de quantidade de movimento. No presente trabalho, um terceiro modelo é proposto, o qual é baseado no primeiro modelo, com uma avaliação mais realista da velocidade da onda na interface. O efeito estabilizante da pressão dinâmica é demonstrado através de um rigoroso teste de convergência de malha. As equações de conservação são discretizadas com o método de volumes finitos, com uma integração temporal de primeira ordem e uma discretização espacial TVD de segunda ordem. Tanto o segundo quanto o terceiro modelo considerados apresentaram solução independente da malha. Parâmetros do escoamento como gradiente de pressão, espessura do filme, e variáveis características da onda obtidos numericamente são comparados com dados experimentais disponíveis na literatura, apresentando boa concordância.

\section{Palavras-chave}

Pressão dinâmica; Modelo de Dois Fluidos 1D; Escoamento Anular Vertical; 


\section{Abstract}

Fontalvo, Eric Mauricio González ; Nieckele, Angela Ourivio (Advisor); Carneiro, João Neuenschwander Escosteguy (Co-Advisor). Assessment of the Dynamic Pressure Closure in 1D Two-Fluid Model for Vertical Annular Flow. Rio de Janeiro, 2016. 97p. MSc. Dissertation - Departamento de Engenharia Mecânica, Pontifícia Universidade Católica do Rio de Janeiro.

A numerical analysis of vertical ascending annular flow with the 1D Two-Fluid model is performed. It is well known that, in vertical flows, the resulting system of equations is unconditionally ill-posed in the absence of stabilizing mechanisms. Therefore, in the present work, to render the system of equations well-posed, modeling of dynamic pressure is included in the momentum equations. Two models available in the literature are examined. The first one only considers the dynamic pressure in the liquid momentum equation, which is based on a simple expression for the interface wave velocity. The second model includes a dynamic pressure contribution to both momentum equations. A third model is proposed based on the first, with a more realistic estimation of the interface wave velocity. A systematic grid convergence test is performed to demonstrate the stabilizing effect of the dynamic pressure. The conservation equations are discretized with the finite volume method, with a first order time integration, and a second order TVD spatial discretization. A grid-independent solution can be found when applying the second and third models considered. Flow parameters such as pressure drop, film thickness and wave characteristics numerically obtained are compared against available experimental data, presenting good agreement.

\section{Keywords}

Dynamic Pressure; 1D Two-Fluid Model; Vertical Annular Flow; 


\section{Sumário}

$1 \quad$ Introdução $\quad 15$

1.1 Padrões de Escoamento Bifásico Gás-Líquido 16

$\begin{array}{lll}1.2 & \text { Revisão Bibliográfica } & 18\end{array}$

$\begin{array}{ll}\text { Características do escoamento bifásico } & 18\end{array}$

Simulação numérica do escoamento bifásico $\quad 21$

$\begin{array}{lll}1.3 \text { Objetivo } & 24\end{array}$

$\begin{array}{lll}1.4 & \text { Organização do trabalho } & 24\end{array}$

2 Modelo Matemático $\quad 25$

2.1 Modelo de Dois Fluidos 25

2.2 Relações de Fechamento 28

Parâmetro de fluxo de quantidade de movimento 28

$\begin{array}{ll}\text { Parâmetros geométricos } & 29\end{array}$

Tensões cisalhantes $\quad 30$

Pressão 31

2.3 Condições de Contorno e Inicial 35

2.4 Grandezas Características do Escoamento Anular 35

Frequências $\quad 35$

$\begin{array}{ll}\text { Velocidade da estrutura } & 37\end{array}$

3 Análise da Hiperbolicidade do Modelo de Dois Fluidos 40

3.1 Modelo 1

3.2 Modelo $2 \quad 45$

3.3 Modelo $3 \quad 46$

4 Método Numérico $\quad 49$

4.1 Fração Volumétrica de Gás 50

Esquema espacial TVD

4.2 Velocidades $\quad 52$

$\begin{array}{lll}4.3 & \text { Pressão } & 55\end{array}$

4.4 Tratamento na Região das Fronteiras 57

4.5 Critérios para Espaçamento da Malha e Passo de Tempo 58

4.6 Critério de Convergência 59

4.7 Procedimento de Execução 59

5 Resultados $\quad 61$

5.1 Seleção de Casos $\quad 61$

5.2 Avaliação da Hiperbolicidade das Equações 64 Teste de malha $\quad 66$

5.3 Avaliação do Esquema Espacial TVD 69

5.4 Parâmetros Característicos do Escoamento Anular 70

Pressão $\quad 71$

Espessura do filme e frequência $\quad 73$

Velocidade da estrutura $\quad 83$ 
6 Comentários Finais $\quad 89$

6.1 Sugestão para Trabalhos Futuros 91

7 Referências Bibliográficas $\quad 92$ 


\section{Lista de Figuras}

1.1 Esquema de um campo de produção de petróleo off-shore. (PETROBRAS, 2016)

1.2 Padrões de escoamento bifásico horizontal (Ghajar \& Tang, 2010) 16

1.3 Padrões de escoamento bifásico vertical ascendente (Ghajar \& Tang, 2010)

2.1 Geometria do escoamento anular.

2.2 Representação do cálculo de frequência mediante a contagem de ondas de grande amplitude em um determinado intervalo de tempo 36

2.3 Espectro de frequências e PSD para um sinal temporal de altura do filme

2.4 Ilustração de uma correlação cruzada aplicada para uma série temporal

2.5 Velocidade da onda em função da distância entre as sondas.

4.1 Arranjo da malha. a)Volume de controle escalar. b)Volume de controle vetorial

4.2 Fronteiras das malha. a)Volume de controle escalar. b)Volume de controle vetorial

5.1 Velocidades superficiais criticas de líquido e gás (Zhao et al., 2013). 63

5.2 Velocidades superficiais criticas de líquido e gás (Kaji, 2008).

5.3 Limite entre bem/mal posto para Modelo 1 variando $D_{L}$ (Zhao et al., 2013)

5.4 Limite entre bem/mal posto para Modelo 3 (Zhao et al., 2013)

5.5 Limite entre bem/mal posto para Modelo 3 (Kaji, 2008)

5.6 Teste de malha para Caso A

5.7 Teste de malha para Caso B utilizando Modelo 2 e Modelo 3.

5.8 Influência do esquema de discretização espacial (1a. ordem upwind e 2a. ordem TVD) no gradiente de pressão e frequência PSD. Caso A. (Zhao et al., 2013).

5.9 Comportamento da pressão no tempo. Caso A. Zhao et al. (2013) 71

5.10 Comportamento da pressão na coordenada axial. Caso A. Zhao et al. (2013)

5.11 Comparação entre gradiente de pressão experimental e numérico

5.12 Gradiente de pressão em função da velocidade superficial do gás

5.13 Representação tridimensional da interface gás-líquido. Configuração I (Zhao et al. (2013)). Caso A.

5.14 Representação tridimensional da interface gás-líquido. Configuração II (Wolf et al. (2001)). Caso C.

5.15 Representação tridimensional da interface gás-líquido. Configuração III (Kaji (2008)). Caso B.

5.16 Comparação entre espessura média do filme experimental e numérica 77

5.17 Comparação entre espessura média do filme experimental e numérica em função da velocidade superficial de gás, para diferentes $R e_{s L} .78$ 
5.18 Evolução temporal da espessura de filme de líquido local adimensional, $h_{L}$ Configuração I. Caso A. (Zhao et al., 2013).

5.19 Evolução temporal da espessura de filme de líquido local adimensional, $h_{L}$ Configuração II. (Wolf et al., 2001).

5.20 Evolução temporal da espessura de filme de líquido local adimensional, $h_{L}$ Configuração III. Caso B. (Kaji, 2008).

5.21 Desenvolvimento da espessura do filme ao longo da direção axial

5.22 Power spectral densities (PSD) do sinal de espessura do filme para diferentes coordenadas axiais. Caso A.

5.23 Desenvolvimento das frequências ao longo da direção axial. Caso A. (Zhao et al., 2013).

5.24 Comparação entre Frequência das Ondas Grandes experimental $\times$ numérica para os Modelos 2 e 3

5.25 Comparação entre Frequência PSD experimental $\times$ numérica para os Modelos 2 e 3

5.26 Comparação entre Frequência PSD experimental e numérica em função da velocidade superficial do gás

5.27 Comparação entre velocidade da estrutura experimental e numérica 85

5.28 Velocidade da estrutura em função da velocidade superficial de gás 85

5.29 Velocidade de deslocamento das ondas em função da velocidade do filme de líquido 


\section{Lista de Tabelas}

2.1 Formulações para Pressão Dinâmica 34

5.1 Casos selecionados 64

5.2 Propriedades dos fluidos. 64

$\begin{array}{lll}5.3 \text { Reynolds Superficiais } & 77\end{array}$

5.4 Queda de Pressão 86

5.5 Filme de líquido $\quad 87$

5.6 Dados de Frequência das Ondas Grandes 87

$\begin{array}{lll}\text { 5.7 Dados de Frequência PSD } & 87\end{array}$

5.8 Dados de Velocidade da Estrutura 88 


\section{Lista de Símbolos}

A Área da seção transversal da tubulação, $\left[\mathrm{m}^{2}\right]$

$C$ parâmetro de fluxo de quantidade de movimento, [-]

$D \quad$ Diâmetro interno da tubulação, $[\mathrm{m}]$

$D_{h} \quad$ diâmetro hidráulico, $[\mathrm{m}]$

$F$ força de atrito por unidade de volume, $[\mathrm{Pa} / \mathrm{m}]$

$g \quad$ aceleração da gravidade, $\left[\mathrm{m} / \mathrm{s}^{2}\right]$

$h_{L} \quad$ altura da superfície do líquido, $[\mathrm{m}]$

L Comprimento da tubulação, [m]

$N_{\sigma} \quad$ Fator de tensão superficial, [-]

$N_{\mu} \quad$ Número de viscosidade, [-]

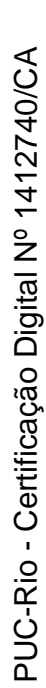

$P \quad$ Pressão, $[\mathrm{Pa}]$

$R_{g} \quad$ constante do gás, $\left[\mathrm{m}^{2} / \mathrm{s}^{2} \mathrm{~K}\right]$

$S \quad$ perímetro molhado ou interfacial, $[\mathrm{m}]$

$T$ temperatura, $[\mathrm{K}]$

$t \quad$ tempo, $[\mathrm{s}]$

$U \quad$ velocidade, $[\mathrm{m} / \mathrm{s}]$

$u_{e} \quad$ velocidade da estrutura, $[\mathrm{m} / \mathrm{s}]$

$U_{\text {onda }}$ velocidade da onda, $[\mathrm{m} / \mathrm{s}]$

$U_{s k} \quad$ velocidade superficial da fase , $[\mathrm{m} / \mathrm{s}]$

$W_{f k} \quad$ Parâmetro empírico, [-]

$x \quad$ coordenada axial, $[\mathrm{m}]$

Re número de Reynolds, [-]

\section{Símbolos gregos}

$\alpha \quad$ fração volumétrica da fase, [-]

$\rho \quad$ massa específica, $\left[\mathrm{kg} / \mathrm{m}^{3}\right]$

$\beta$ ângulo de inclinação da tubulação com respeito à horizontal, [o]

$\Delta \quad$ variação de uma grandeza, [-]

$\mu \quad$ viscosidade dinâmica, $[\mathrm{Pa} \mathrm{s}]$ 
$\nu$ frequência, $[\mathrm{N} / \mathrm{m}]$

$\sigma \quad$ tensão superficial, $[\mathrm{N} / \mathrm{m}]$

$\tau \quad$ tensão de cisalhamento, $[\mathrm{Pa}]$

\section{Subscritos}

E referente ao centro do volume de controle escalar a leste

$G \quad$ fase gás

$i \quad$ interface

$k \quad$ referente à fase gás ou líquido

L fase líquido

$O G \quad$ Ondas Grandes

$P \quad$ centro do volume de controle principal

$W \quad$ referente ao centro do volume de controle escalar a oeste

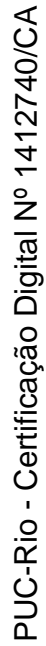

$w \quad$ parede

e,w faces leste e oeste do volume de controle principal

PSD referente ao Power Spectral Density 


\section{Introdução}

Escoamentos multifásicos consistem no escoamento simultâneo de duas ou mais fases (gás, líquido ou sólido) separadas por uma interface definida. Em um sistema multifásico pode existir interação química entre as fases, como por exemplo no escoamento de água e vapor de água ou de petróleo e gás natural; ou sem interação química, por exemplo, no escoamento óleo-água.

Escoamentos multifásicos são encontrados em diversas aplicações industriais: processos biológicos, geração de energia convencional e nuclear, torres de destilação e, de particular interesse ao presente trabalho, nos sistemas de produção offshore de óleo e gás através de tubulações que podem se estender por quilômetros a partir dos poços produtores até as plataformas de processamento (Fig. 1.1).

O conhecimento detalhado e capacidade de previsão do escoamento multifásico através das tubulações é de fundamental importância para o dimensionamento das instalações e equipamentos, além de tornar algumas situações operacionais mais eficientes e seguras.

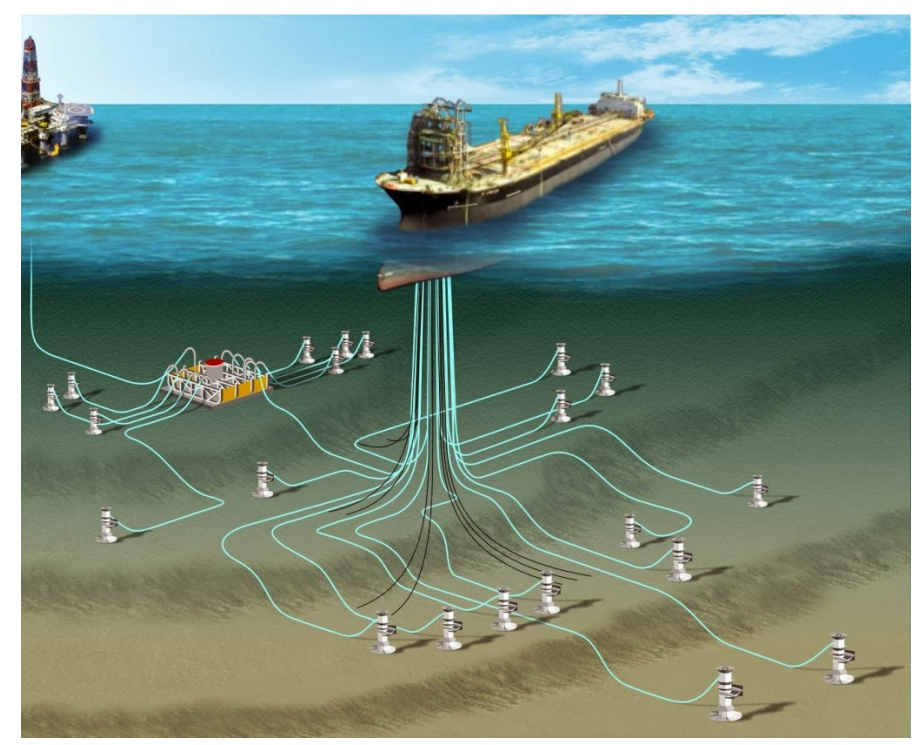

Figura 1.1: Esquema de um campo de produção de petróleo off-shore. (PETROBRAS, 2016) 


\section{1}

\section{Padrões de Escoamento Bifásico Gás-Líquido}

Uma das principais dificuldades do escoamento bifásico deve-se ao fato de que a geometria do escoamento é desconhecida a priori. Assim, a depender da geometria da tubulação (dimensão, inclinação), condições de operação (vazão, pressão, temperatura) e das propriedades dos fluidos (densidade, viscosidade e tensão superficial), as fases podem se arranjar de diversas formas ou padrões, cada uma com características distintas.

Observando as Figs. 1.2 e 1.3, referentes às configurações horizontal e vertical, respectivamente, no escoamento bifásico gás-líquido, os padrões que podem ser encontrados são:

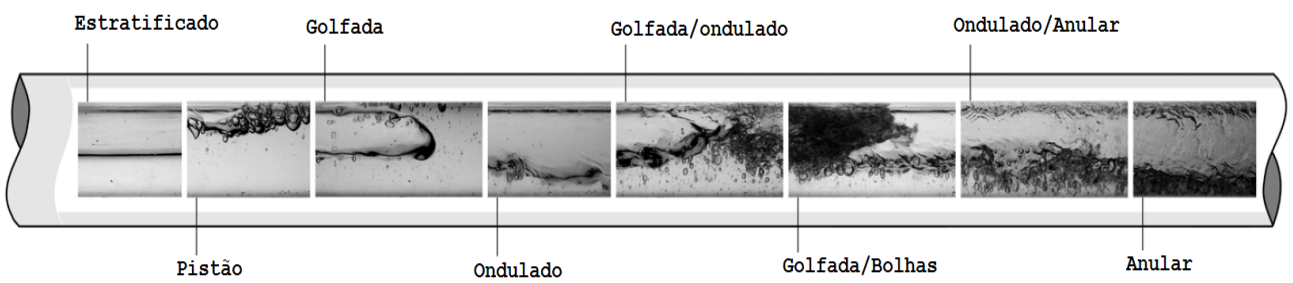

Figura 1.2: Padrões de escoamento bifásico horizontal (Ghajar \& Tang, 2010)

\section{Padrões de escoamento em tubulação horizontal}

- Bolhas dispersas: Ocorre a altas vazões de líquido. O líquido é a fase contínua, enquanto o gás se encontra disperso como pequenas bolhas, as quais variam de tamanho e forma, porém de um diâmetro muito menor do que a tubulação, e se concentram principalmente próximo à parede superior da mesma.

- Estratificado: Ocorre a baixas vazões de gás e líquido. Devido a efeitos gravitacionais, as fases são separadas em duas camadas, onde a fase gasosa escoa por cima da camada de líquido, ambas separadas por uma suave interface.

- Ondulado: Com incremento da vazão do gás, a força de cisalhamento incrementa causando ondas na interface.

- Pistão: Bolhas alongadas de gás escoam no topo da tubulação e acima da fase líquida.

- Golfada: As grandes bolhas de gás escoam alternadamente com pacotes líquido em frequência aleatórias. Parte do gás encontra-se no pistão de líquido em forma de bolhas dispersas. 
- Anular: Para altas vazões de gás, o líquido forma um filme assimétrico ao redor da circunferência da tubulação enquanto o gás concentra-se na parte central, que também pode conter gotas de líquido dispersas.

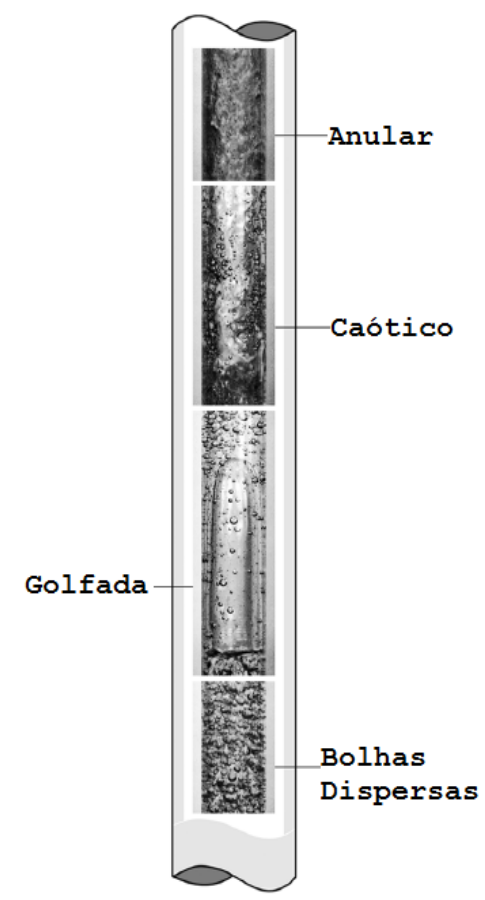

Figura 1.3: Padrões de escoamento bifásico vertical ascendente (Ghajar \& Tang, 2010)

\section{Padrões de escoamento em tubulação vertical}

- Bolhas: De igual forma que para o escoamento horizontal, o gás constitui a fase dispersa composta de pequenas bolhas distribuídas mais uniformemente na fase líquida contínua.

- Golfada: Caracterizado pela alternância de pacotes de líquido com pequenas bolhas de gás dispersas, e largas bolhas de Taylor, ao redor do qual escoa um filme de líquido.

- Agitado: Se produz com um incremento na velocidade superficial do gás, o qual gera um escoamento altamente caótico e intermitente, com alternância de fluxo ascendente e descendente.

- Anular: O gás ascende como uma fase contínua no centro da tubulação e o líquido escoa co-corrente ou contracorrente com o gás, como um filme que rodeia a circunferência do duto e separa a fase gasosa da parede. Um parte da distribuição do líquido encontra-se como gotículas no núcleo do gás. 
As diversas características e a complexa interação entre as diversas fases escoando na tubulação representam grandes desafios relativos à modelagem matemática para descrever e prever rigorosamente cada fenômeno.

Nesta dissertação o regime de escoamento de interesse é o anular para tubulações verticais. Este padrão de escoamento é extremamente relevante para situações em que a vazão de gás é elevada, como por exemplo para poços com alta RGO (razão gás-óleo, a qual representa a razão entre as vazões de gás e líquido), nas seções finais da coluna de produção e risers. Em poços de gás, a corrente gasosa vem usualmente acompanhada de uma mistura líquida contendo condensado, e possivelmente óleo e/ou água, em escoamento tipicamente no padrão anular no início de sua vida produtiva.

Um dos principais desafios ao operar poços de gás se dá principalmente com o declínio da pressão de operação. Como consequência da diminuição da vazão de gás, há o risco de que as forças de arrasto (pela corrente gasosa) não sejam suficientes para vencer a ação das forças gravitacionais sobre o filme de líquido, podendo acumular no fundo da coluna e, numa situação crítica, inclusive causar o bloqueio do poço (fenômeno conhecido como liquid loading - Belt et al., 2010; Waltrich et al., 2013). Portanto, a previsão deste fenômeno e características associadas é de fundamental importância para operação de poços de gás. Por exemplo, em decorrência da diminuição da vazão é comum a ocorrência de altas intermitências, características de transição do escoamento anular para o escoamento caótico. Modelos que sejam capazes de prever os diferentes padrões de escoamento, assim como a transição entre eles, podem encontrar a sua utilidade em aplicações deste tipo.

\section{2}

\section{Revisão Bibliográfica}

Muitos trabalhos foram desenvolvidos com o fim de compreender em detalhes os mecanismos de geração de instabilidades e as transições entre os diversos regimes, posto que a identificação dos padrões de escoamento é necessária para a adequada seleção das relações de fechamento.

A presente revisão bibliográfica está sub-dividida na revisão de artigos cujo foco são as características do escoamento anular, seguida da revisão de estudos numéricos do padrão anular.

\subsection{1}

\section{Características do escoamento bifásico}

O primeiro mapa de padrão de escoamento atribui-se a Baker (1954) no qual, mediante observações de dados experimentais, foram categorizados os 
diversos arranjos das fases, discutidos na seção anterior.

Mandhane et al. (1974) propõem um mapa de padrões de escoamento para tubulações horizontais baseado nas velocidades superficiais do líquido e do gás. Pouco tempo depois, Taitel \& Dukler (1976) desenvolveram um modelo teórico mecanicista capaz de prever as transições entre os diversos regimes de escoamento para tubulações horizontais e levemente inclinadas.

Diversos trabalhos decorreram da metodologia proposta por Taitel \& Dukler (1976), resultando em um progresso substancial nesta área. Porém a maioria dos modelos se restringia a uma faixa especifica de inclinações da tubulação.

Barnea (1987) apresentou um modelo unificado para tubulações horizontais, verticais e inclinadas, com aplicações principalmente para escoamento ar-água em dutos de pequenos diâmetro e baixas pressões, não podendo ser generalizados para outros fluidos, diâmetros e condições de operação.

Conforme dito anteriormente, o padrão anular ocorre para uma grande faixa de velocidades de líquido e gás e para todas as inclinações, consequentemente, é encontrado com bastante frequência em muitas aplicações industriais. No escoamento anular o núcleo de gás é turbulento devido às altas vazões caraterísticas deste padrão e o líquido escoa sob forma de um filme de pequena espessura que reveste a parede do tubo. Durante anos se desenvolveram diversos trabalhos sobre as características mais relevantes do padrão anular como espessura do filme, velocidade e frequência das ondas, arrastramento e deposição de gotículas de líquido, e diversas correlações para o fator de atrito na interface (Jayanti et al., 1990; Paras \& Karabelas (1991); Wolf et al., 2001; Kaji, 2008; Farias et al., 2012; McCaslin \& Desjardins, 2014; Alves, 2014; Silva \& Nieckele, 2016).

Para o caso horizontal, pelo efeito da gravidade, a distribuição do filme de líquido ao longo da circunferência é desigual, sendo de interesse determinar os principais mecanismos que conseguem manter o filme na parede superior do duto (Jayanti et al., 1990; Paras \& Karabelas (1991); Farias et al., 2012). Já no caso vertical, a qual a distribuição do líquido ao longo da circunferência pode ser considerada aproximadamente simétrica ( Fowler \& Lisseter, 1992; ; Belt et al., 2010; Zhao et al., 2013).

Como a diferença de velocidades entre gás e líquido é grande, uma característica importante do escoamento anular é a formação de ondas ou pertubações na interface do filme e o núcleo de gás. De acordo com diversos autores (Paras \& Karabelas, 1991; Schubring \& Shedd, 2008; Farias et al., 2012; Zhao et al., 2013; Berna et al., 2014) é assumido que dois tipos de ondas podem existir na superfície do filme de líquido: as de grande amplitude ou 
disturbance waves e as de baixas amplitudes ou ripples.

Sekoguchi \& Takeishi (1989) apresentaram imagens de ondas de grande amplitude, enfatizando que para o escoamento vertical ascendente, suas características se distribuem uniformemente ao longo da circunferência do duto.

Por outro lado, Paras \& Karabelas (1991) mostraram que em condições de escoamento horizontal a distribuição das características das ondas é altamente assimétrica para baixas velocidades superficiais de gás $(40-50 \mathrm{~m} / \mathrm{s})$, para todas as vazões de líquido que foram testadas por eles. Porém, a medida que a vazão de gás cresce, o escoamento tende a se distribuir mais uniformemente.

Fore \& Dukler (1995) estudaram os processos de entranhamento e deposição de gotículas de líquido advindas do filme ondulado, através de experimentos e análises de balanço de quantidade de movimento.

Diversos autores desenvolveram correlações para o cálculo do atrito interfacial, uma vez que o mesmo é de extrema importância para a transferência de quantidade movimento entre gás e líquido. Uma das correlações mais amplamente utilizadas é a proposta por Wallis (1969). Whalley \& Hewitt (1978) propõem uma expressão bastante similar, porém levando em consideração a razão de densidades. Fore et al. (2000) desenvolveram uma nova correlação para o fator de atrito interfacial levando-se em consideração o número de Reynolds o gás e utilizando com base a correlação de Wallis (1969). Belt et al. (2010), por outro lado, argumentam que a rugosidade efetiva da interface líquido-gás pode ser considerada proporcional à altura da onda, e que não há evidência física para a incorporação do Reynolds do gás na expressão.

Schubring \& Shedd (2008) realizaram experimentos para medir a velocidade e frequência das ondas e determinaram que as ondas de grande amplitude se movimentam numa velocidade maior do que a superfície do líquido, com uma frequência menor, enquanto que as ondas menores se movimentam com menor velocidade, com baixas amplitudes e maior frequência. Devido à forte turbulência do gás, as ondas de baixa amplitude encontram-se sempre presentes na superfície do filme. Ondas de grande amplitude aparecem quando a vazão do líquido cresce. Neste caso, o desprendimento de gotículas de líquido também pode acontecer, as quais são arrastadas pelo núcleo gasoso.

Zhao et al. (2013) realizaram experimentos em um duto de curto comprimento, com medidas do desenvolvimento axial das características das ondas.

Berna et al. (2014) recentemente apresentaram uma vasta revisão das correlações para espessura do filme, frequência média e velocidade da onda existentes na literatura para escoamento anular e propuseram correlações alternativas para essas variáveis, com boa concordância com dados disponíveis. 


\section{2 .2}

\section{Simulação numérica do escoamento bifásico}

Para analisar o escoamento bifásico ao longo de tubulações, uma abordagem unidimensional é frequentemente empregada, uma vez que modelos multidimensionais possuem um alto custo computacional, restringindo sua aplicação a seções curtas. Para o desenvolvimento de uma formulação unidimensional, médias espaciais e temporais são aplicadas. As abordagens resultantes normalmente se dividem em: (i) Modelo Homogêneo; (ii) Modelo de Escorregamento (Drift-Flux Model) (Zuber \& Findlay, 1965) e (iii) Modelo de Dois Fluidos (Ishii \& Hibiki, 2011)).

Os Modelos Homogêneos tratam as duas fases como um único fluido, assumindo que as fases escoam com a mesma velocidade na tubulação. $\mathrm{O}$ modelo necessita de correlações empíricas para, por exemplo, prever a perda de carga e frações volumétricas no escoamento, que são dependentes do padrão de escoamento vigente. Este é o modelo mais rudimentar de escoamento bifásico, e sua incapacidade de tratar o escorregamento entre as fases pode resultar em grandes erros.

Por outro lado, o Modelo de Escorregamento incorpora relações para determinar o movimento relativo entre as fases. Neste modelo, o escoamento do fluido é modelado através de equações de conservação para a mistura (massa, quantidade de movimento e energia), utilizando relações constitutivas (ajustadas por correlações empíricas) para determinar o movimento relativo entre fases. O modelo é relativamente simples, sendo capaz de prever a dinâmica do escoamento quando o movimento entre as fases é fortemente acoplado. Uma característica deste tipo de modelagem é o baixo custo computacional envolvido. Todavia, esta modelagem é fortemente dependente das correlações escolhidas para descrever as características das golfadas, incorporando incertezas nos resultados.

No Modelo de Dois Fluidos, as equações de conservação de massa, quantidade de movimento e energia são resolvidas para cada fase, sendo o acoplamento entre fases modelado através de termos interfaciais nas equações. $\mathrm{O}$ modelo exige um número maior de equações, exigindo maior esforço computacional em sua solução (quando comparado aos demais modelos). Entretanto, é capaz de descrever as interações entre fases com um maior grau de sofisticação. O Modelo de Dois Fluidos foi introduzido por Ishii (1975), com aplicações na indústria nuclear. Outra abordagem, que possui menor dependência com correlações empíricas, é o método de seguimento de pistão ou slug tracking (Bendiksen et al., 1991; Nydal \& Banerjee, 1996). Neste método, um sistema de coordenadas Lagrangeano é adotado, de forma a acompanhar a intermitên- 
cia no escoamento.

Issa \& Kempf (2003) demonstraram que o Modelo de Dois Fluidos unidimensional é capaz de prever corretamente o aparecimento de instabilidades hidrodinâmicas intrínsecas ao escoamento estratificado, dando origem ao escoamento em golfadas, assim como a subsequente evolução do mesmo ao longo da tubulação. Esta abordagem, denominada Slug Capturing, requer malhas refinadas e passos de tempo pequenos para capturar corretamente o surgimento, crescimento e evolução das ondas interfaciais e golfadas. A metodologia proposta por Issa \& Kempf (2003) vem sendo aplicada com sucesso em diversos trabalhos por seu grupo de pesquisa, envolvendo aplicações específicas, como por exemplo: escoamento em golfadas com consideração do entranhamento de bolhas (Bonizzi, 2003); escoamento trifásico (óleo, água e gás) no regime de golfadas (Bonizzi \& Issa, 2003); transição de escoamento estratificado e anular em dutos horizontais (Emamzadeh \& Issa, 2013). O grupo de pesquisa da PUC-Rio também vem aplicando com sucesso essa metodologia, com a previsão detalhada dos parâmetros estatísticos das golfadas (Nieckele et al., 2013); analisando escoamento em golfadas com transferência de calor (Simões et al., 2014) e escoamento estratificado e golfadas envolvendo óleos viscosos (Pasqualette et al., 2015), dentre outros.

Para tubulações verticais, é conhecido que o Modelo de Dois Fluidos se torna incondicionalmente mal posto, devido a ausência do termo de variação de altura associado à distribuição hidrostática de pressão, ou de outros termos diferenciais estabilizantes. Este problema tem sido extensivamente estudado na literatura, com a proposta por diversos autores de diferentes relações de fechamento aplicados à tubulações verticais.

Bestion (1990), por exemplo, apresenta um modelo de pressão dinâmica para cada uma das fases, o qual depende das massas específicas, frações volumétricas e das velocidades de cada uma das fases. Han \& Guo (2015) mostram como a pressão dinâmica proposta por Bestion ajuda a estabilizar o sistema de equações para conseguir prever o fenômeno de golfada severa em uma tubulação vertical.

Fowler \& Lisseter (1992) apresentam um modelo de pressão dinâmica obtido a partir da equação de Bernoulli em função da velocidade da onda, para escoamentos verticais. Através de uma análise matemática, demostraram que com o modelo proposto, o sistema de equações resultante é bem posto. Porém eles também consideram um parâmetro de fluxo de quantidade de movimento maior do que 1.

Song \& Ishii (2001) exploraram com detalhes a influência do escoamento transversal, discutindo a presença do parâmetro de fluxo nos termos convecti- 
vos das equações de conservação de quantidade de movimento.

Issa \& Montini (2010) também analisaram o parâmetro de fluxo de quantidade de movimento. Mostraram que para escoamento horizontais, o parâmetro de fluxo de quantidade de movimento para o líquido auxilia a tornar o sistema de equações bem posto, porém cuidados devem ser tomados a respeito dos valores utilizados e da sua interpretação física. Uma boa revisão no assunto é apresentada por Montini (2011).

Carneiro (2006) realizou uma análise da hiperbolicidade do Modelo de Dois Fluidos isotérmico, e verificou que a introdução de um salto de pressão na interface não promoveu melhora significativa da estabilidade do modelo para os escoamentos horizontais estudados. Inácio (2012) estudou duas relações de fechamento ao considerar escoamento intermitente na vertical: salto devido à curvatura na interface e o parâmetro de distribuição de fluxo de quantidade de movimento, confirmando que o primeiro não mostra significativa melhora, enquanto que parâmetro relacionado a distribuição da fase líquida ampliou a região em que o sistema de equações é bem posto.

Holmås et al. (2008) sugeriram a inclusão de difusão artificial nas equações de conservação de quantidade de movimento do Modelo de Dois Fluidos, visando ampliar a região em que o modelo é bem posto.

Outras possibilidades existem para estabilizar o sistema de equações, com a introdução por exemplo de massa virtual, conforme detalhado por Alves et al. (2012).

Recentemente, Galleni \& Issa (2015) e Issa \& Galleni (2015) publicaram um trabalho onde argumentam que é possível a captura de diferentes regimes na vertical e demonstram que as características do regime de golfadas são reproduzidas de modo satisfatório. Para tal, os autores utilizam um esquema de discretização espacial de primeira ordem, argumentando que a difusão numérica é suficiente para dissipar os comprimentos de onda espúrios de alta frequência que eventualmente se desenvolvem. No entanto, uma análise de estabilidade de von Neumann realizado pelos mesmos autores revela que o espaçamento da malha não pode ser muito reduzido.

De acordo com o levantamento bibliográfico realizado, observa-se que existe uma lacuna na literatura com relação a solução do sistema de equações do Modelo de Dois-Fluidos uni-dimensional, para prever escoamentos ao longo de tubulações verticais e prever todas as características do escoamento de padrão anular. 


\section{3 \\ Objetivo}

O objetivo do presente trabalho é ampliar a aplicação do Modelo de Dois Fluidos unidimensional, no contexto similar ao da metodologia de "Slug Capturing", para ser capaz de modelar e simular o padrão bifásico anular, vertical ascendente com captura automática da evolução das ondas de grande amplitude.

\section{4}

Organização do trabalho

No Capítulo 2 é apresentada a modelagem matemática para o Modelo de Dois Fluidos unidimensional, bem como as relações de fechamento utilizadas.

No Capitulo 3 é apresentada uma análise de hiperbolicidade do Modelo de Dois Fluidos e os critérios que devem ser satisfeitos para se obter o bom condicionamento do sistema de equações. Já no Capítulo 4 é apresentado o método de solução numérica, detalhando as técnicas para discretizar as equações através do método de volumes finitos, assim como o procedimento de solução utilizado.

No Capítulo 5 avalia-se a região que o sistema de equações é bem/mal posto para os diferentes modelos de pressão dinâmica considerados no presente trabalho. Realiza-se também, um teste de malha rigoroso, identificando se os modelos, realmente, são capazes de fornecer solução independente da malha. Finalmente, realiza-se uma validação da metodologia, através de comparações dos resultados numéricos obtidos com dados experimentais existentes na literatura, para escoamentos ascendentes de água e ar em tubulações verticais de diferentes diâmetros e comprimentos.

A conclusão e algumas sugestões para trabalhos futuros são apresentados no Capítulo 6. 


\section{2}

\section{Modelo Matemático}

Neste capítulo é apresentada a formulação matemática utilizada no presente trabalho para determinar o escoamento vertical no padrão anular.

\section{1}

\section{Modelo de Dois Fluidos}

O modelo matemático selecionado neste trabalho para prever o escoamento bifásico ao longo de tubulações é o Modelo de Dois Fluidos (Ishii, 1975). O Modelo de Dois Fluidos consiste em resolver um conjunto de equações de conservação para cada uma das fases. O modelo é baseado na determinação de médias volumétricas referentes a cada fase $k$, definidas como

$$
\left\langle f_{k}\right\rangle=\frac{\int_{\forall_{k}} f_{k} d \forall}{\int_{\forall_{k}} d \forall}
$$

onde $f_{k}$ é uma função relativa à fase $k$ e $\forall_{k}$ é o volume ocupado pela fase $k$. A fração volumétrica associada a fase $k$ é

$$
\alpha_{k}=\frac{\forall_{k}}{\forall}
$$

e naturalmente, a seguinte restrição se aplica

$$
\sum_{k} \alpha_{k}=1
$$

Uma vez que nas situações de interesse deste trabalho, o escoamento ocorre ao longo de tubulações muito longas, considera-se que as variações ao longo da tubulação são mais significativas que na seção transversal, permitindo a introdução da hipótese de escoamento uni-dimensional. Ao derivar o modelo de dois fluidos em sua forma uni-dimensional, todas as grandezas do escoamento são integradas ao longo da área (A) da seção transversal do duto, sendo substituídos por valores médios. A definição de média ao longo da área da seção transversal do duto para uma grandeza $f$ é dada por: 


$$
\bar{f}=\frac{1}{A} \int_{A} f d A
$$

Por simplicidade, neste trabalho é omitido o uso dos símbolos de médias na fase e média na área, i.e., daqui em diante, todas as grandezas do escoamento são assumidas como médias na fase e na área.

As equações de conservação utilizadas para determinar o escoamento vertical ascendente foram obtidas considerando as seguintes hipóteses:

(i) Escoamento 1-D

(ii) Massa específica constante para a fase líquida $\left(\rho_{L}\right)$

(iii) Massa específica da fase gasosa $\left(\rho_{G}\right)$ se comporta como gás ideal

(iv) Viscosidade dinâmica constante para cada fase, $\mu_{G}$ e $\mu_{L}$

(v) Não há entranhamento nem deposição de gotículas de líquido na fase gasosa

(vi) Fluxo difusivo viscoso axial desprezível

(vii) Isotérmico

A partir das hipóteses acima, as equações do Modelo de Dois Fluidos unidimensional (Ishii \& Hibiki (2011), Ishii \& Mishima (1984)) podem ser escritas como:

\section{Conservação de massa para o gás}

$$
\frac{\partial\left(\alpha_{G} \rho_{G}\right)}{\partial t}+\frac{\partial\left(\alpha_{G} \rho_{G} U_{G}\right)}{\partial x}=0
$$

\section{Conservação de massa para o líquido}

$$
\frac{\partial\left(\alpha_{L} \rho_{L}\right)}{\partial t}+\frac{\partial\left(\alpha_{L} \rho_{L} U_{L}\right)}{\partial x}=0
$$




\section{Conservação de quantidade de movimento linear para o gás}

$$
\begin{aligned}
& \frac{\partial\left(\alpha_{G} \rho_{G} U_{G}\right)}{\partial t}+\frac{\partial\left(C_{G} \alpha_{G} \rho_{G} U_{G}^{2}\right)}{\partial x}= \\
& \quad-\alpha_{G} \frac{\partial P_{G_{i}}}{\partial x}-\frac{\partial \alpha_{G}\left(P_{G}-P_{G i}\right)}{\partial x}-\alpha_{G} \rho_{G} g \sin \beta-F_{w_{G}}-F_{i}
\end{aligned}
$$

\section{Conservação de quantidade de movimento linear para o líquido}

$$
\begin{aligned}
& \frac{\partial\left(\alpha_{L} \rho_{L} U_{L}\right)}{\partial t}+\frac{\partial\left(C_{L} \alpha_{L} \rho_{L} U_{L}^{2}\right)}{\partial x}= \\
& \quad-\alpha_{L} \frac{\partial P_{L_{i}}}{\partial x}-\frac{\partial \alpha_{L}\left(P_{L}-P_{L i}\right)}{\partial x}-\alpha_{L} \rho_{L} g \sin \beta-F_{w_{L}}+F_{i}
\end{aligned}
$$

onde os subscritos $L$ e $G$ se referem às fases líquida e gasosa, respectivamente. O subscrito $i$ refere à interface entre as duas fases. $\rho_{k}$ é a massa específica e $u_{k}$ é a velocidade da fase $k$. $C_{k}$ é o parâmetro de distribuição de quantidade de movimento. $P_{k}$ é a média da pressão na seção transversal e $P_{k_{i}}$ é a pressão da fase $k$ em cada lado da interface. $\beta$ é o ângulo de inclinação do duto e $g$ é a aceleração devido à gravidade. $F_{w_{L}}, F_{w_{G}}$ representam as forças de atrito por unidade de volume entre cada fase e a parede e $F_{i}$ a força de atrito por unidade de volume entre as fases, a qual tem sinal oposto para cada fase $k$.

Conforme as hipóteses apresentadas, considerou-se a massa específica do líquido constante, sendo a massa específica do gás governada pela lei de gás ideal como:

$$
\rho_{G}=\frac{P_{G}}{R_{G} T_{r e f}} \approx \frac{P_{G_{i}}}{R_{G} T_{r e f}}
$$

onde $R_{G}$ é a constante do gás, e $T_{r e f}$ é a temperatura de referência do escoamento isotérmico. A pressão média do gás $P_{G}$ é considerada, por simplicidade, igual ao valor na interface $P_{G_{i}}$.

Para ser possível resolver o conjunto de equações de conservação, Eqs. (2.5 - 2.8), relações adicionais de fechamento referentes aos parâmetro de distribuição, forcas de atrito, pressão média na seção e na interface, precisam ser introduzidas, e são apresentadas nos itens a seguir. Sendo a formulação 1D, informações relacionadas à distribuição das fases na seção transversal 
também são necessárias para auxiliar na determinação de algumas das relações de fechamento mencionadas.

\section{2}

\section{Relações de Fechamento}

As equações de conservação apresentadas são válidas para os diferentes padrões de escoamento e inclinações da tubulação. O foco do presente trabalho é o estudo do escoamento vertical ascendente no padrão anular, e algumas das relações de fechamento serão particularizadas a seguir visando esta condição de operação. No entanto, testes de validação da metodologia também foram realizados considerando escoamento ao longo de tubulações horizontais e com diferentes padrões.

\subsection{1}

\section{Parâmetro de fluxo de quantidade de movimento}

Devido à não uniformidade do perfil de velocidade na seção transversal, a média da velocidade ao quadrado não é igual ao quadrado da média. $\mathrm{O}$ parâmetro de fluxo (também denominado parâmetro de forma) é exatamente esta razão, sendo definido da seguinte maneira:

$$
C_{k}=\frac{\overline{\left\langle U_{k}^{2}\right\rangle}}{{\overline{\left\langle U_{k}\right\rangle}}^{2}}
$$

Este termo atua como um multiplicador no fluxo de quantidade de movimento (termo convectivo), conforme visto nas Eqs. (2.7 e 2.8).

Para escoamentos monofásicos totalmente desenvolvidos, é possível determinar os valores do parâmetro de forma através da integração dos perfis analíticos de velocidade. Para o caso laminar (escoamento de Poiseuille), $C_{k}=4 / 3=1,33$ é um resultado clássico da mecânica dos fluidos. Escoamentos turbulentos apresentam perfis mais achatados, portanto há a tendência de se obter valores inferiores àquele obtido para o caso laminar. Tomando por exemplo o perfil de potência $1 / 7$, o valor analítico do fator de forma se torna aproximadamente $C_{k}=1,02$.

A introdução de $C_{k}$ tem o objetivo de restaurar alguma informação sobre a distribuição do escoamento ao longo da seção transversal. Song \& Ishii (2001) avaliaram a influência deste parâmetro para o escoamento no padrão de bolhas dispersas, considerando-o, no entanto constante, dependendo apenas da geometria e condições de entrada. Montini (2011) analisou escoamento horizontal e argumenta que, de uma forma geral, este parâmetro deve variar 
com as densidades, velocidades e frações volumétricas das fases, porém, suas análises foram realizadas considerando $C_{k}$ constante. Inácio (2012) investigou a influência do parâmetro de fluxo de quantidade de movimento, para escoamento vertical, tendo adotado o parâmetro constante para cada uma das fases. Inácio (2012) recomendou, assim como Montini (2011), que este parâmetro só deve ser utilizado para o líquido. Fowler \& Lisseter (1992) utilizam na equação de quantidade de movimento do líquido um parâmetro de fluxo de quantidade de movimento igual a 1,3 .

\subsection{2}

\section{Parâmetros geométricos}

Conforme mencionado, o padrão de escoamento de interesse neste trabalho é o padrão anular. De acordo com a configuração ilustrada na Fig. 2.1, considera-se que o diâmetro da tubulação é $D$, o diâmetro da região central ocupada pelo gás é $D_{G}$ e a espessura do filme de líquido é $h_{L}$. No caso particular do padrão anular, Fig. 2.1, a fase gasosa não tem contato com a parede da tubulação e consequentemente o perímetro molhado do gás $S_{G}$ é nulo. O perímetro molhado do líquido $S_{L}$ coincide com o perímetro da tubulação e o perímetro da interface gás-líquido $S_{i}$ é o perímetro do núcleo de gás

$$
S_{G}=0 \quad S_{L}=\pi D \quad S_{i}=\pi\left(D-2 h_{L}\right)
$$

As áreas ocupadas por cada fase na seção transversal são

$$
A_{G}=\frac{\pi}{4} D_{G}^{2} \quad, \quad A_{L}=\frac{\pi D^{2}}{4}-A_{G}
$$

onde

$$
D_{G}=D-2 h_{L}
$$

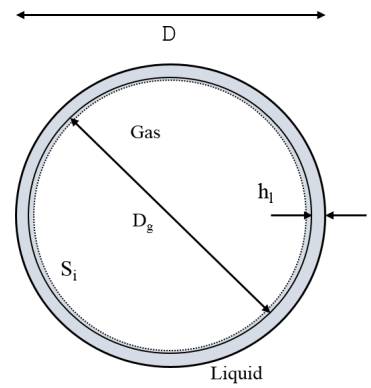

Figura 2.1: Geometria do escoamento anular. 
Na formulação 1D, a razão de áreas coincide com a razão volumétrica, pois $\forall=A d x$, logo a fração volumétrica de gás pode ser relacionada com a espessura do filme através de

$$
\alpha_{G}=\frac{A_{G}}{A}=\left(1-\frac{2 h_{L}}{D}\right)^{2}
$$

consequentemente, a espessura do filme pode ser obtida em função da fração de volumétrica do gás com

$$
h_{L}=\frac{D}{2}\left(1-\sqrt{\alpha_{G}}\right)
$$

\subsection{3}

\section{Tensões cisalhantes}

As equações de conservação de quantidade de movimento, Eqs. 2.5 - 2.8, dependem da forças cisalhantes na parede e na interface. As forças cisalhantes por unidade de volume $F_{k}$, tanto entre as fases e a parede e na interface podem ser modeladas como:

$$
F_{k}=\frac{S_{k} \tau_{k}}{A}
$$

onde $\tau_{k}$ é a tensão cisalhante e pode ser avaliada em função de coeficientes de atrito $f_{k}$, considerando escoamento localmente hidrodinâmicamente desenvolvido, de acordo com

$$
\tau_{k}=\frac{1}{2} f_{k} \rho_{k}\left|U_{r}\right| U_{r}
$$

onde $U_{r}$ é a velocidade relativa entre a fase e parede, $U_{k}$ ou entre fases, $U_{G}-U_{L f}$, onde $U_{L f}$ é a velocidade do filme de líquido na interface. Para escoamento anular, assume-se que não existe interação entre a fase gasosa e a parede, por conseguinte $F_{w_{G}}=0$.

Para calcular o fator de atrito $\left(f_{k}\right)$ existem numerosas correlações na literatura que variam dependendo da forma e tipo do escoamento, portanto a escolha é de grande importância. As correlações utilizadas no escoamento anular em tubulações verticais e que são recomendadas pelos trabalhos de Inácio (2012), Berna et al. (2014) e Alves et al. (2012) são:

Para a interação líquido-parede: 


$$
f_{L}= \begin{cases}\frac{24}{R e_{S_{L}}} & R e_{L}<2100 \\ \frac{0,0262}{\left(\alpha_{L} R e_{S_{L}}\right)^{0,139}} & R e_{L} \geq 2100\end{cases}
$$

O fator de atrito na interface é calculado como:

$$
f_{i}= \begin{cases}\frac{16}{R e_{i}}\left[1+24\left(\frac{\rho_{L}}{\rho_{G}}\right)^{1 / 3} \frac{h_{L}}{D}\right] & R e_{i}<2100 \\ \frac{0,079}{\left(R e_{i}\right)^{0,25}}\left[1+24\left(\frac{\rho_{L}}{\rho_{G}}\right)^{1 / 3} \frac{h_{L}}{D}\right] & R e_{i} \geq 2100\end{cases}
$$

Os números de Reynolds para cada uma das fases e interface são definidos conforme Taitel \& Dukler (1976):

$$
\begin{array}{r}
R e_{s_{L}}=\frac{\rho_{L}\left|U_{s_{L}}\right| D}{\mu_{L}} ; U_{S_{L}}=\alpha_{L} U_{L} \\
R e_{L}=\frac{\rho_{L}\left|U_{L}\right| D_{h_{L}}}{\mu_{L}} ; D_{h_{L}}=\frac{4 A_{L}}{S_{L}} \\
\operatorname{Re}_{i}=\frac{\rho_{G}\left|\left(U_{G}-U_{L}\right)\right| D_{h_{i}}}{\mu_{G}} ; D_{h_{i}}=\frac{4 A_{G}}{S_{i}}
\end{array}
$$

$\mu_{G}$ e $\mu_{L}$ são as viscosidades dinâmicas do gás e do líquido, respetivamente. $U_{S_{L}}$ é a velocidade superficial do líquido. Os parâmetros geométricos utilizados $S_{L}$, $S_{i}, A_{G}$ e $A_{L}$ foram calculados pelas Eqs. 2.11 e 2.12 na seção 2.2.2. $D_{h_{L}}$ e $D_{h_{i}}$ são os diâmetros hidráulicos do líquido e interface.

Para evitar variações abruptas no fator de atrito, que poderiam causar instabilidades numéricas (Inácio, 2012), considerou-se escoamento laminar para números de Reynolds menores que 2000 e turbulento para números de Reynolds maiores que 2100. Entre os dois valores, o fator de atrito foi obtido mediante uma interpolação linear entre os valores correspondentes aos dois regimes.

\subsection{4}

\section{Pressão}

As equações de conservação de quantidade de movimento, Eqs. (2.7) e (2.8) apresentam duas parcelas associadas à pressão. A primeira está associada às pressões das fases na interface, pois a pressão na interface do lado do gás não é necessariamente igual à pressão no lado do líquido. A segunda está 
associada a diferença entre a pressão média da fase a a pressão da fase reinante na interface. Ambos os termos precisam de condições de fechamento para completar o sistema de equações.

- Salto de pressão na interface

A diferença de pressão entre as fases na interface depende da tensão superficial $\sigma$ e da curvatura da interface $\kappa$, de acordo com a equação de YoungLaplace,

$$
P_{G_{i}}-P_{L_{i}}=\sigma \kappa \quad ; \quad \kappa=\frac{1}{R}
$$

onde $R$ é o raio de curvatura principal da superfície elementar ao redor de uma dada posição. Se o raio de curvatura for muito grande esta parcela é desprezível. No caso de escoamento anular, existem dois raios de curvatura da interface. Um associado a curvatura na seção transversal e outra associado com as ondulações axiais. Enquanto a primeira contribuição desestabiliza o sistema de equações, a segunda ajuda a tornar o sistema bem-posto.

Inácio (2012) mostrou que o salto de pressão amplia a região onde o sistema de equações é bem posto somente na presença de pequenos cumprimentos de onda. Apesar da existência de ondulações na interface do padrão anular, o salto de pressão foi desprezado no presente trabalho, i.e., Eq. (2.24), seguindo as formulações de Fowler \& Lisseter (1992) e Han \& Guo (2015).

$$
P_{G_{i}}=P_{L_{i}}
$$

- Pressão média na seção transversal

Estudos desenvolvidos por Banerjee \& Chan (1980) mostraram a importância de considerar a existência de uma diferença entre a pressão média na seção transversal $P_{k}$ e a pressão na interface $P_{k_{i}}$, de forma a ampliar a região na qual o sistema definido pelas nas Eqs. (2.7) e (2.8) é bem posto. No caso horizontal é comum, relacionar esta diferença com um efeito hidrostático ( Issa \& Kempf, 2003;Carneiro, 2006; Montini, 2011).

$$
-\frac{\partial\left[\alpha_{k}\left(P_{k}-P_{k i}\right)\right]}{\partial x}=-\rho_{k} \alpha_{k} g \cos \beta \frac{\partial h_{L}}{\partial x}
$$

Lembrando que o filme do líquido depende diretamente da fração volumétrica do gás, logo pode-se convenientemente rescrever a equação acima como

$$
-\frac{\partial\left[\alpha_{k}\left(P_{k}-P_{k i}\right)\right]}{\partial x}=-\rho_{k} \alpha_{k} g \Gamma \cos \beta \frac{\partial \alpha_{G}}{\partial x}
$$

onde 


$$
\Gamma=\frac{\partial h_{L}}{\partial \alpha_{G}}
$$

No caso vertical, este termo desaparece e de acordo com Fowler \& Lisseter (1992) e Bestion (1990) esta diferença de pressão pode ser associada a existência de uma pressão dinâmica, a qual pode ser representada por

$$
P_{k}-P_{k_{i}}=\Delta P_{k_{d i n}}=W_{f_{k}} \rho_{\text {ref }}\left(U_{L}-U_{\text {onda }}\right)^{2}
$$

onde $W_{f_{k}}$ é um parâmetro empírico e $U_{\text {onda }}$ é a velocidade da onda formada na interface entre as fases.

No modelo proposto por Fowler \& Lisseter (1992), o termo associado com a pressão dinâmica só é considerado na equação do líquido, i.e., $\Delta P_{G_{\text {din }}}=0$. Neste modelo, o coeficiente empírico $W_{f_{k}}$ é definido igual a 0,02 e a velocidade da onda é considerada como sendo diretamente proporcional a velocidade do líquido, $U_{\text {onda }}=\chi U_{L}$, com $\chi=2$.

$$
P_{L}-P_{L_{i}}=\Delta P_{L_{d i n}}=W_{f_{L}} \rho_{L}(1-\chi)^{2} U_{L}^{2}
$$

No modelo utilizado por Fowler \& Lisseter (1992) a velocidade da onda $U_{\text {onda }}$ também é utilizada no cálculo da velocidade relativa para avaliação da tensão de cisalhamento interfacial, i.e., na Eq. (2.17), $U_{r}=\left(U_{G}-U_{\text {onda }}\right)=$ $\left(U_{G}-\chi U_{L}\right)$.

Já no modelo utilizado por (Bestion, 1990), o escoamento vertical é afetado tanto pela pressão dinâmica no líquido como no gás. A velocidade da onda na Eq. (2.28) é a velocidade do gás, $U_{G}$, senda a massa específica de referência, um valor médio de massa específica, obtida combinando as massas específicas de cada fase com as frações volumétricas, de acordo com

$$
\rho_{\text {ref }}=\rho_{m}=\frac{\alpha_{L} \alpha_{G} \rho_{L} \rho_{G}}{\alpha_{G} \rho_{L}+\alpha_{L} \rho_{G}}
$$

Uma análise da literatura disponível mostra que a velocidade das ondas na interface do escoamento anular pode ser melhor avaliada levando em consideração características de ambas as fases. Berna et al. (2014) desenvolveram uma nova correlação para calcular a velocidade da onda na interface a qual segundo os autores se ajusta muito bem aos dados experimentais, sendo uma melhor aproximação do que a do modelo proposto por Fowler \& Lisseter (1992) A correlação é: 


$$
U_{\text {onda }}=50 \frac{\sqrt{\rho_{G}} U_{s_{G}}+\sqrt{\rho_{L}} U_{s_{L}}}{\sqrt{\rho_{G}}+\sqrt{\rho_{L}}} R_{s_{G}}^{-0.38} R_{s_{L}}^{0.16} C_{\sigma}^{-0.13}
$$

onde $R e_{s_{L}}$ é calculado com a equação (2.20). $R e_{s_{G}}$ é baseado na velocidade superficial do gás $U_{s_{G}}$, sendo igual a

$$
R e_{s_{G}}=\frac{\rho_{G}\left|U_{s_{G}}\right| D}{\mu_{G}} \quad ; \quad U_{s_{G}}=\alpha_{G} U_{G}
$$

$C_{\sigma}$ está relacionado a tensão interfacial $\sigma$, sendo definido pela seguinte correlação

$$
C_{\sigma}=\left\{\begin{array}{cl}
\frac{0,028}{N_{\mu}^{4 / 5}} & N_{\mu} \leq \frac{1}{15} \\
0,250 & N_{\mu}>\frac{1}{15}
\end{array}\right.
$$

onde

$$
N_{\mu}=\frac{\mu_{l}}{\left(\rho_{l} \sigma \sqrt{\frac{\sigma}{g\left(\rho_{L}-\rho_{G}\right)}}\right)^{1 / 2}}
$$

O novo modelo de pressão dinâmica proposto neste trabalho, utiliza a velocidade da onda conforme apresentado por Berna et al. (2014), e trata o termo de pressão dinâmica de acordo com a Eq. (2.28).

\begin{tabular}{|c|c|c|}
\hline Modelo & Referência & Formulação \\
\hline \multirow[t]{2}{*}{1} & $\begin{array}{l}\text { Fowler \& Lisseter } \\
(1992)\end{array}$ & $\begin{array}{c}\Delta P_{G_{d i n}}=0 \\
\Delta P_{L_{d i n}}=W_{f_{L} \rho_{L}}\left(U_{L}-U_{\text {onda }}\right)^{2}\end{array}$ \\
\hline & & $W_{f L}=0,02 \quad ; \quad U_{\text {onda }}=\chi U_{L} \quad ; \quad \chi=2$ \\
\hline \multirow[t]{3}{*}{2} & Bestion & $\Delta P_{k_{d i n}}=W_{f_{k}} \rho_{m}\left(U_{L}-U_{G}\right)^{2}$ \\
\hline & & $\rho_{m}=\frac{\alpha_{L} \alpha_{G} \rho_{L} \rho_{G}}{\alpha_{G} \rho_{L}+\alpha_{L} \rho_{G}}$ \\
\hline & $(1990)$ & $\begin{array}{c}W_{f_{k}}=1,2 \quad, \theta=90 \\
W_{f_{k}}=0 \quad, \theta \neq 90\end{array}$ \\
\hline \multirow[t]{2}{*}{3} & $\begin{array}{l}\text { Presente } \\
\text { [Fowler \& Lisseter }\end{array}$ & $\begin{array}{c}\Delta P_{G_{d i n}}=0 \\
\Delta P_{L_{d i n}}=W_{f_{L} \rho_{L}}\left(U_{L}-U_{\text {onda }}\right)^{2}\end{array}$ \\
\hline & $(1992)+$ Berna $(2014)]$ & $W_{f_{L}}=0,02 \quad ; \quad U_{\text {onda }}=f\left(U_{L}, U_{G}, \rho_{L}, \rho_{G}\right)$ \\
\hline
\end{tabular}

A Tabela 2.1 resume as formulações utilizadas para definir a pressão dinâmica.

Tabela 2.1: Formulações para Pressão Dinâmica 
No Capitulo 3 realiza-se uma análise para identificar as regiões onde o sistema de equações é bem posto para cada um dos modelos, visando identificar a influência da pressão dinâmica na hiperbolicidade das equações do Modelo de Dois Fluidos. Verificação do desempenho dos modelos comparando-se com dados experimentais é realizada no Capítulo 5.

\section{3}

\section{Condições de Contorno e Inicial}

Para resolver o sistema de equações é necessário definir as condições de contorno e iniciais do problema. Como condição de contorno, as velocidades superficiais de cada uma das fases são impostas na entrada da tubulação e a pressão é prescrita na saída.

A condição inicial imposta, consistiu em impor ao longo de todo o domínio os valores de velocidade e pressão prescritos nas fronteiras.

\section{4}

\section{Grandezas Características do Escoamento Anular}

O escoamento anular é caraterizado por um filme de líquido junto a parede, sendo o núcleo formado por gás. Sabe-se que o filme de líquido pode ser variável ao longo da seção transversal (Zhao et al. (2013)). No entanto, este comportamento não pode ser capturado por uma modelagem 1D. Dessa forma, somente pode-se avaliar a espessura média na seção transversal, $h_{L}$.

Sabe-se ainda que o filme de líquido apresenta ondulações espaciais e temporais em sua interface com o gás. Logo, para caracterizar um escoamento anular, além da espessura do filme de líquido na seção transversal, é necessário avaliar a velocidade e frequência de propagação das ondas interfaciais.

A espessura média no tempo do filme de líquido pode ser avaliada com

$$
\overline{h_{L}}=\frac{1}{\Delta t} \int_{\Delta t \rightarrow \infty} h_{L} d t
$$

Já a espessura média de filme no tempo e ao longo da tubulação é

$$
\overline{\overline{h_{L}}}=\frac{1}{L} \int_{L} \overline{h_{L}} d x
$$

\subsection{1}

\section{Frequências}

Dois tipos de frequências podem ser utilizadas para caracterizar o comportamento do filme de líquido. A primeira é denominada Frequência das On- 
das Grandes $\left(\nu_{O G}\right)$ e a segunda é Frequência PSD - Power Spectrum Density $\left(\nu_{P S D}\right)$.

A frequência das ondas grandes $\left(\nu_{O G}\right)$, em uma determinada coordenada espacial, é obtida mediante a contagem das ondas grandes durante um intervalo de tempo. De acordo com a sugestão de Zhao et al. (2013), são consideradas ondas grandes, as ondas que possuem amplitude superior à 1,6 vezes a espessura média no tempo do filme $\left(\overline{h_{L}}\right)$. A Fig. 2.2 ilustra a variação temporal da espessura do filme normalizada pela espessura média do filme no tempo $\left(h_{L} / \overline{h_{L}}\right)$. O intervalo de tempo utilizado para calcular a frequência de ondas grandes foi de $30 \mathrm{~s}$ e a contagem das ondas se realizou utilizando uma função do software MATLAB (2012), denominada "findpeaks", a qual identifica o valor do pico e sua localização no conjunto de dados. Observa-se na Fig. 2.2 o valor limite definido para contagem das ondas grandes e a identificação destas.

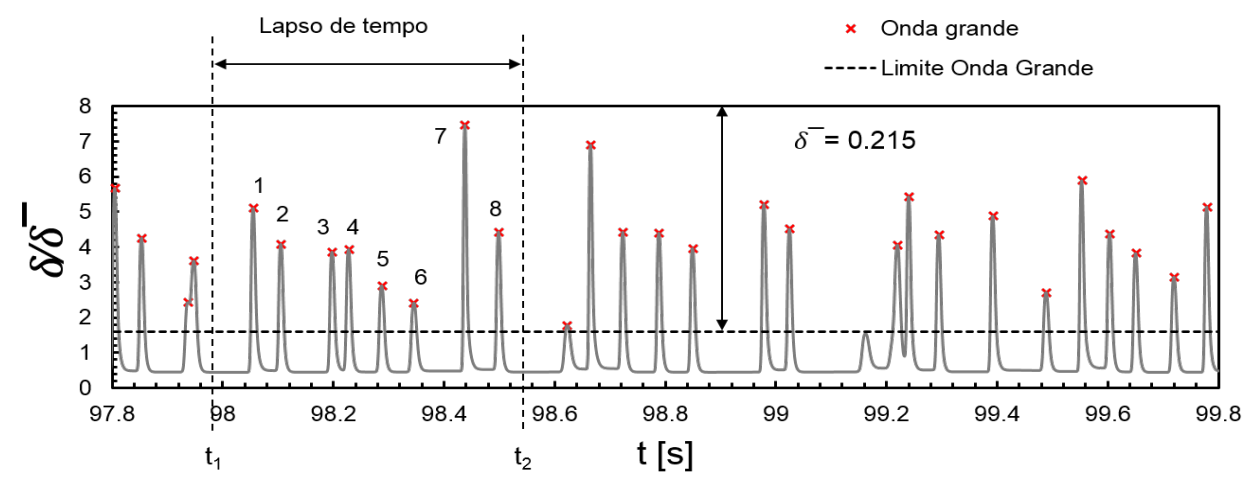

Figura 2.2: Representação do cálculo de frequência mediante a contagem de ondas de grande amplitude em um determinado intervalo de tempo

O segundo tipo de frequência calculado é a frequência PSD, a qual é obtida pela determinação da densidade espectral de potência do sinal, PSD (Bendat, 1971). Esta frequência possui informações relativas ao conteúdo espectral dos dados de espessura de filme de líquido. Para avaliar a frequência das ondas interfaciais, utilizou-se uma frequência de adquisição de dados de espessura de filme de $1 \mathrm{kHz}$ ou $\Delta t=0,001 \mathrm{~s}$, durante um intervalo de tempo de $30 \mathrm{~s}$.

O espectro de densidade de potência é construído utilizando uma Transformada Rápida de Fourier (FFT) a partir da série temporal da espessura do filme, referente a uma coordenada espacial, utilizando o comando do Matlab. A Fig. 2.3(a) ilustra um espectro típico de frequência, o qual abrange todo o conjunto de ondas, desde ondas de pequena amplitude, até as de grande amplitude. A frequência PSD corresponde ao valor máximo da PSD, encontrando-se 
entre zero e a frequência Nyquist (Kaji, 2008), definida como $1 /(2 \Delta t)$. No entanto, como pode-se observar na Fig. 2.3(a), o ruído presente no espectro dificulta a identificação da amplitude máxima (indicada vermelho no gráfico) para a determinação da frequência.

Visando obter uma melhor identificação da frequência correspondente ao pico do PSD, utilizou-se uma técnica de janelamento do sinal original de espessura de filme, de forma a suavizar o sinal resultante. Para obter a suavização do sinal, selecionou um sub-intervalo de tempo de 1 segundo (dentro do intervalo de $30 \mathrm{~s}$ ), e calculou-se a fft do sinal de altura de líquido. Este procedimento foi repetido 50 mil vezes, sendo o instante inicial de determinação da FFT, determinado através de um procedimento aleatório dentro do intervalo de 30 s. O PSD resultante foi então obtido usando a função "smooth"do Matlab, aplicada à média das diversas FFT. A Fig. 2.3(b) ilustra o resultado obtido, onde somente as frequências positivas são mostradas. A partir desta curva suavizada, a frequência correspondente ao pico da PSD é facilmente obtido.
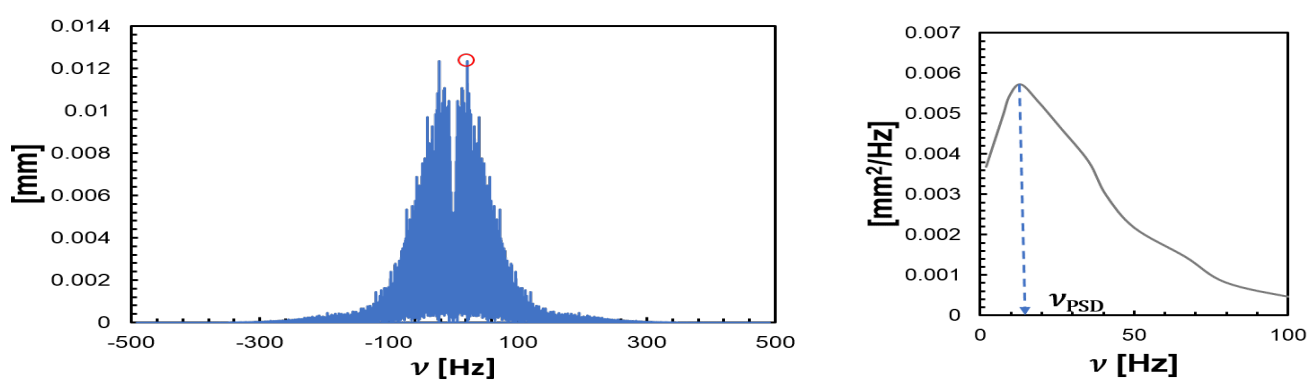

Figura 2.3: Espectro de frequências e PSD para um sinal temporal de altura do filme

\subsection{2}

\section{Velocidade da estrutura}

A velocidade da estrutura pode ser determinada ao se identificar o intervalo de tempo $\left(\Delta t_{\max }\right)$ que uma determinada estrutura leva para viajar entre duas coordenadas espaciais $x_{1}$ e $x_{2}$. Considere a série ilustrada na Fig. 2.4, correspondente a coordenada $x_{1}, h_{L} /\left.\overline{h_{L}}\right|_{x_{1}}(t)$. Procura-se na série $h_{L} /\left.\overline{h_{L}}\right|_{x_{2}}(t)$ correspondente a coordenada $x_{2}$, a porção de tempo no qual a mesma estrutura pode ser encontrada. $\Delta t_{\max }$. Logo a velocidade translacional média da estrutura $\left(u_{e}\right)$ é

$$
u_{e}=\frac{x_{2}-x_{1}}{\Delta t_{\max }}
$$



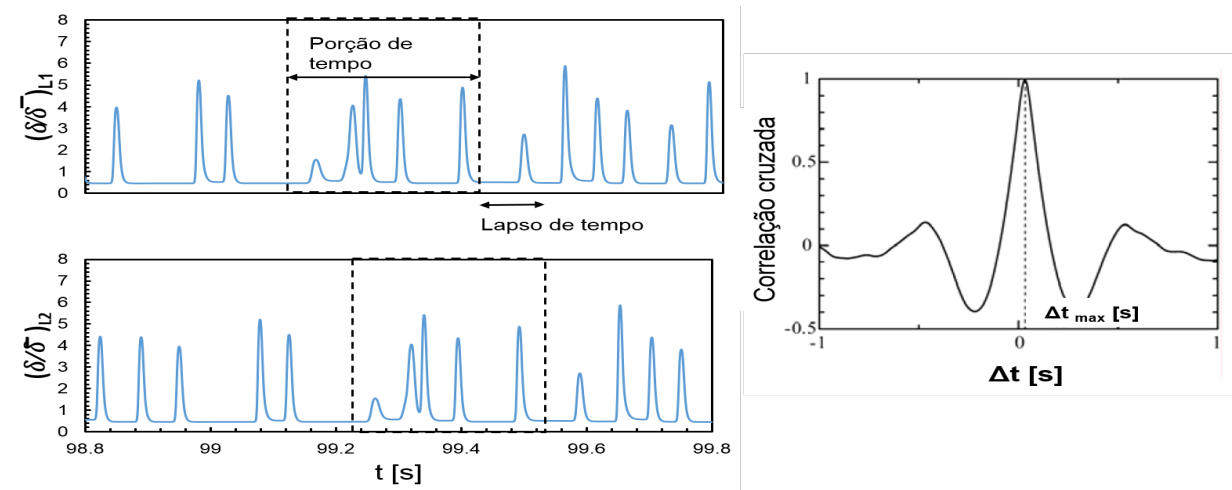

Figura 2.4: Ilustração de uma correlação cruzada aplicada para uma série temporal

Para determinar $\Delta t_{\text {max }}$, utiliza-se uma correlação cruzada de dois sinais de espessura de líquido no tempo referentes a duas coordenadas. O intervalo de tempo desejado é determinado em função do valor máximo da correlação cruzada, conforme ilustrado em Fig. 2.4. Como já mencionado a Transformada de Fourier para cada sinal é obtido com o comando "fft"do MATLAB (2012), e a Transformada Inversa de Fourier com o comando "ifft".

A determinação da distância entre as sondas, $\Delta L=x_{2}-x_{1}$, para determinação da velocidade da estrutura é crítica para a avaliação adequada da velocidade. As sondas não podem estar distante demais, tal que coalescência das ondas afete o resultado, ou posicionadas a distancias muito próximas, tal que o intervalo de tempo seja pequeno demais. Dessa forma, a coordenada $x_{1}$ é mantida constante e a velocidade da estrutura é avaliada, conforme descrito acima utilizando a correlação cruzada, variando-se a posição $x_{2}$, i.e., alterando a distância entre as sondas. Avalia-se então, como a velocidade da estrutura varia em função da distância entre as sondas, conforme ilustrado na Fig. 2.5. A velocidade desejada corresponde ao valor que independe da distância entre as sondas. 


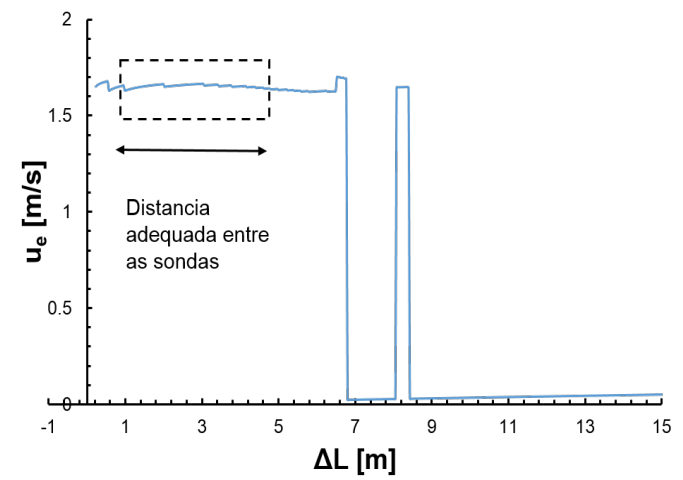

Figura 2.5: Velocidade da onda em função da distância entre as sondas. 


\section{3}

\section{Análise da Hiperbolicidade do Modelo de Dois Fluidos}

Como mencionado, o processo de média para a obtenção da modelagem unidimensional do Modelo de Dois Fluidos leva à perda de informações relativas aos transporte de massa e quantidade de movimento, e o sistema de equações pode ser mal posto. Segundo Courant \& Lax (1949), uma modelagem é dita bem posta, quando as equações constituintes atendem às condições de Hadamard, isto é:

- A solução existe

- A solução é única

- A solução depende continuamente das condições iniciais e de contorno

Um problema mal posto não possui solução única, e qualquer solução obtida em problemas deste tipo faz parte de um conjunto infinito de soluções, todas elas igualmente inválidas. A aplicação de uma perturbação infinitesimal implicará na obtenção de uma nova solução que pode diferir significativamente da solução original. O comportamento de um sistema mal posto se traduz tipicamente na impossibilidade de obtenção de uma solução independente do refinamento da malha.

Para determinar se o sistema de equações é bem ou mal posto, é conveniente reescrever o sistema de equações diferenciais na forma matricial como:

$$
\mathbf{A}(\mathbf{v}) \frac{\partial}{\partial t} \mathbf{v}+\mathbf{B}(\mathbf{v}) \frac{\partial}{\partial x} \mathbf{v}+\mathbf{C}(\mathbf{v})=0
$$

onde $\mathbf{v}$ é o vetor de variáveis independentes, que no presente caso, contém a solução do sistema representado pelo Modelo de Dois Fluidos

$$
\mathbf{v}=\left[\begin{array}{llll}
\alpha_{G} & U_{G} & U_{L} & P_{G_{i}}
\end{array}\right]^{T}
$$

$\mathrm{Na}$ Eq. (3.1) A e B são as matrizes Jacobianas de dimensão $n \times n$ e C é um vetor coluna de dimensão $n$. O sistema definido pela equação (3.1) representa um problema de valor inicial, e consiste em achar a solução para o sistema na região $0 \leq x \leq L$ ( $L$ é o comprimento da tubulação) e $t \geq 0$, sujeito à condição inicial $v(0, x)=v_{\text {ini }}(x)$. 
Para verificar o caráter matemático das equações, as características do sistema devem ser avaliadas. As características $\lambda_{n}$ são definidas tais que:

$$
\operatorname{det}\left(\mathbf{B}-\lambda_{n} \mathbf{A}\right)=0
$$

A equação acima possui $n$ raízes $\left(\lambda_{n}\right)$ para as $n$ equações do sistema, o qual é considerado bem-posto se, e somente se, todas as raízes forem reais. É importante notar que a vetor $\mathbf{C}$ não influencia no cálculo de $\lambda_{n}$.

Tendo como base as raízes $\lambda_{n}$ é possível definir uma classificação para o sistema de equações diferenciais parciais como descrito abaixo:

- Se todas as $n$ raízes $\left(\lambda_{n}\right)$ forem reais e distintas, o sistema é hiperbólico.

- Se houver a presença de raízes reais iguais, o sistema é parabólico.

- Se raízes complexas forem obtidas, o sistema é elíptico (as raízes complexas serão pares conjugados, uma vez que os coeficientes das matrizes $\mathbf{A}$ e B são reais).

Se todas as características forem reais e distintas, o problema é bemposto e a informação se propaga no domínio real. O número de grandezas a ser prescrito para o problema de valor inicial equivale ao número de características obtidas. Características complexas implicam na propagação de informação do plano complexo para o plano real e o problema de valor inicial é mal-posto. A obtenção de solução seria possível com a prescrição de condições de contorno em todo o espaço-tempo (problema de valor de contorno), o que implicaria na necessidade (fisicamente impossível) de prover informações de tempos futuros (Prosperetti \& Tryggvason, 2007).

Problemas transientes governados por sistemas hiperbólicos ou parabólicos são bem-postos, enquanto que problemas elípticos são mal-postos. A Eq. (3.1) é normalmente denominada equação característica e as raízes do sistema, dadas por $\lambda_{n}=\mathbf{B A}^{\mathbf{- 1}}=\frac{\mathbf{d x}}{\mathbf{d t}}$, determinam as velocidades características, que também definem as direções ao longo das quais as informações se propagam através dos campos de escoamento.

Para avaliar os coeficientes do sistema dado pela Eq. (3.1) e determinar a região em que o sistema é bem/mal posto, considerou-se ambas as fases como incompressíveis. O sistema de equações dado pelas Eqs. (2.5) - (2.8) é reescrito em função dos componentes de v, Eq. (3.2). Lembrando que $\partial \alpha_{L} / \partial x=-\partial \alpha_{G} / \partial x$ e expandindo as derivadas, tem-se

$$
\rho_{G} \frac{\partial \alpha_{G}}{\partial t}+\alpha_{G} \rho_{G} \frac{\partial U_{G}}{\partial x}+\rho_{G} U_{G} \frac{\partial \alpha_{G}}{\partial x}=0
$$




$$
-\rho_{L} \frac{\partial \alpha_{G}}{\partial t}+\alpha_{L} \rho_{L} \frac{\partial U_{L}}{\partial x}-\rho_{L} U_{L} \frac{\partial \alpha_{G}}{\partial x}=0
$$

As equações de conservação de quantidade de movimento linear para o gás e líquido reescritas em função da pressão do gás na interface e expandidas são dadas por:

$$
\begin{aligned}
\rho_{G} & U_{G} \frac{\partial \alpha_{G}}{\partial t}+\alpha_{G} \rho_{G} \frac{\partial U_{G}}{\partial t}+C_{G} \rho_{G} U_{G}^{2} \frac{\partial \alpha_{G}}{\partial x}+2 C_{G} \alpha_{G} \rho_{G} U_{G} \frac{\partial U_{G}}{\partial x} \\
& +\alpha_{G} \frac{\partial P_{G_{i}}}{\partial x}+\left(P_{G}-P_{G i}\right) \frac{\partial \alpha_{G}}{\partial x}+\alpha_{G} \frac{\partial\left(P_{G}-P_{G i}\right)}{\partial x} \\
& +\alpha_{G} \rho_{G} g \Gamma \sin \beta \frac{\partial \alpha_{G}}{\partial x}=-\alpha_{G} \rho_{G} g \cos \beta-\frac{\tau_{w_{G}} S_{G}}{A}-\frac{\tau_{i} S_{i}}{A}
\end{aligned}
$$

e

$$
\begin{gathered}
-\rho_{L} U_{L} \frac{\partial \alpha_{G}}{\partial t}+\alpha_{L} \rho_{L} \frac{\partial U_{L}}{\partial t}-C_{L} \rho_{L} U_{L}^{2} \frac{\partial \alpha_{G}}{\partial x}+2 C_{L} \alpha_{L} \rho_{L} U_{L} \frac{\partial U_{L}}{\partial x} \\
+\alpha_{L} \frac{\partial P_{G_{i}}}{\partial x}-\left(P_{L}-P_{L i}\right) \frac{\partial \alpha_{G}}{\partial x}+\alpha_{L} \frac{\partial\left(P_{L}-P_{L i}\right)}{\partial x} \\
+\alpha_{L} \rho_{L} g \Gamma \sin \beta \frac{\partial \alpha_{G}}{\partial x}=-\alpha_{L} \rho_{L} g \cos \beta-\frac{\tau_{w_{L}} S_{L}}{A}+\frac{\tau_{i} S_{i}}{A}
\end{gathered}
$$

, respectivamente. Bonizzi (2003) constatou que a os auto-valores do sistema linear não se alteram significativamente ao se considerar ambas as fases incompressíveis. A mesma conclusão foi obtida por Carneiro (2006) ao realizar uma análise uma análise de ordem de grandeza nas equações.

Assim, as matrizes Jacobianas A e B para as fases incompressíveis são:

$\mathbf{A}=\left[\begin{array}{cccc}\rho_{G} & 0 & 0 & 0 \\ -\rho_{L} & 0 & 0 & 0 \\ \rho_{G} U_{G} & \rho_{G} \alpha_{G} & 0 & 0 \\ -\rho_{L} U_{L} & 0 & \rho_{L} \alpha_{L} & 0\end{array}\right] \quad ; \quad \mathbf{B}=\left[\begin{array}{cccc}\rho_{G} U_{G} & \rho_{G} \alpha_{G} & 0 & 0 \\ -\rho_{L} U_{L} & 0 & \rho_{L} \alpha_{G} & 0 \\ B_{31} & B_{32} & B_{33} & B_{34} \\ B_{41} & B_{42} & B_{43} & B_{44}\end{array}\right](\beta .10)$

sendo

$$
\mathbf{B}-\lambda \mathbf{A}=\left[\begin{array}{cccc}
a_{1} & a_{2} & 0 & 0 \\
b_{1} & 0 & b_{3} & 0 \\
c_{1} & c_{2} & c_{3} & c_{4} \\
d_{1} & d_{2} & d_{3} & d_{4}
\end{array}\right]
$$


O determinante da matriz $\left(\mathbf{B}-\lambda_{n} \mathbf{A}\right)$ é

$$
\operatorname{det}\left(\mathbf{B}-\lambda_{n} \mathbf{A}\right)=\phi_{1}+\phi_{2}+\phi_{3}+\phi_{4}+\phi_{5}+\phi_{6}
$$

onde

$$
\begin{aligned}
\phi_{1} & =-a_{1} b_{3} c_{2} d_{4} \\
\phi_{2} & =a_{2} b_{1} c_{4} d_{3} \\
\phi_{3} & =a_{2} b_{3} c_{1} d_{4} \\
\phi_{4} & =-a_{2} b_{3} c_{4} d_{1} \\
\phi_{5} & =a_{1} b_{3} c_{4} d_{2} \\
\phi_{6} & =-a_{2} b_{1} c_{3} d_{4}
\end{aligned}
$$

Resolvendo $\operatorname{det}\left(\mathbf{B}-\lambda_{n} \mathbf{A}\right)=0$ obtém-se quatro autovalores,

$$
\left[\begin{array}{llll}
\lambda_{1} & \lambda_{2} & 0 & 0
\end{array}\right]
$$

sendo dois nulos. Os dois autovalores diferentes de zero são dados pelas raízes da equação quadrática na forma característica $a \lambda^{2}+b \lambda+c=0$, e:

$$
\lambda_{1,2}=\frac{-b \pm \sqrt{\Delta}}{2 a}
$$

onde

$$
\Delta=b^{2}-4 a c
$$

Para definir se o sistema é bem posto e garantir a hiperbolicidade do sistema, é necessário que $\Delta \geq 0$.

\section{1}

\section{Modelo 1}

Fowler \& Lisseter (1992) estabelecem que:

$$
P_{G}-P_{G_{i}}=0 \quad ; \quad P_{L}-P_{L_{i}}=W_{f_{L}} \rho_{L}(\chi-1)^{2} U_{L}^{2}
$$

Neste caso o termo da pressão dinâmica pode ser incorporado no termo convectivo da equação de quantidade de movimento, o qual passa a ser

$$
\frac{\partial C_{L} \rho_{L} \alpha_{L} U_{L}^{2}}{\partial x}+\frac{\partial \alpha_{L} \Delta P_{L_{d i n}}}{\partial x}=\frac{\partial D_{L} \rho_{L} \alpha_{L} U_{L}^{2}}{\partial x}
$$


onde

$$
D_{L}=C_{L}+W_{f_{L}}(\chi-1)^{2}
$$

Os coeficientes $a, b$ e $c$ necessários para encontrar as raízes de $\Delta$, Eq. (3.16) do Modelo 1 são

$$
\begin{gathered}
a=\alpha_{G} \rho_{L}+\alpha_{L} \rho_{G} \\
b=-2\left[C_{G} \alpha_{L} \rho_{G} U_{G}+D_{L} \alpha_{G} \rho_{L} U_{L}\right] \\
c=C_{G} \alpha_{L} \rho_{G} U_{G}^{2}+D_{L} \alpha_{G} \rho_{L} U_{L}^{2}+\alpha_{G} \alpha_{L} g \Gamma\left(\rho_{L}-\rho_{G}\right) \cos \beta
\end{gathered}
$$

Para definir se o sistema é bem posto e garantir a hiperbolicidade do sistema, é necessário que $\Delta=b^{2}-4 a c \geq 0$, o qual leva ao seguinte critério:

$$
\begin{aligned}
& -\left(C_{G} U_{G}-D_{L} U_{L}\right)^{2} \\
& \quad+\left[\left(\frac{\alpha_{G} \rho_{L}+\alpha_{L} \rho_{G}}{\rho_{L} \rho_{G} \alpha_{G} \alpha_{L}}\right)\left[\alpha_{L} \rho_{G} U_{G}^{2} C_{G}\left(C_{G}-1\right)+\alpha_{G} \rho_{L} U_{L}^{2} D_{L}\left(D_{L}-1\right)\right]\right. \\
& \left.\quad-\left(\frac{\alpha_{G}}{\rho_{G}}+\frac{\alpha_{L}}{\rho_{L}}\right) g \Gamma\left(\rho_{L}-\rho_{G}\right) \cos \beta\right] \geq 0
\end{aligned}
$$

Se a pressão dinâmica for desprezada na Eq. (3.19), $D_{L}=C_{L}$. Adicionalmente, se considerarmos os parâmetros de fluxo de quantidade de movimento como $C_{L}=C_{G}=1$, obtêm-se o critério de estabilidade do Modelo de Dois Fluidos "clássico"( Issa \& Kempf, 2003; Carneiro, 2006 e Montini, 2011).

$$
\begin{aligned}
-( & \left.U_{G}-U_{L}\right)^{2} \\
& \left.-\left(\frac{\alpha_{G}}{\rho_{G}}+\frac{\alpha_{L}}{\rho_{L}}\right) g \Gamma\left(\rho_{L}-\rho_{G}\right) \cos \beta\right] \geq 0
\end{aligned}
$$

Note-se que para escoamento vertical $\left(\cos 90^{\circ}=0\right)$, a Eq. (3.23) indica que o sistema de equações é incondicionalmente mal-posto para $U_{L} \neq U_{G}$.

De acordo com o exposto, pode-se concluir que o Modelo de Dois Fluidos " clássico "só será bem posto se a distribuição hidrostática de pressão ou pressão 
dinâmica for introduzida ou o parâmetro de fluxo $C_{L}$ for considerado $\left(C_{L}>1\right)$ conforme estudado por Montini (2011) e Inácio (2012).

Analisando o termo de pressão dinâmica proposto por Fowler \& Lisseter (1992), observa-se que o efeito do mesmo é muito pequeno, pois $\chi=2 \mathrm{e}$ $W_{f}=0,02$, resultando em um aumento pouco significativo no parâmetro de distribuição, pois $D_{L}=C_{L}+W_{f}(\chi-1)^{2}=1+0.02$.

\section{2}

\section{Modelo 2}

Segundo Bestion (1990), a pressão média tanto do gás como do líquido são diferentes dos valores reinantes na interface, e esta diferença é a pressão dinâmica de cada fase, definida como:

$$
P_{k}-P_{k_{i}}=W_{f_{k}} \rho_{m}\left(U_{L}-U_{G}\right)^{2} \quad ; \quad W_{f_{G}}=W_{f_{L}}=W_{c}
$$

onde para escoamento vertical $W_{c}=1,2$, sendo a massa específica de referência $\rho_{m}$ igual a

$$
\rho_{m}=\frac{\rho_{L} \rho_{G} \alpha_{G} \alpha_{L}}{\alpha_{G} \rho_{L}+\alpha_{L} \rho_{G}}
$$

Neste caso, os coeficientes da equação quadrática na forma característica $a \lambda^{2}+b \lambda+c=0$ são

$$
a=\alpha_{G} \rho_{L}+\alpha_{L} \rho_{G}
$$

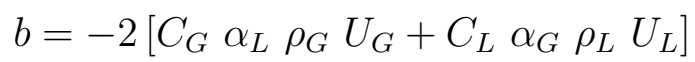

$c=C_{G} \alpha_{L} \rho_{G} U_{G}^{2}+C_{L} \alpha_{G} \rho_{L} U_{L}^{2}+\alpha_{L} \alpha_{G} g \Gamma\left(\rho_{L}-\rho_{G}\right) \cos \beta-\rho_{m} W_{c}\left(U_{L}-U_{G}\right)^{2}$

Para garantir a hiperbolicidade do sistema $b^{2}-4 a c \geq 0$, obtém-se o 
seguinte critério:

$$
\begin{aligned}
& -\left(C_{G} U_{G}-C_{L} U_{L}\right)^{2} \\
& \quad+\left[\left(\frac{\alpha_{G} \rho_{L}+\alpha_{L} \rho_{G}}{\rho_{L} \rho_{G} \alpha_{G} \alpha_{L}}\right)\left[\alpha_{L} \rho_{G} U_{G}^{2} C_{G}\left(C_{G}-1\right)+\alpha_{G} \rho_{L} U_{L}^{2} C_{L}\left(C_{L}-1\right)\right]\right. \\
& \left.\quad+W_{c}\left(U_{L}-U_{G}\right)^{2}-\left(\frac{\alpha_{G}}{\rho_{G}}+\frac{\alpha_{L}}{\rho_{L}}\right) g \Gamma\left(\rho_{L}-\rho_{G}\right) \cos \beta\right] \geq 0
\end{aligned}
$$

Se $C_{G}=C_{L}=1$ e o escoamento for vertical, então:

$$
W_{c}\left(U_{L}-U_{G}\right)^{2} \geq\left(U_{G}-U_{L}\right)^{2}
$$

logo, temos que o sistema será sempre bem posto se

$$
W_{c} \geq 1
$$

Bestion (1990) estabelece $W_{c}$ como uma constante igual a 1,2 para escoamentos em tubulações verticais $\left(\beta=90^{\circ}\right)$, garantindo que o Modelo de Dois Fluidos seja hiperbólico para qualquer conjunto de velocidades.

Este critério de estabilidade é uma boa aproximação para avaliar os coeficientes do sistema, apesar da aproximação de que ambas as fases são incompressíveis. Conforme mencionado anteriormente, as análises de Bonizzi (2003) e Carneiro (2006) mostra que razoável supor que as conclusões da análise de hiperbolicidade para o sistema incompressível também são válidas para o caso compressível.

\section{3}

\section{Modelo 3}

O modelo proposto neste trabalho emprega o modelo de pressão dinâmica proposto por Fowler \& Lisseter (1992), utilizando a correlação de velocidade da onda proposta por Berna et al. (2014). Dessa forma a pressão dinâmica do gás é nula, porém, a pressão dinâmica do líquido é bem mais complexa.

$$
P_{G}-P_{G_{i}}=0 \quad ; \quad P_{L}-P_{L_{i}}=W_{f_{L}} \rho_{L}\left(U_{L}-U_{\text {onda }}\right)^{2}
$$

sendo $U_{\text {onda }}=f\left(U_{L}, U_{G}, \alpha_{G}\right)$.

Os coeficientes da equação característica $a \lambda^{2}+b \lambda+c=0$ são calculados resolvendo $\operatorname{det}\left(\mathbf{B}-\lambda_{n} \mathbf{A}\right)=0$ tal que: 


$$
a=\alpha_{G} \rho_{L}+\alpha_{L} \rho_{G}
$$

$$
b=-2\left[C_{G} \alpha_{L} \rho_{G} U_{G}+\alpha_{G} \rho_{L} U_{L}\left(C_{L}+W_{f_{L}} \Pi \Omega\right)\right]
$$

$$
\begin{aligned}
c= & C_{G} \alpha_{L} \rho_{G} U_{G}^{2}+\left(D_{L}+W_{f_{L}} \Pi(\Omega-\Pi)\right) \alpha_{G} \rho_{L} U_{L}^{2} \\
& +\alpha_{G} \alpha_{L} g \Gamma\left(\rho_{L}-\rho_{G}\right) \cos \beta \\
& -2 \alpha_{G} \rho_{L} W_{f_{L}} U_{L} \Pi\left[\alpha_{L} \frac{\partial U_{\text {onda }}}{\partial \alpha_{G}}-\left(U_{G}-U_{L}\right) \xi\right]
\end{aligned}
$$

com

$$
D_{L}=C_{L}+W_{f_{L}} \Pi \Omega
$$

Para satisfazer o critério $b^{2}-4 a c \geq 0$ de forma a obter sistema bem posto, tem-se:

$$
\begin{aligned}
& -\left[C_{G} U_{G}-D_{L} U_{L}\right]^{2} \\
& \quad+\left\{( \frac { \alpha _ { G } \rho _ { L } + \alpha _ { L } \rho _ { G } } { \rho _ { L } \rho _ { G } \alpha _ { G } \alpha _ { L } } ) \left[\alpha_{L} \rho_{G} U_{G}^{2} C_{G}\left(C_{G}-1\right)+\alpha_{G} \rho_{L} U_{L}^{2} D_{L}\left(D_{L}-1\right)\right.\right. \\
& \left.-\alpha_{G} \rho_{L} W_{f_{L}} U_{L} \Pi\left(U_{L}(\Omega-\Pi)-2\left[\alpha_{L} \frac{\partial U_{\text {wave }}}{\partial \alpha_{G}}-\left(U_{G}-U_{L}\right) \xi\right]\right)\right] \\
& \left.-\left(\frac{\alpha_{G}}{\rho_{G}}+\frac{\alpha_{L}}{\rho_{L}}\right) g \Gamma\left(\rho_{L}-\rho_{G}\right) \cos \beta\right\} \geq 0
\end{aligned}
$$

Note que se a velocidade da onda for definida como proposto por Fowler \& Lisseter (1992), i.e., $U_{\text {onda }}=\chi U_{L}$, o critério apresentado na Eq. (3.39) recai no critério apresentado para o Modelo 1, Eq. (3.23), pois $\partial U_{\text {onda }} / \partial \alpha_{G}=0$, $\xi=0, \Omega=(1-\chi)$ e $\Pi=(1-\chi)$. 
As derivadas da velocidade da onda necessárias para avaliar o critério dado pela Eq. (3.39) são

$$
\begin{gathered}
\frac{\partial U_{\text {onda }}}{\partial U_{L}}=1,16 \frac{U_{\text {onda }}}{U_{L}} \frac{\sqrt{\rho_{L}} U_{s L}}{\sqrt{\rho_{G}} U_{s G}+\sqrt{\rho_{L}} U_{s L}} \\
\frac{\partial U_{\text {onda }}}{\partial U_{G}}=\frac{U_{\text {onda }}}{U_{G}}\left(\frac{\sqrt{\rho_{G}} U_{s G}}{\sqrt{\rho_{G}} U_{s G}+\sqrt{\rho_{L}} U_{s L}}-0,38\right) \\
\frac{\partial U_{\text {onda }}}{\partial \alpha_{G}}=\frac{U_{\text {onda }}}{\alpha_{G}} \frac{0,62 \alpha_{L}-0,16 \alpha_{G}}{\alpha_{L}}
\end{gathered}
$$

A utilização do modelo de velocidade da onda proposto por Berna et al. (2014) torna o critério bem/mal posto bem mais complexo, como pode ser observado na Eq. (3.39). 


\section{4}

\section{Método Numérico}

As equações de conservação de massa e quantidade de movimento do Modelo de Dois Fluidos uni-dimensional apresentadas no Capítulo 2 foram discretizadas pelo método de Volumes Finitos (Patankar, 1980). Este método basea-se em dividir o domínio computacional em pequenos volumes de controles, e integrar temporalmente e espacialmente as equações de transporte em cada volume de controle, estabelecendo um sistema de equações algébricas, que expressem as mesmas leis de conservação em cada um deles.

Visando minimizar problemas de instabilidades, e seguindo a recomendação de Patankar (1980), as variáveis escalares (frações volumétricas, pressão, massas específicas) são armazenadas nos nós principais, enquanto as velocidades são armazenadas nas faces do volume de controle, conforme ilustrado na Fig. 4.1. Na Figura 4.1, os símbolos maiúsculos referem-se aos pontos nodais principais do volume de controle, sendo $P$ o volume principal e os vizinhos oeste ( $W$, "west") e leste ( $E$, "east"), respectivamente. Já os símbolos minúsculos correspondem às faces dos volumes de controle, onde as velocidades são armazenadas. Os símbolos w e $e$, referem-se às faces oeste e leste do volume de controle. $\Delta x$ é o tamanho do volume de controle, i.e., a distância entre as faces w e e, e $\delta x$ é a distância entre o nós principais. Neste trabalho o espaçamento no volume de controle é mantido constante, consequentemente $\Delta x=\delta x$. Vale ressaltar no entanto, que nas fronteiras, utiliza-se $1 / 2$ volumes de controle.

a)

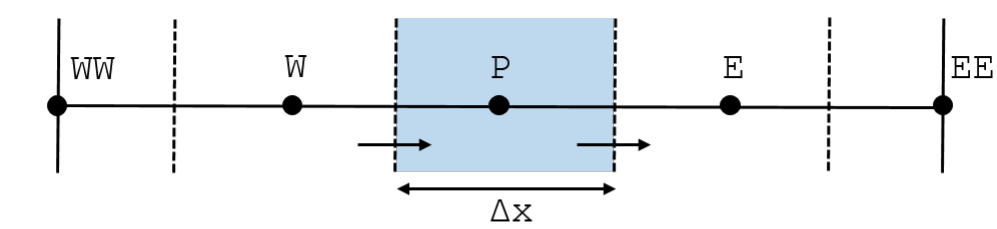

b)

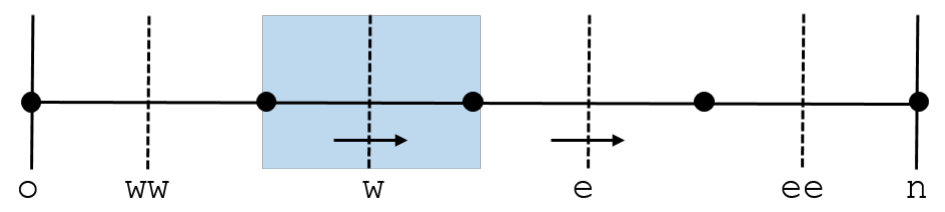

Figura 4.1: Arranjo da malha. a)Volume de controle escalar. b)Volume de controle vetorial

A modelagem da pressão dinâmica foi introduzida em um código desenvolvido pelo Grupo de Dinâmica dos Fluidos Computacional (DFC) (Ortega 
\& Nieckele, 2005, Carneiro, 2006, Inácio, 2012, Simões et al., 2014) do Departamento de Engenharia Mecânica da PUC-Rio. No presente trabalho, além da introdução da pressão dinâmica, foi implementado um modelo de 2a ordem para a discretização espacial da equações de conservação. Detalhes da discretização das equações de conservação, algoritmo de solução e critérios de convergência são apresentados a seguir.

\section{1}

\section{Fração Volumétrica de Gás}

A fração volumétrica do gás $\alpha_{G}$ é obtida através a solução da equação de conservação de massa da fase gasosa. A fração volumétrica da fase líquida é determinada a partir de $\alpha_{L}=1-\alpha_{g}$.

A equação discretizada é obtida pela integração no tempo e no volume de controle da Eq. (2.5) no volume de controle principal da Figura 4.1a, com dimensão $\Delta \forall=A \Delta x$ de acordo com

$$
\int_{\mathrm{w}}^{\mathrm{e}} \int_{t}^{t+\Delta t} \frac{\partial\left(\alpha_{G} \rho_{G}\right)}{\partial t} d t A d x+\int_{t}^{t+\Delta t} \int_{\mathrm{w}}^{\mathrm{e}} \frac{\partial\left(\alpha_{G} \rho_{G} U_{G}\right)}{\partial x} A d x d t=0
$$

Utilizando para a integração temporal um esquema de primeira ordem totalmente implícito, a equação (4.1) fica da forma:

$$
\left.\left.\left[\rho_{G} \alpha_{G}\right)_{P}-\rho_{G} \alpha_{G}\right)_{P}^{o}\right] \frac{A \Delta x}{\Delta t}+\left(\rho_{G} U_{G} A\right)_{\mathrm{e}} \alpha_{G_{\mathrm{e}}}-\left(\rho_{G} U_{G} A\right)_{\mathrm{w}} \alpha_{G_{\mathrm{w}}}=0
$$

onde os subscritos indicam a posição onde as grandezas são avaliadas. O superscrito $o$ indica instante de tempo $t$ e os termos sem superscrito correspondem ao novo instante de tempo $t+\Delta t$.

Existem na literatura muitos esquemas para avaliar o valor de $\alpha_{G}$ nas faces do volume de controle. O esquema de primeira ordem Upwind (Patankar, 1980) apresentou bons resultados em trabalhos de Inácio (2012), Carneiro (2006), Simões et al. (2014), para prever o padrão estratitificado e de golfadas. No entanto, o esquema Upwind, apesar de ser muito estável, é conhecido pelo problema da falsa difusão. Visando aprimorar o código desenvolvido pelo grupo DFC, implementou-se um esquema de ordem superior, baseado na metodologia TVD, Total Variation Diminishing, (Versteeg \& Malalasekera, 2007), o qual é descrito a seguir. A implementação da metodologia TVD foi verificada e validada de acordo com os procedimentos de Roache (1998), realizando testes que demonstraram que precisão de segunda ordem no espaço foi obtida. 


\subsection{1}

\section{Esquema espacial TVD}

O TVD (Total Variation Diminishing) é um esquema de ordem superior ao esquema Upwind, formulado com o fim de minimizar a falsa difusão, mantendo a estabilidade (Versteeg \& Malalasekera, 2007).

O esquema TVD considera o valor da grandeza $\alpha_{G}$ na face leste $e$ como:

$$
\begin{array}{r}
\alpha_{G_{\mathrm{e}}}=\left[\left|\operatorname{sinal}\left(U_{G_{\mathrm{e}}}\right), 0\right|\right] \alpha_{G_{P}}+\left[\left|-\operatorname{sinal}\left(U_{G_{\mathrm{e}}}\right), 0\right|\right] \alpha_{G_{E}} \\
-\operatorname{sinal}\left(U_{G_{\mathrm{e}}}\right) \frac{\psi\left(r_{\alpha_{\mathrm{e}}}\right)}{2}\left(\alpha_{G_{P}}-\alpha_{G_{E}}\right)
\end{array}
$$

onde $U_{G_{\mathrm{e}}}$ é a velocidade na face, $\left[\left|\operatorname{sinal}\left(U_{G_{\mathrm{e}}}\right), 0\right|\right]$ é o operador que denota o máximo entre o sinal de $U_{G_{\mathrm{e}}}$ e 0 com resultado 1 e $0 . \psi\left(r_{\alpha_{\mathrm{e}}}\right)$ representa uma função limitadora de fluxo, sendo $r_{\alpha_{\mathrm{e}}}$ a relação entre o gradiente Upwind e o gradiente Downwind de $\alpha_{G}$ avaliado na face leste, assim:

$$
r_{\alpha_{\mathrm{e}}}=\left[\left|\operatorname{sinal}\left(U_{G_{\mathrm{e}}}\right), 0\right|\right] \frac{\left(\alpha_{G_{P}}-\alpha_{G_{W}}\right)}{\left(\alpha_{G_{E}}-\alpha_{G_{P}}\right)}+\left[\left|-\operatorname{sinal}\left(U_{G_{\mathrm{e}}}\right), 0\right|\right] \frac{\left(\alpha_{G_{E E}}-\alpha_{G_{E}}\right)}{\left(\alpha_{G_{E}}-\alpha_{G_{P}}\right)}
$$

Segundo Versteeg \& Malalasekera (2007), as formulações mais populares para a função limitadora de fluxo $\psi(r)$ são as de Van Leer (1974), Van Albada et al. (1997) e Sweby (1984). Neste trabalho, a função limitadora de fluxo proposta por Van Leer foi selecionada, sendo definida como:

$$
\psi(r)=\frac{r+|r|}{1+r}
$$

A equação de discretização resultante para a fração volumétrica de gás, considerando o esquema TVD é:

$$
a_{P} \alpha_{G_{P}}=a_{E} \alpha_{G_{E}}+a_{W} \alpha_{G_{W}}+b
$$

onde os coeficientes são:

$$
\begin{gathered}
a_{E}=\left[\left|-\bar{F}_{e}, 0\right|\right] \quad ; \quad a_{W}=\left[\left|\bar{F}_{\mathrm{w}}, 0\right|\right] \quad ; \quad a_{P}^{o}=\rho_{G_{P}}^{o} \frac{A \Delta x}{\Delta t} \\
a_{P}=\rho_{G_{P}} \frac{A \Delta x}{\Delta t}+\left[\left|\bar{F}_{\mathrm{e}}, 0\right|\right]+\left[\left|-\bar{F}_{\mathrm{w}}, 0\right|\right] \quad ; \quad b=a_{P}^{o} \alpha_{G_{P}}^{o}+b_{T V D}
\end{gathered}
$$

$\bar{F}_{\text {w }}$ e $\bar{F}_{\text {e }}$ são pseudo fluxos de massa avaliados nas faces w e e

$$
\bar{F}_{\mathrm{w}}=\widehat{\rho}_{G_{\mathrm{w}}} U_{G_{\mathrm{w}}} A ; \quad \bar{F}_{\mathrm{e}}=\widehat{\rho}_{G_{\mathrm{e}}} U_{G_{\mathrm{e}}} A
$$


sendo a massa específica do gás nas faces determinada com a aproximação Upwind

$$
\begin{aligned}
& \widehat{\rho}_{G_{\mathrm{e}}}=\rho_{G_{P}}\left[\left|\operatorname{sinal}\left(U_{G_{e}}\right), 0\right|\right]-\rho_{G_{E}}\left[\left|-\operatorname{sinal}\left(U_{G_{e}}\right), 0\right|\right] \\
& \widehat{\rho}_{G_{\mathrm{w}}}=\rho_{G_{W}}\left[\mid \operatorname{sinal}\left(U_{G_{\mathrm{w}}}, 0 \mid\right]-\rho_{G_{P}}\left[\mid-\operatorname{sinal}\left(U_{G_{\mathrm{w}}}, 0 \mid\right]\right.\right.
\end{aligned}
$$

O termo $b_{T V D}$ é referente a contribuição da fração de gás dos nós vizinhos ao valor da face, de acordo com o esquema TVD, sendo nulo no caso da formulação Upwind. Este termo é

$$
b_{T V D}=-\frac{1}{2}\left|\bar{F}_{\mathrm{e}}\right| \psi\left(r_{\alpha_{\mathrm{e}}}\right)\left(\alpha_{G_{E}}-\alpha_{G_{P}}\right)-\frac{1}{2}\left|\bar{F}_{\mathrm{w}}\right| \psi\left(r_{\alpha_{\mathrm{w}}}\right)\left(\alpha_{G_{W}}-\alpha_{G_{P}}\right)
$$

\section{2 \\ Velocidades}

As velocidades das fases gasosa e líquida são obtidas a partir da solução das equações da conservação de quantidade de movimento para gás e o líquido, Eqs.(2.7) e (2.8), respetivamente. A discretização para as ditas equações diferenciais é similar à discretização da equação de conservação de massa de gás, porém sendo feita sobre o volume de controle deslocado, centrada nas faces do volume de controle principal, conforme ilustrado na Figura 4.1b. Uma vez que a pressão não é conhecida, a pressão aparece explicitamente nas equações discretizadas para as velocidades. A forma discretizada das equações para o gás e líquido são:

$$
\begin{aligned}
& \frac{a_{G_{\mathrm{w}}}}{\gamma} U_{G_{\mathrm{e}}}=a_{G_{\mathrm{e}}} U_{G_{\mathrm{e}}}+a_{G_{\mathrm{ww}}} U_{G_{\mathrm{ww}}}+b_{G}+(1-\gamma) \frac{a_{G_{\mathrm{w}}}}{\gamma} U_{G_{\mathrm{w}}}^{*}-\alpha_{G_{\mathrm{w}}} A\left(P_{P}-P_{W}\right) \\
& \frac{a_{L_{\mathrm{w}}}}{\gamma} U_{L_{\mathrm{e}}}=a_{L_{\mathrm{e}}} U_{L_{\mathrm{e}}}+a_{L_{\mathrm{ww}}} U_{L_{\mathrm{w}}}+b_{L}+(1-\gamma) \frac{a_{L_{\mathrm{w}}}}{\gamma} U_{L_{\mathrm{w}}}^{*}-\alpha_{L_{\mathrm{w}}} A\left(P_{P}-P_{W}\right)
\end{aligned}
$$

onde o fator de sub relaxação $\gamma$ foi introduzidos nas equações (4.12) e (4.13) para reduzir a taxa de variação entre iterações, conforme recomendado para soluções de problemas não lineares (Patankar, 1980). Para os casos presentes especificou-se um fator de sub-relaxação $\gamma=0,7$. Os termos $U_{G_{\mathrm{w}}}^{*}$ e $U_{L_{\mathrm{w}}}^{*}$ correspondem ao valor da velocidade do gás e líquido na iteração anterior. Os coeficientes são dados por: 


$$
\begin{aligned}
& a_{k_{\mathrm{e}}}=C_{k}\left[\left|-F_{k_{P}}, 0\right|\right] \quad ; \quad a_{k_{\mathrm{ww}}}=C_{k}\left[\left|F_{k_{W}}, 0\right|\right] \\
& b_{k}=a_{k_{\mathrm{w}}}^{o} U_{k_{\mathrm{w}}}^{o}+S c_{k} \Delta x+b_{T V D} \quad ; \quad a_{k_{\mathrm{w}}}^{o}=\widetilde{\rho}_{k_{\mathrm{w}}}^{o} \widetilde{\alpha}_{k_{\mathrm{w}}}^{o} \frac{A \Delta x}{\Delta t} \\
& b_{T V D}=-\frac{C_{k}}{2}\left|F_{k_{P}}\right| \psi\left(r_{U_{k_{P}}}\right)\left(U_{k_{\mathrm{e}}}-U_{k_{\mathrm{w}}}\right) \\
& -\frac{C_{k}}{2}\left|F_{k_{W}}\right| \psi\left(r_{U_{k_{W}}}\right)\left(U_{k_{\mathrm{w}}}-U_{k_{\mathrm{ww}}}\right) \\
& a_{k_{\mathrm{w}}}=\widetilde{\rho}_{k_{\mathrm{w}}} \widetilde{\alpha}_{k_{\mathrm{w}}} \frac{A \Delta x}{\Delta t}+C_{k}\left[\left|F_{k_{P}}, 0\right|\right]+C_{k}\left[\left|-F_{k_{W}}, 0\right|\right]+S p_{k} \Delta x
\end{aligned}
$$

onde $k$ faz referência à fase gasosa $(G)$ ou líquida $(L)$. Nas equações acima a massa específica do gás na face $\mathrm{w}, \widetilde{\rho}_{G_{\mathrm{w}}}$, e a fração volumétrica de ambas as fases $k$ na face $\mathrm{w}, \widetilde{\alpha}_{k_{\mathrm{w}}}$, são obtidas utilizando uma média aritmética

$$
\widetilde{\rho}_{G_{\mathrm{w}}}=\frac{\rho_{G_{W}}+\rho_{G_{P}}}{2} \quad ; \quad \widetilde{\alpha}_{k_{\mathrm{w}}}=\frac{\alpha_{k_{W}}+\alpha_{k_{P}}}{2}
$$

$F_{k_{P}}$ e $F_{k_{W}}$ são os fluxos de massa da fase $k$ avaliados nos pontos nodais principais $P$ e $W$.

$$
\left.\left.F_{k_{P}}=\rho_{k} \alpha_{k} U_{k} A\right)_{P} \quad ; \quad F_{k_{W}}=\rho_{k} \alpha_{k} U_{k} A\right)_{W}
$$

Estes fluxos de massa são obtidos a partir dos fluxos de massa avaliados nas faces dos volume de controle principal. Este procedimento é utilizado a fim de conservar a massa tanto no volume de controle principal como no volume deslocado (vetorial)

$$
F_{k_{P}}=\frac{F_{k_{\mathrm{w}}}+F_{k_{\mathrm{e}}}}{2} \quad ; \quad F_{k_{W}}=\frac{F_{k_{\mathrm{ww}}}+F_{k_{\mathrm{w}}}}{2}
$$

Os fluxos de massa nas faces w, e e ww são determinados em função da massa específica obtidas com a aproximação Upwind, Eq. (4.11) e da fração volumétrica utilizando a aproximação TVD dada pela Eq. (4.4)

$$
F_{k_{\mathrm{ww}}}=\widehat{\rho}_{k_{\mathrm{ww}}} \alpha_{k_{\mathrm{ww}}} U_{k_{\mathrm{ww}}} A, \quad F_{k_{\mathrm{w}}}=\widehat{\rho}_{k_{\mathrm{w}}} \alpha_{k_{\mathrm{w}}} U_{k_{\mathrm{w}}} A, \quad F_{k_{e}}=\widehat{\rho}_{k_{e}} \alpha_{k_{e}} U_{k_{e}} A
$$

Os termos $S_{P_{k}}$ e $S_{C_{k}}$ nas Eqs. (4.14) representam os termos fontes da equação de conservação de quantidade de movimento correspondente à fase $k$. 
Para a fase gás os termos de fonte são

$$
\begin{array}{r}
S_{P_{G}}=b_{\text {parede }_{G}}+b_{\text {interface }_{\text {face }}} \\
S_{C_{G}}=b_{\text {grav }_{G}}+b_{h_{G}}+b_{\text {interface }} U_{\text {onda }}+b_{\text {dyn }_{G}}
\end{array}
$$

e para a fase líquida são

$$
\begin{array}{r}
S_{P_{L}}=b_{\text {parede }_{L}} \\
S_{C_{L}}=b_{\text {grav }_{L}}++b_{h_{L}}+b_{\text {interface }}\left(U_{G}-U_{\text {onda }}\right)+b_{\text {dyn }}
\end{array}
$$

O atrito de cada uma das fases com a parede é dado por

$$
b_{\text {parede }_{G}}=\frac{1}{2} f_{G_{\mathrm{w}}} \widetilde{\rho}_{G_{\mathrm{w}}}\left|U_{G_{\mathrm{w}}}\right| S_{G_{\mathrm{w}}} \quad, \quad b_{\text {parede }_{L}}=\frac{1}{2} f_{L_{\mathrm{w}}} \widetilde{\rho}_{L}\left|U_{L_{\mathrm{w}}}\right| S_{L_{\mathrm{w}}}
$$

Para o padrão anular, $b_{\text {parede }_{G}}=0$. A contribuição do atrito na interface é

$$
b_{\text {interface }}=\frac{1}{2} f_{i_{\mathrm{w}}} \widetilde{\rho}_{G_{\mathrm{w}}}\left|U_{G_{\mathrm{w}}}-U_{\text {onda }}\right| S_{i_{\mathrm{w}}}
$$

onde $U_{\text {onda }}=\chi U_{L}$ para o Modelo $1, U_{\text {onda }}=U_{L}$, para Modelo 2 e $U_{\text {onda }}=$ $f\left(U_{L}, U_{G}, \alpha_{G}\right)$ para Modelo 3. Os fatores de atrito devem ser especificados conforme indicado no Capítulo 2.

O termo gravitacional para cada fase é

$$
b_{\operatorname{grav}_{G}}=-\widetilde{\rho}_{G_{\mathrm{w}}} \widetilde{\alpha}_{G_{\mathrm{w}}} A g \sin \beta \quad, \quad b_{\operatorname{grav}_{L}}=-\widetilde{\rho}_{L} \widetilde{\alpha}_{L_{\mathrm{w}}} A g \sin \beta
$$

Conforme apresentado na seção 2.2.4, as parcelas associadas com a variação da pressão hidrostática na seção transversal são

$b_{h_{G}}=-\widetilde{\rho}_{G_{\mathrm{w}}} \widetilde{\alpha}_{G_{\mathrm{w}}} A g \cos \beta\left(h_{L_{P}}-h_{L_{W}}\right) \quad, \quad b_{h_{L}}=-\widetilde{\rho}_{L} \widetilde{\alpha}_{L_{\mathrm{w}}} A g \cos \beta\left(h_{L_{P}}-h_{L_{W}}\right)$

Para escoamento vertical $b_{h_{k}}=0$.

Finalmente, os termos devido a introdução da pressão dinâmica são

$$
\begin{array}{r}
b_{d y n_{G}}=W_{f_{G}} A\left[\alpha_{G_{P}} \rho_{r e f_{P}}\left(U_{L_{P}}-U_{\text {onda }_{P}}\right)^{2}-\right. \\
\left.\alpha_{G_{W}} \rho_{r e f_{W}}\left(U_{L_{W}}-U_{\text {onda }}\right)^{2}\right] \\
b_{d y n_{L}}=W_{f_{L}} A\left[\alpha_{L_{P}} \rho_{\text {ref }_{P}}\left(U_{L_{P}}-U_{\text {onda }_{P}}\right)^{2}-\right. \\
\left.\alpha_{L_{W}} \rho_{r e f_{W}}\left(U_{L_{W}}-U_{\text {ond }_{W}}\right)^{2}\right]
\end{array}
$$

onde $W_{f_{G}}$ só é não nulo para o Modelo 2 . As velocidades nos pontos nodais $P$ 
e $W$ sâo obtidas utilizando meia aritmética, tal que:

$$
U_{k_{P}}=\frac{U_{k_{\mathrm{e}}}+U_{k_{\mathrm{w}}}}{2} ; \quad U_{k_{W}}=\frac{U_{k_{\mathrm{w}}}+U_{k_{\mathrm{ww}}}}{2}
$$

\section{3 \\ Pressão}

A pressão é determinada de forma a satisfazer o balanço global de massa. Esta equação pode ser obtida somando as equações de conservação de massa de cada fase. No entanto, devido à grande diferença de ordem de grandeza na massa específica dos gases e líquidos, Issa \& Kempf (2003), Bonizzi (2003) e Carneiro (2006) recomendam que cada uma dessas equações seja normalizada pela massa específica de referência antes de somá-las, resultando na seguinte equação

$$
\frac{\partial\left(\alpha_{L}\right)}{\partial t}+\frac{\partial\left(\alpha_{L} U_{L}\right)}{\partial x}+\frac{1}{\rho_{G_{r e f}}}\left(\frac{\partial\left(\alpha_{G} \rho_{G}\right)}{\partial t}+\frac{\partial\left(\alpha_{G} \rho_{G} U_{G}\right)}{\partial x}\right)=0
$$

Para determinar a pressão a Eq. (4.33) é discretizada de forma similar à equação de conservação de massa do gás, resultando em

$$
\begin{array}{r}
\left(\alpha_{L_{P}}-\alpha_{L_{P}}^{o}\right) \frac{A \Delta x}{\Delta t}+\left[\alpha_{L_{\mathrm{e}}} U_{L_{\mathrm{e}}} A-\alpha_{L_{\mathrm{w}}} U_{L_{\mathrm{w}}} A\right] \\
+\frac{1}{\rho_{G_{r e f}}}\left[\left(\alpha_{G_{P}} \rho_{G_{P}}-\rho_{G_{P}}^{o} \alpha_{G_{P}}^{o}\right) \frac{A \Delta x}{\Delta t}+\left(\widehat{\rho}_{G_{\mathrm{e}}} \alpha_{G_{\mathrm{e}}} U_{G_{\mathrm{e}}} A-\widehat{\rho}_{G_{\mathrm{w}}} \alpha_{G_{\mathrm{w}}} U_{G_{\mathrm{w}}} A\right)\right]=0
\end{array}
$$

sendo a massa específica do gás $\widehat{\rho}_{G}$ avaliada nas faces com a aproximação Upwind, (4.11), e a fração volumétrica de cada fase $k$, com a aproximação TVD, dada pela Eq. (4.4).

No entanto, a equação resultante não envolve a pressão. Seguindo um procedimento semelhante ao algoritmo PRIME (Ortega \& Nieckele (2005),Simões et al. (2014)), a pressão é incorporada na Eq. (4.34) ao avaliar as velocidades das fases nas faces a partir das equações de quantidade de movimento discretizadas, as quais podem ser reescritas da seguinte forma:

$$
U_{k_{\mathrm{w}}}=\hat{U}_{k_{\mathrm{w}}}-\frac{\widetilde{\alpha}_{k_{\mathrm{w}}} A}{a_{k_{\mathrm{w}}} / \gamma}\left(P_{P}-P_{W}\right)
$$

onde a pseudo velocidade na face oeste do nó $i$ é: 


$$
\hat{U}_{k_{\mathrm{w}}}=\frac{a_{k_{\mathrm{e}}} U_{k_{\mathrm{e}}}+a_{k_{\mathrm{ww}}} U_{k_{\mathrm{ww}}}+b_{k}+(1-\gamma)\left(a_{k_{\mathrm{w}}} / \gamma\right) U_{k_{\mathrm{w}}}^{*}}{a_{k_{\mathrm{w}}} / \gamma}
$$

As velocidades na face leste do nó $i$ são iguais as velocidades oeste do nó $i+1$, dessa forma

$$
U_{k_{\mathrm{e} i}}=U_{k_{\mathrm{w} i+1}}=\hat{U}_{k_{\mathrm{w} i+1}}-\frac{\widetilde{\alpha}_{k_{\mathrm{w} i+1}} A}{a_{k_{\mathrm{w} i+1}} / \gamma}\left(P_{E}-P_{P}\right)
$$

A massa específica do gás, no ponto nodal depende da pressão através da equação de gases ideais.

$$
\rho_{G}=\frac{P_{P}}{R T}=\rho_{G_{r e f}} \frac{P_{P}}{P_{r e f}}
$$

Sendo assim, a equação de discretização da pressão assume a seguinte

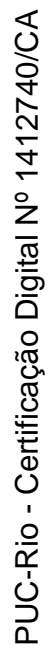
forma:

$$
a_{P} P_{P}=a_{E} P_{E}+a_{W} P_{W}+b_{P}
$$

Os coeficientes são determinados pelas expressões abaixo.

$$
\begin{gathered}
a_{E}=\frac{\left(\widehat{\rho}_{G_{\mathrm{e}}} \alpha_{G_{\mathrm{e}}} A\right) \widetilde{\alpha}_{G_{\mathrm{w} i+1}} A}{\left(a_{G_{\mathrm{w} i+1}} / \gamma\right) \rho_{G_{r e f}}}+\frac{\left(\alpha_{L_{\mathrm{e}}} A\right) \widetilde{\alpha}_{L_{\mathrm{w} i+1}} A}{\left(a_{L_{\mathrm{w} i+1}} / \gamma\right)} \\
a_{W}=\frac{\left(\widehat{\rho}_{G_{\mathrm{w}}} \alpha_{G_{\mathrm{w}}} A\right) \widetilde{\alpha}_{G_{\mathrm{w} i}} A}{\left(a_{G_{\mathrm{w} i}} / \gamma\right) \rho_{G_{r e f}}}+\frac{\left(\alpha_{L_{\mathrm{w}}} A\right) \widetilde{\alpha}_{L_{\mathrm{w} i}} A}{\left(a_{L_{\mathrm{w} i}} / \gamma\right)} \\
a_{P}=\frac{\alpha_{G_{P}}}{P_{r e f}} \frac{A \Delta x}{\Delta t}+a_{E}+a_{W} \\
b_{P}=\left[\alpha_{G_{P}}-\alpha_{G_{P}}^{o}+\left(\frac{\rho_{G_{P}}^{o}}{\rho_{G_{r e f}}} \alpha_{G_{P}}^{o}\right)\right] \frac{A \Delta x}{\Delta t} \\
+\left(\frac{\widehat{\rho}_{G_{\mathrm{w}}} \alpha_{G_{\mathrm{w}}} \hat{U}_{G_{\mathrm{w} i}} A}{\rho_{G_{r e f}}}-\frac{\widehat{\rho}_{G_{\mathrm{e}}} \alpha_{G_{\mathrm{e}}} \hat{U}_{G_{\mathrm{w} i+1}} A}{\rho_{G_{r e f}}}\right)+\left(\alpha_{L_{\mathrm{w}}} \hat{U}_{L_{\mathrm{w} i}} A-\alpha_{L_{\mathrm{e}}} \hat{U}_{L_{\mathrm{w} i+1}}\right)
\end{gathered}
$$




\section{4}

\section{Tratamento na Região das Fronteiras}

Tanto na entrada como na saída do domínio, o volume de controle é a metade do volume de controle utilizado na interior do domínio (Figura 4.2). Uma vez que a formulação apresentada foi para espaçamento uniforme, é necessário utilizar um tratamento especial na região das fronteiras.

a)

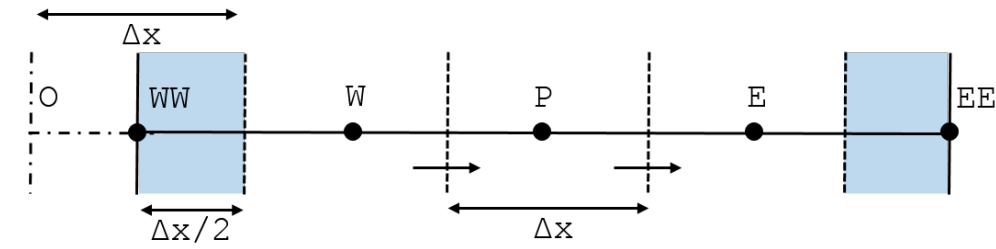

b)

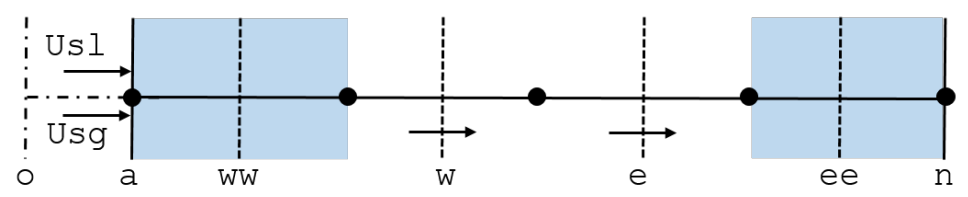

Figura 4.2: Fronteiras das malha. a)Volume de controle escalar. b)Volume de controle vetorial

$\mathrm{Na}$ entrada, as velocidades superficiais da fase gasosa $\left(U_{s_{G}}\right)$ e da fase líquida $\left(U_{s_{L}}\right)$ são prescritas, sendo necessário determinar a fração volumétrica do gás $\left(\alpha_{G}\right)$ e a pressão $(P)$, resolvendo as Eqs. (2.5) e (4.33) para o meio volume de controle. Para calcular os fluxos convectivos nas faces dos meiosvolumes de controle, é necessário avaliar o parâmetro $r$, definido pelas razões de gradientes do esquema TVD, Eq. (4.4), o qual depende de vizinhos inexistentes à montante da fronteira de entrada. Observando a Figura 4.2a, Versteeg \& Malalasekera (2007) propõe que existe uma relação linear entre o valor das variáveis na entrada e um valor a montante da forma $\alpha_{O}=2 \alpha_{W W}-\alpha_{W}$, e igualmente para seu valor na face $U_{G_{O}}=2 U_{G_{a}}-U_{G_{\mathrm{ww}}}$ e $U_{L_{O}}=2 U_{L_{a}}-U_{L_{\mathrm{ww}}}$, obtendo-se :

$$
\begin{aligned}
r_{\alpha_{\mathrm{ww}}=} & \frac{\left(\alpha_{W W}-\alpha_{O}\right)}{\left(\alpha_{W}-\alpha_{W W}\right)}\left[\left|\operatorname{sinal}\left(U_{G_{\mathrm{ww}}}\right), 0\right|\right]+ \\
& \frac{\left(\alpha_{P}-\alpha_{W}\right)}{\left(\alpha_{W}-\alpha_{W W}\right)}\left[\left|-\operatorname{sinal}\left(U_{G_{\mathrm{ww}}}\right), 0\right|\right] \\
r_{U_{k_{W}}}= & \frac{2\left(U_{k_{\mathrm{ww}}}-U_{k_{o}}\right)}{\left(U_{k_{\mathrm{w}}}-U_{k_{\mathrm{ww}}}\right)}\left[\left|\operatorname{sinal}\left(F_{k_{W}}\right), 0\right|\right]+ \\
& \frac{\left(U_{k_{\mathrm{e}}}-U_{k_{\mathrm{w}}}\right)}{\left(U_{k_{\mathrm{w}}}-U_{k_{\mathrm{ww}}}\right)}\left[\left|-\operatorname{sinal}\left(F_{k_{W}}\right), 0\right|\right]
\end{aligned}
$$


onde $U_{G_{\mathrm{ww}}}$ corresponde à velocidade do gás na face $w w$ e $F_{k_{W}}$ ao fluxo convectivo da fase $\mathrm{k}$ no ponto nodal principal $W W \cdot r_{\alpha_{\mathrm{ww}}}$ e $r_{U_{k_{W}}}$ representam o gradientes downwind e upwind para o primeiro volume de controle escalar e vetorial, respectivamente.

Já na saída, a pressão é conhecida, sendo necessário determinar velocidades, e fração de gás. Considerando o aspecto fortemente convectivo da formulação e na ausência de informações de velocidades na saída do domínio, uma extrapolação linear é realizada utilizando-se os dois primeiros vizinhos internos, tal que:

$$
\begin{gathered}
\frac{U_{k_{N+1}}-U_{k_{N}}}{\Delta x / 2}=\frac{U_{k_{N}}-U_{k_{N-1}}}{\Delta x} \quad ; \quad U_{k_{N+1}}=\frac{3 U_{k_{N}}-U_{k_{N-1}}}{2} \\
\frac{\alpha_{G_{N}}-\alpha_{G_{N-1}}}{\Delta_{x}}=\frac{\alpha_{G_{N-1}}-\alpha_{G_{N-2}}}{\Delta_{x}} \quad ; \quad \alpha_{G_{N}}=2 \alpha_{G_{N-1}}-\alpha_{G_{N-2}}
\end{gathered}
$$

\section{5}

\section{Critérios para Espaçamento da Malha e Passo de Tempo}

Para fornecer resultados com a precisão desejada é necessário se definir um espaçamento da malha $(\Delta x)$ apropriado para ser utilizado no processo de discretização. Testes de malha são comumente realizados para garantir independência da solução na malha, o qual é só conseguido quando o sistema de equações for bem posto (Montini (2011), Carneiro (2006),Inácio (2012)). O Capítulo 5 apresenta uma análise detalhada referente a definição da malha.

De forma análoga ao espaçamento, o passo de tempo $(\Delta t)$ também é um parâmetro importante na solução numérica do escoamento. Para capturar as ondas e instabilidades geradas no escoamento anular este parâmetro tem que ser suficientemente pequeno. A condição de Courant-Friedrichs-Levy (ou Número de Courant, $C$ ) estabelece uma relação entre o passo de tempo e o espaçamento da malha, tal que:

$$
C=\max (|U|) \frac{\Delta t}{\Delta x}
$$

onde $\max (|U|)$ representa a velocidade máxima em todo o domínio considerando as duas fases. O número de Courant pode ser interpretado como uma medida de quantos volumes de controle uma partícula de fluido consegue avançar em um passo de tempo. O valor unitário de $C$ ajusta o passo de tempo $\Delta t$ para que uma partícula avance, no máximo, um volume de controle. Quanto mais densa for a malha menor deve ser o passo de tempo. Deste modo, a densidade da malha e o número de Courant requerido devem ser definidos levando 
em conta as características físicas do problema e as limitações computacionais (tempo de execução, capacidade de memória disponível, entre outros aspectos). Neste trabalho o número do Courant (C) foi definido como sendo igual a 0,5.

\section{6}

\section{Critério de Convergência}

A convergência do sistema de equações algébricas resultante da discretização é verificada a cada passo de tempo, onde a solução é considerada convergida quando o critério do resíduo máximo de todas as equações for inferior a uma tolerância $(t o l)$ especificada.

$$
R e s_{\max } \leq \text { tol }
$$

O resíduo máximo de cada equação é obtido de acordo com a seguinte expressão:

$$
R e s_{\max }=\max \left(\left|a_{P} \varphi_{P}-a_{E} \varphi_{E}-a_{W} \varphi_{W}-b\right|\right)
$$

Na equação acima, $R e s_{\max }$ é o resíduo máximo obtido em todo o domínio, $a_{P}$, $a_{E}, a_{W}$ e $b$ são os coeficientes da equação de discretização de $\varphi$ e $\varphi$ a grandeza dependente de interesse $\left(\alpha_{G}, U_{L}, U_{G}, P\right)$. No presente trabalho foi utilizada uma tolerância de $10^{-4}$.

\section{7}

\section{Procedimento de Execução}

Nas equações governantes discretizadas, o nó principal depende apenas dos nós adjacentes, formando matrizes tri-diagonais de solução para cada equação. Estas matrizes são resolvidas diretamente pelo algoritmo TDMA (Patankar, 1980). Como as equações governantes do presente modelo são não lineares e acopladas, é necessário o uso de um processo iterativo de solução para o sistema de equações. Uma adaptação do algoritmo PRIME, descrita na seção 4.3 foi adotada neste trabalho, e sua escolha foi recomendada por Ortega \& Nieckele (2005). A sequência pode ser descrita com os seguintes itens:

1. Definição das condições iniciais do problema (inicialização das velocidades, pressão e frações volumétricas).

2. Utilização da solução do passo de tempo anterior como estimativa inicial para o passo de tempo atual.

3. Determinação das velocidades das fases, através da solução das equações de quantidade de movimento para o líquido e gás, utilizando o campo de 
pressões estimado, Eqs. (4.12) e (4.13).

4. Determinação da pressão através da solução da equação de conservação de massa global, Eq. (4.39).

5. As velocidades são corrigidas explicitamente mediante a Eq. (4.35).

6. Solução da equação de conservação de massa da fase gasosa para obter a fração volumétrica de gás.

7. Verificar os resíduos de todas as equações. Se todos estes forem inferiores ao critério de tolerância pré-determinado, voltar ao passo 2. Caso contrário, retornar ao passo 3 e repetir o procedimento até obter convergência. 


\section{5 \\ Resultados}

No presente trabalho, a formulação uni-dimensional do Modelo de Dois Fluidos, apresentada no Capítulo 2, foi aplicada para prever o escoamento no padrão anular vertical ascendente. Inicialmente, selecionou-se um conjunto de casos disponíveis na literatura, analisados experimentalmente, para avaliar o desempenho da metodologia. A seguir, um rigoroso teste de malha foi realizado, tendo por objetivo principal avaliar a capacidade de cada um dos três modelos de pressão dinâmica de apresentar solução independente da malha, indicando que a introdução da pressão dinâmica conseguiu transformar o sistema de equações em um sistema bem-posto. Finalmente, o desempenho dos modelos de pressão dinâmica foi avaliado através de comparação da espessura média do filme de líquido e dados experimentais disponíveis de pressão, frequência das ondas e velocidade de estrutura.

\section{1}

\section{Seleção de Casos}

Sendo o foco do presente trabalho em escoamentos verticais ascendentes no padrão anular, selecionou-se os trabalhos de Wolf et al. (2001), Kaji (2008) e Zhao et al. (2013) para avaliar a metodologia proposta. Nos três experimentos, os fluidos de trabalho são água e ar. Zhao et al. (2013) e Wolf et al. (2001) utilizaram configurações com o diâmetro interno da tubulação muito similar, $D_{i}=0,0345 \mathrm{~m}$ e $D_{i}=0,0318 \mathrm{~m}$, respectivamente. Porém, a tubulação empregada por Zhao et al. (2013) é bem curta, com apenas $L=2 \mathrm{~m}$ de comprimento, em relação a tubulação utilizada por Wolf et al. (2001), com $L=10,80 \mathrm{~m}$. O diâmetro utilizado por Kaji (2008) é bem menor, igual a $D_{i}=0,019 \mathrm{~m}$ e a tubulação é o cumprimento da tubulação é de $L=6,87 \mathrm{~m}$. Os autores dos três trabalhos investigaram ampla faixa de velocidades superficiais de gás e líquido. No entanto, como a presente formulação não incorpora os fenômenos de entranhamento e deposição de gotículas, o primeiro passo para selecionar os casos a serem investigados, consistiu em identificar as regiões nos mapas de padrão de escoamento, onde o entranhamento pode a princípio ser desprezado. Para identificar essas regiões, selecionou-se as correlações de Ishii \& Grolmes (1975). Eles estabelecem um valor crítico de Reynolds para o líquido $\left(\operatorname{Re}_{s L_{C E}}\right)$ de 160, enquanto a velocidade de gás necessária para o começo do 
entranhamento é dada por:

$$
\begin{aligned}
\frac{\mu_{L} U_{s G}}{\sigma} \sqrt{\frac{\rho_{G}}{\rho_{L}}} \geq 11,78 N_{\mu}^{0,28} R e_{s L}^{-1 / 3} \quad ; \quad N_{\mu} \leq \frac{1}{15} ; 160 \leq R e_{s L} \leq 1635 \\
\frac{\mu_{L} U_{s G}}{\sigma} \sqrt{\frac{\rho_{G}}{\rho_{L}}} \geq 1,35 R e_{s L}^{-1 / 3} \quad ; \quad N_{\mu}>\frac{1}{15} ; 160 \leq R e_{s L} \leq 1635
\end{aligned}
$$

onde $\operatorname{Re}_{s L}$ é calculado a partir da Eq. (2.20) e $N_{\mu}$ pela Eq. (2.34). Os critérios para $R e_{s L} \geq 1635$ não são apresentados.

Outro critério recomendado por Berna et al. (2014) e bastante utilizado para determinar o número de Reynolds crítico de líquido para que o entranhamento ocorra é dado por (Owen \& Hewitt, 1987):

$$
R e_{s L_{C E}}=\exp \left(5,8405+0,4249 \frac{\mu_{G}}{\mu_{L}}\left(\frac{\rho_{L}}{\rho_{G}}\right)^{0.5}\right)
$$

sendo a velocidade de gás acima da qual existe entranhamento dada pelo critério do número de Kutateladze (Ku)

$$
U_{s G} \geq \sqrt{\frac{\left(61,241-0,0312 R e_{s L}\right) \sqrt{\sigma g \rho_{L}}}{\rho_{G}}} \quad ; \quad 160 \leq R e_{s L} \leq 1635
$$

A Fig. 5.1 apresenta o mapa de padrão de escoamento correspondente ao experimento de Zhao et al. (2013), onde a curva que separa a região de escoamento anular e golfada foi incluída, assim como as curvas referentes aos dois critérios (curvas tracejadas) delimitando a região onde ocorre entranhamento. Adicionou-se no mapa os diversos casos investigados por Zhao et al. (2013). Os testes realizados por Wolf et al. (2001) também foram incluídos no mapa, uma vez que o diâmetro das duas tubulações é bem semelhante. Observa-se que a correlação de Ishii \& Grolmes, Eq. (5.1), apresenta uma menor região sem entranhamento do que a correlação de Owen \& Hewitt, Eq. (5.3), pois o número de Reynolds crítico para o filme de líquido estabelecido por Ishii \& Grolmes é $\operatorname{Re}_{s L_{C E}}=160$, valor inferior ao calculado pela correlação de Owen $\&$ Hewitt, $\operatorname{Re}_{s L_{C E}}=414$.

A maioria dos dados de Wolf et al. (2001) encontram-se na região de entranhamento, enquanto os dados de Zhao et al. (2013) encontram-se na região de transição. A Figura 5.1(b) apresenta uma ampliação da região de transição para facilitar a identificação dos casos selecionados para serem testados. Do conjunto de dados de Zhao et al. (2013), somente dois apresentam um volume maior de informações e por esta razão foram selecionados para 


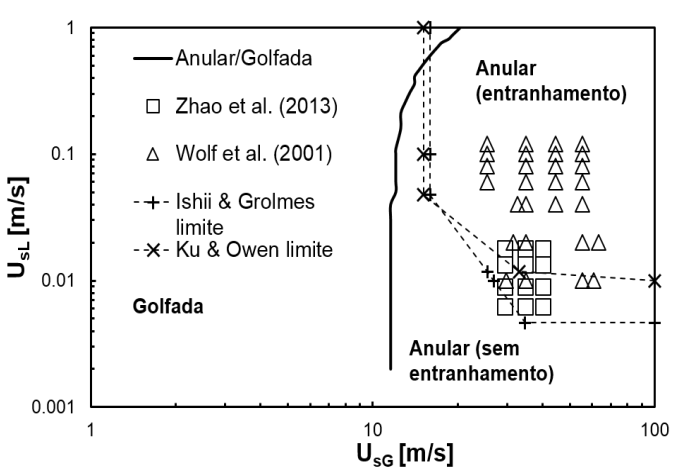

5.1(a): Mapa de padrão de escoamento

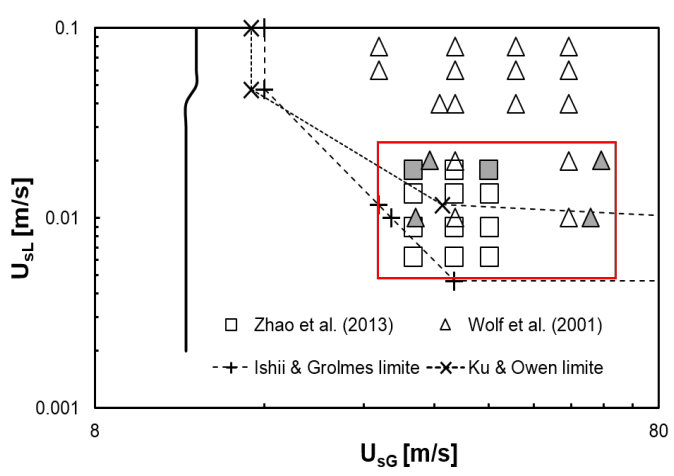

5.1(b): Ampliação da região de transição do entranhamento

Figura 5.1: Velocidades superficiais criticas de líquido e gás (Zhao et al., 2013).

serem investigados (símbolos sombreados de cinza). Dois dos casos de Wolf et al. (2001) foram os selecionados por estarem na região sem entranhamento segundo o critério de de Owen \& Hewitt. Os outros 2 casos foram selecionados por apresentarem velocidade superficial do líquido semelhante aos casos de Zhao et al. (2013).

O mapa correspondente a configuração de Kaji (2008) é apresentado na Fig. 5.2. Com esta configuração, selecionou-se os casos mais próximos da condição crítica de entranhamento, correspondendo as menores velocidades superficiais de líquido. Dois casos adicionais na região de entranhamento também foram selecionados.

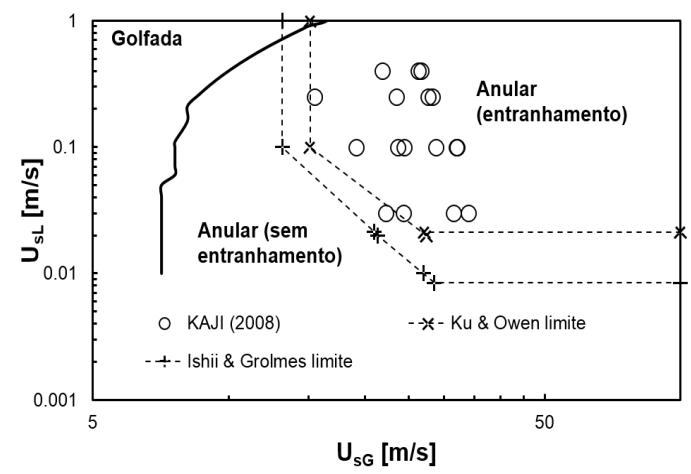

5.2(a): Mapa de padrão de escoamento

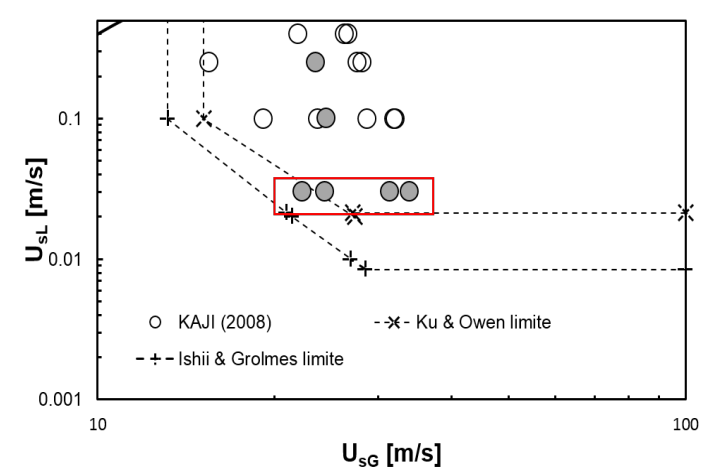

5.2(b): Ampliação da região de transição do entranhamento

Figura 5.2: Velocidades superficiais criticas de líquido e gás (Kaji, 2008).

Um resumo das velocidades superficiais do gás e líquido dos casos selecionados é apresentado na Tabela 5.1. Nesta tabela, a pressão imposta na saída também é apresentada. Para todos os casos, a massa específica da água, a viscosidade absoluta da água e do ar foram mantidos constantes. A 
massa específica do ar é determinada utilizando a equação de gases ideais, considerando a temperatura de referência igual a $T_{r e f}=25^{\circ} \mathrm{C}$ e a constante do ar igual a $R_{a r}=287 \mathrm{~N} \mathrm{~m} /(\mathrm{kg} \mathrm{K})$. As propriedades dos fluidos são apresentadas na Tabela 5.2. Nos casos da configuração II, os dados de pressão fornecidos por Wolf et al. (2001) correspondem aos valores na entrada. Dessa forma, os valores indicado na Tabela 5.1 referentes a essa configuração, foram obtidos extrapolando os dados de pressão medidos por Wolf et al. (2001) das duas últimas estações de medida para a saída.

Tabela 5.1: Casos selecionados

\begin{tabular}{cccccc}
\hline Configuração & $D[\mathrm{~m}]$ & $L[\mathrm{~m}]$ & $U_{s G}[\mathrm{~m} / \mathrm{s}]$ & $U_{s L}[\mathrm{~m} / \mathrm{s}]$ & $P_{\text {saida }}[\mathrm{k} \mathrm{Pa}]$ \\
\hline I & 0,0345 & 2,00 & 29,42 & 0,0175 & 101 \\
Zhao et al. $(2013)$ & & & $\mathbf{4 0 , 1 0}$ & $\mathbf{0 , 0 1 7 5}$ & \\
\hline II & 0,0318 & 10,80 & 29,72 & 0,01 & 204 \\
Wolf et al. $(2001)$ & & & 60,74 & 0,01 & 175 \\
& & & 31,43 & 0,02 & 193 \\
& & & 63,42 & 0,02 & 167 \\
\hline III & 0,0190 & 6,87 & 22,30 & 0,03 & 150 \\
Kaji $(2008)$ & & & $\mathbf{2 4 , 3 6}$ & $\mathbf{0 , 0 3}$ & \\
& & & 31,42 & 0,03 & \\
& & & 33,92 & 0,03 & \\
& & & 24,49 & 0,10 & \\
& & & 23,51 & 0,25 & \\
\hline
\end{tabular}

Tabela 5.2: Propriedades dos fluidos.

\begin{tabular}{cccc}
\hline Configuração & Fluidos & Ar & Água \\
\hline I & $\rho\left[\mathrm{kg} / \mathrm{m}^{3}\right]$ & 1,18 & 998,2 \\
II & & 1,95 & 998,2 \\
III & & 1,75 & 998,2 \\
I, II, III & $\mu[\mathrm{Pa} \mathrm{s}]$ & $1,79 \times 10^{-5}$ & $1,00 \times 10^{-3}$ \\
\hline
\end{tabular}

\section{2}

\section{Avaliação da Hiperbolicidade das Equações}

Como discutido no Capítulo 3 a presença do termo de pressão dinâmica pode tornar o sistema de equações hiperbólico.

Para o Modelo 1, foi discutido que a influência do modelo de pressão dinâmica proposto por Fowler \& Lisseter (1992) é insuficiente para tornar o sistema de equações bem posto. Contudo, o modelo 1 influi no parâmetro de fluxo de quantidade de movimento, tal que, $D_{L}=C_{L}+W_{f L}(\chi-1)^{2}$ (Eq. (3.19)) sendo $C_{L}=1, \chi=2$ e $W_{f_{L}}=0,02$. Para $D_{L}=1.02$ o sistema de equações é sempre mal posto. Na Fig. 5.3 é apresentado as curvas que separam a região de 
bem posto (lado direito da curva) e mal posto (lado esquerdo da curva) para valores de $D_{L}$ de 1,$06 ; 1,1 ; 1,33$ e 1,8 . Pode-se observar como o aumento de $D_{L}$ amplia a região de modelo bem-posto para tubulações verticais. O valor de $D_{L}$ é incrementado por um aumento do $C_{L}$ ou um aumento de $W_{f L}$ ou um valor de $\chi>2$. Os resultados obtidos com o incremento de $D_{L}$ concordam com o observado por Montini (2011) e Inácio (2012), com relação a variações de $C_{L}$. O valor de $C_{L}$ proposto por Fowler \& Lisseter (1992) foi de 1,33, contudo, neste trabalho, deseja-se identificar a eficácia do modelo de pressão dinâmica, e para isso o $C_{L}$ sempre foi mantido constante e igual a 1 . Com relação ao coeficiente $W_{f_{L}}$, este foi mantido como 0,02 conforme definido por Fowler \& Lisseter (1992).

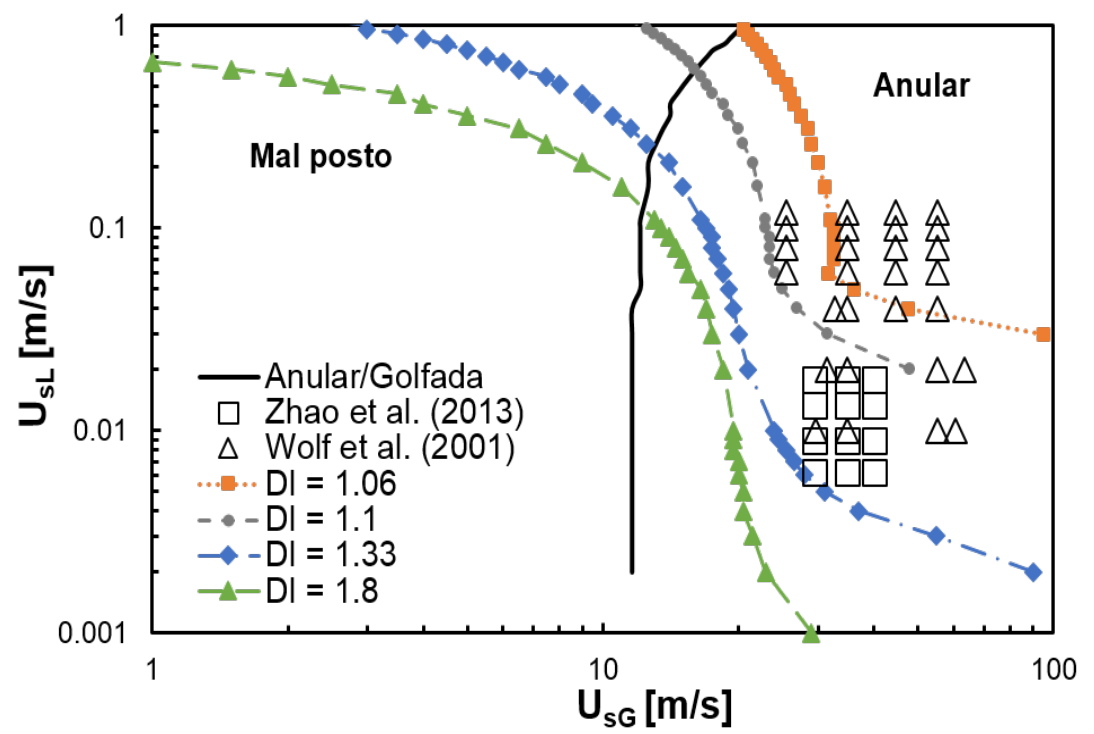

Figura 5.3: Limite entre bem/mal posto para Modelo 1 variando $D_{L}$ (Zhao et al., 2013)

O critério obtido para o Modelo 2 na Eq. (3.31), estabelece que o sistema será bem posto para valores de $W_{c} \geq 1$. O valor estipulado para dito parâmetro é de 1,2 (Han \& Guo, 2015) para escoamentos em tubulações verticais, garantindo que o Modelo de Dois Fluidos seja hiperbólico para qualquer conjunto de velocidades.

A curva que separa a região de bem/mal posto do Modelo 3 para o escoamento de Zhao et al. (2013) (configuração I) é ilustrada na Fig. 5.4, enquanto que a Fig. 5.5 corresponde à configuração III (Kaji (2008)). Comparando as Figs. 5.3 e 5.4, pode-se observar que uma melhor aproximação para a velocidade da onda (Modelo 3 em relação ao Modelo 1) aumenta significativamente a região onde o sistema de equações do modelo de Dois 
Fluidos é bem posto. Com o Modelo 3, as velocidades superficiais testadas para todas as configurações, encontram-se na região de modelo bem posto (Fig. 5.4 e 5.5). Contudo, para velocidades superficiais de líquido e de gás baixas, para as três configurações, o sistema de equações é mal posto.

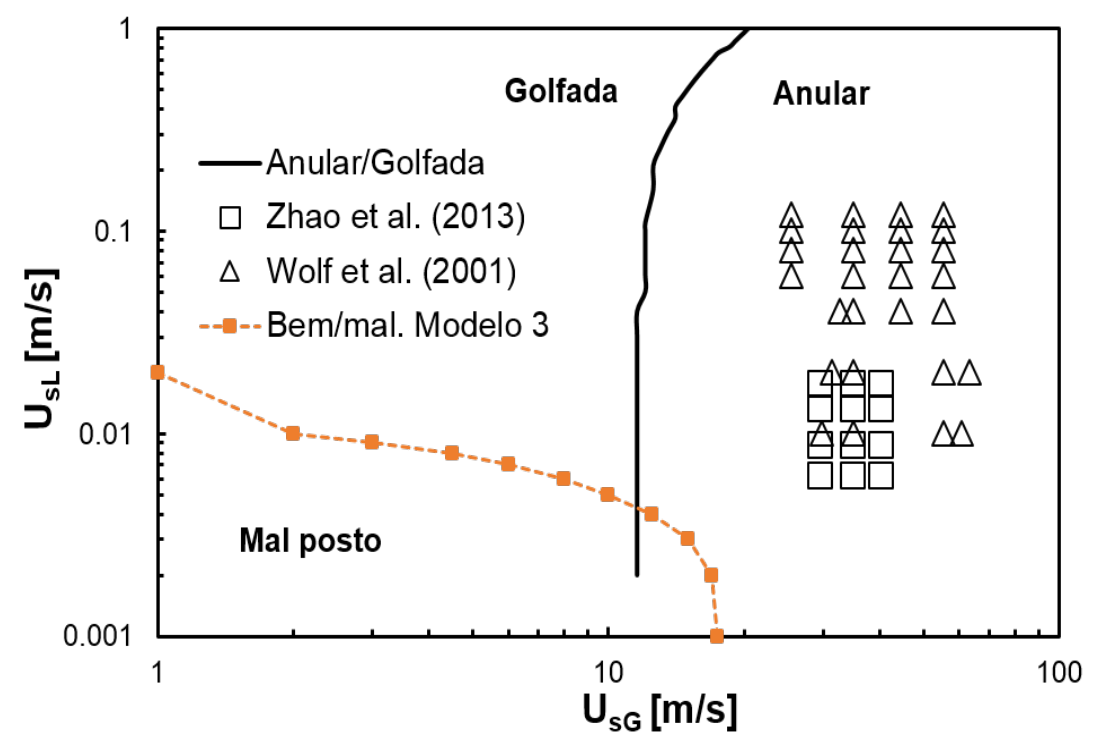

Figura 5.4: Limite entre bem/mal posto para Modelo 3 (Zhao et al., 2013)

O critério de hiperbolicidade desenvolvido para o modelo diferencial, conforme dito anteriormente é uma boa aproximação para avaliar os coeficientes do sistema, porém devido às aproximações, é necessário avaliar os resultados numéricos utilizando um teste de malha para os 3 modelos e analisar o comportamento do resultado quando a malha é refinada.

\subsection{1}

\section{Teste de malha}

A análise anterior foi obtida a partir das equações diferenciais parciais, considerando propriedades constantes. Esta análise permite avaliar se a contribuição da pressão dinâmica é significativa para a obtenção de um sistema de equações bem posto. No entanto, numericamente, esta região é um pouco diferente, devido a discretização das equações (Galleni \& Issa, 2015), e pelo fato da massa específica do ar não ser constante.

Desta forma, tendo como objetivo avaliar a influência da pressão dinâmica na solução numérica, selecionou-se um dos casos da configuração I (Zhao et al. (2013)), indicado em negrito na Tabela $5.1\left(U_{s_{G}}=40,1 \mathrm{~m} / \mathrm{s}\right.$ e $U_{s_{L}}=0,0175$ $\mathrm{m} / \mathrm{s}$ ), o qual será referido como Caso A. Realizou-se um teste de malha 


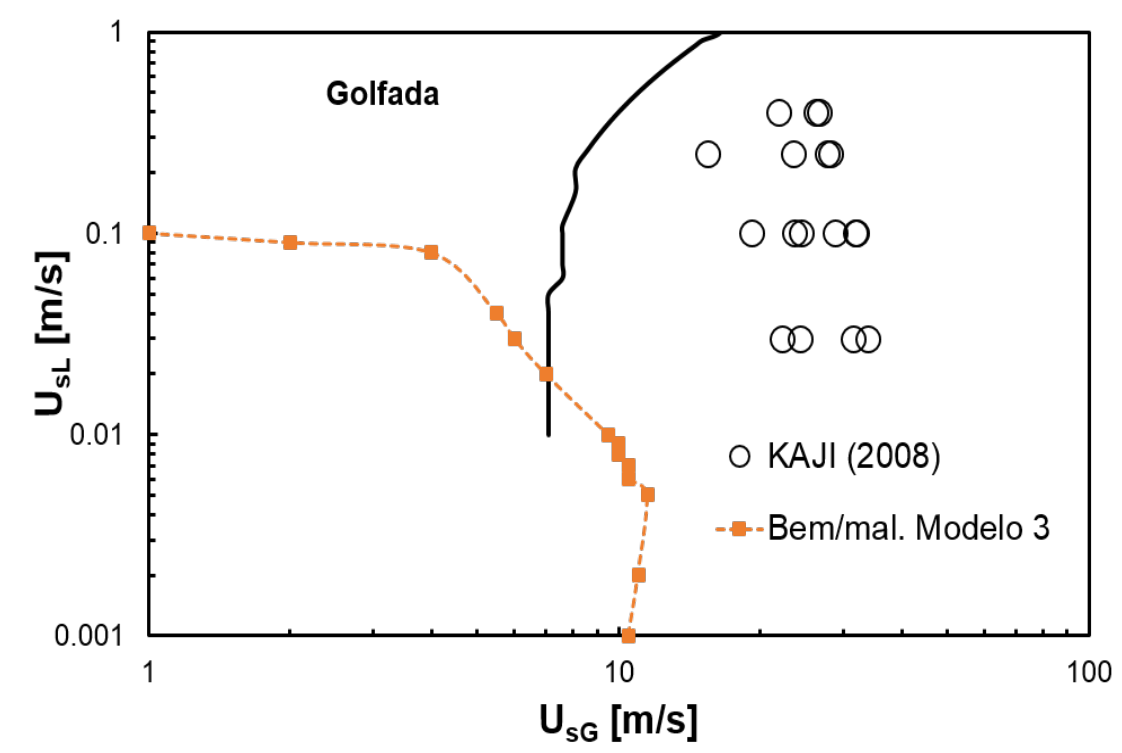

Figura 5.5: Limite entre bem/mal posto para Modelo 3 (Kaji, 2008)

empregando os três modelos de pressão dinâmica apresentados no Capítulo 2, com o espaçamento da malha $\Delta x / D$ variando de 0,3 a 0,05 .

Os resultados obtidos com os três modelos para os valores médios no tempo correspondentes ao gradiente de pressão $(\Delta P / \Delta L)$, à espessura média do filme $\overline{h_{L}}$ e à frequência dominante do PSD (Power Spectral density), Seção 2.4, são comparados com as medidas experimentais de Zhao et al. (2013) nas Figs. 5.6(a) - 5.6(c). Pode-se observar que as três grandezas aumentam a medida que a malha é refinada quando o Modelo 1 (Fowler \& Lisseter, 1992) é empregado, se afastando do valor experimental, sendo que o afastamento cresce de forma considerável com a malha mais fina.

A falha de convergência da solução para uma resposta única é uma das consequências de um sistema mal posto. Conforme discutido por Montini (2011) e Inácio (2012) se o sistema é mal posto, ao refinar a malha, a presença de pequenos comprimentos de onda proporcionais ao espaçamento da malha induzem perturbações no escoamento, as quais podem se propagar levando a uma nova solução.

No Capítulo 3 foi analisada a hiperbolicidade do sistema de equações do modelo de Dois Fluidos ao incluir a formulação de Fowler \& Lisseter (1992) o qual resulta não ser apropriada para tornar o sistema bem posto, porém, que um aumento do $D_{L}$ poderia tornar o modelo de Dois Fluidos bem posto.

Ainda analisando os resultados apresentados nas Figs. 5.6(a) - 5.6(c), pode-se observar como a solução tende a um valor aproximadamente constante 


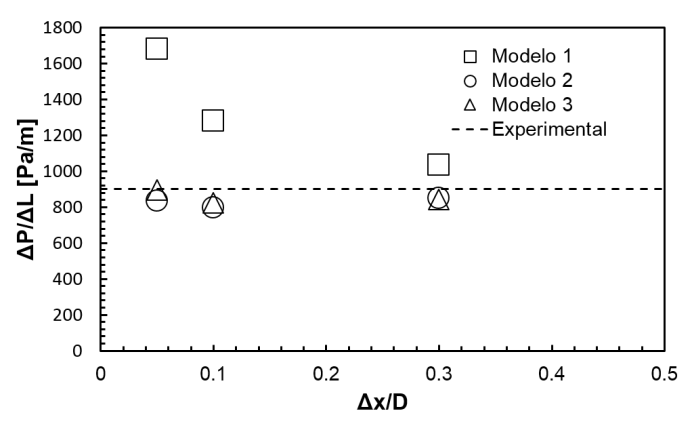

5.6(a): Gradiente de pressão

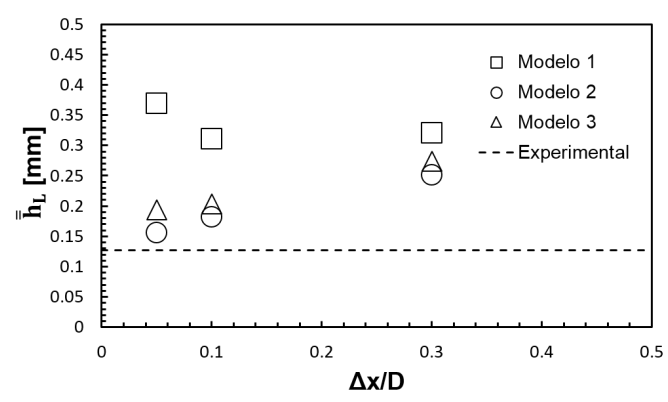

5.6(b): Espessura do Filme

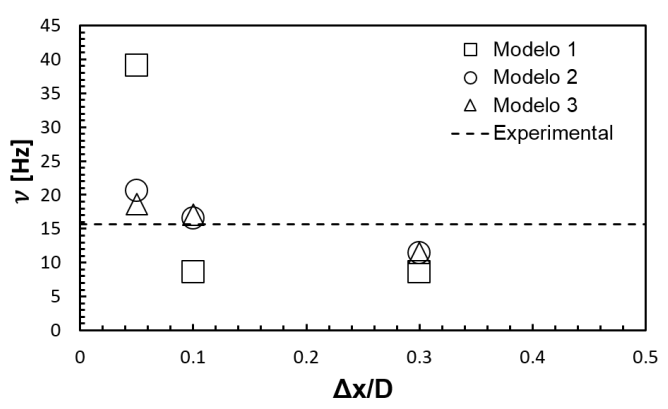

5.6(c): Frequência PSD

Figura 5.6: Teste de malha para Caso A

quando o Modelo 2, proposto por Bestion (1990) e Modelo 3 proposto neste trabalho, são empregados. Para o Caso A, nota-se que a solução é independente da malha para espaçamentos menores ou iguais a 0,1 , tanto para o Modelo 2 quanto para o Modelo 3. Observa-se ainda uma boa concordância dos dois modelos (Modelo 2 e 3) com respeito ao valor experimental, sendo o Modelo 3 ligeiramente superior. A previsão numérica obtida pode ser considerada muito boa, especialmente, tendo em vista que as incertezas associadas ao valor experimental para gradiente de pressão variam aproximadamente de $1 \%$ a $15 \%$ (Zhao et al. (2013)).

Uma vez que a definição da pressão dinâmica do Modelo 1 não forneceu solução independente da malha, pode-se afirmar que o sistema de equações continuou mal posto. Novo teste foi realizado, porém o Modelo 1 foi descartado. O teste foi denominado Caso B, e utiliza a configuração utilizada por Kaji (2008), com tubulação com diâmetro menor. O par de velocidades superficiais selecionado (em negrito na Tabela 5.1) é $U_{s_{L}}=0,03 \mathrm{~m} / \mathrm{s}$ e $U_{s_{G}}=24,36 \mathrm{~m} / \mathrm{s}$.

As Figs. 5.7(a) - 5.7(d) apresentam uma comparação entre resultados numéricos obtidos com os Modelos 2 e 3 para diferentes malhas e os dados experimentais de gradiente de pressão, espessura média do filme, frequência dominante do PSD e velocidade da estrutura obtidos com os Modelos 2 e 3. 


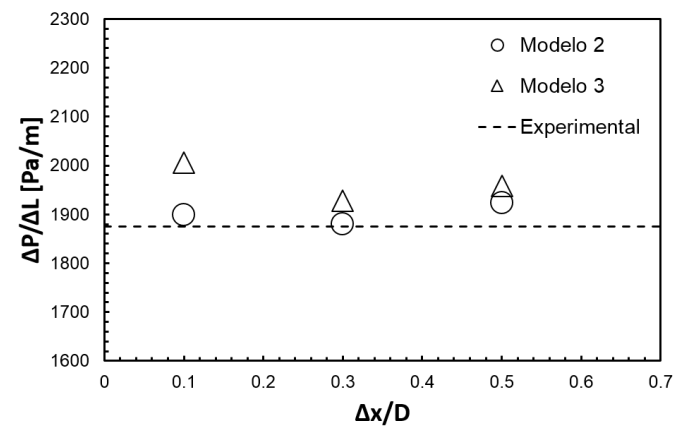

5.7(a): Gradiente de pressão

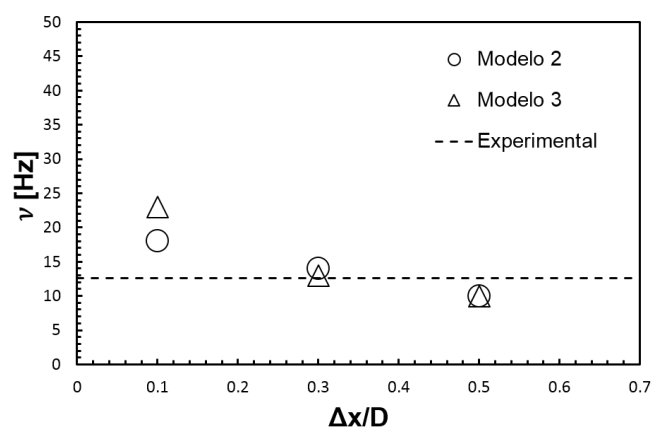

5.7(c): Frequência PSD

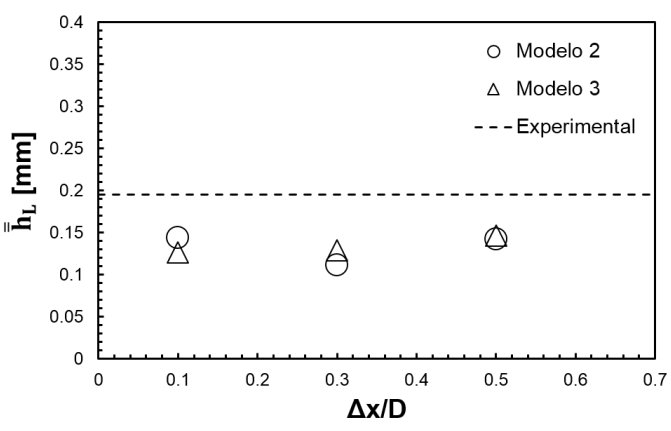

5.7(b): Espessura do Filme

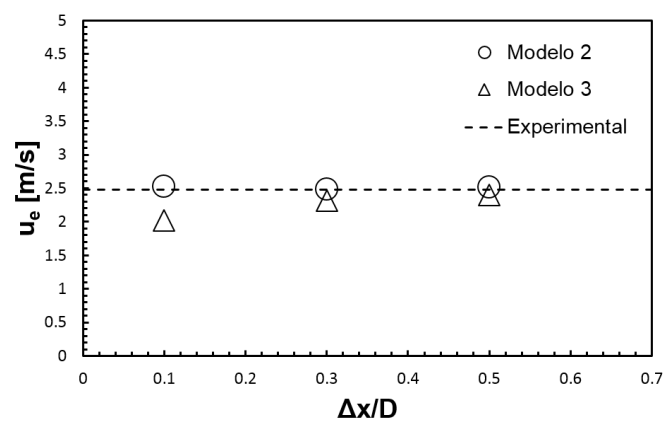

5.7(d): Velocidade da estrutura

Figura 5.7: Teste de malha para Caso B utilizando Modelo 2 e Modelo 3.

Pode-se observar que, para a maioria das variáveis, o resultado é independente da malha para valores de espaçamento adimensional menores a 0,3. Observa-se ainda que os dois modelos foram capazes de prever razoavelmente bem os dados experimentais. O gradiente de pressão, frequência e velocidade da estrutura apresentam erros relativos ao valor experimental de aproximadamente 1\%, $2 \%$ e $15 \%$, respectivamente, valores inferiores a incerteza experimental associada à espessura do filme, é de aproximadamente 20\% (Kaji, 2008). Neste caso, o Modelo 2 se mostrou um pouco superior ao Modelo 3.

A avaliação do critério de modelo bem/mal posto realizada com os três modelos, juntamente com o teste de malha apresentado para dois casos representativos do conjunto, permitiu concluir que o Modelo 1 proposto por Fowler \& Lisseter (1992) contribui muito pouco para tornar o sistema de equações bem-posto. Porém, os Modelos 2 e 3 se mostraram bastante promissores. Dessa forma, o Modelo 1 foi descartado das avaliações seguintes.

\section{3}

\section{Avaliação do Esquema Espacial TVD}

Para avaliar o desempenho do esquema de discretização espacial de segunda ordem TVD, uma comparação com o esquema de primeira ordem 
Upwind foi realizada. Selecionou-se o Caso A de Zhao et al. (2013) $\left(U_{s_{G}}=\right.$ $40,1 \mathrm{~m} / \mathrm{s}$ e $\left.U_{s_{L}}=0,0175\right)$ e realizou-se um teste de malha. A Fig. 5.8(a) apresenta a influência do espaçamento na queda de pressão para os dois esquemas, enquanto a Fig. 5.8(b) corresponde a frequência PSD. Observa-se uma melhor estimativa do gradiente de pressão com o TVD, com resultado muito mais próximo ao dado experimental. Com relação a frequência PSD, ambos os esquemas apresentaram resultados equivalentes.

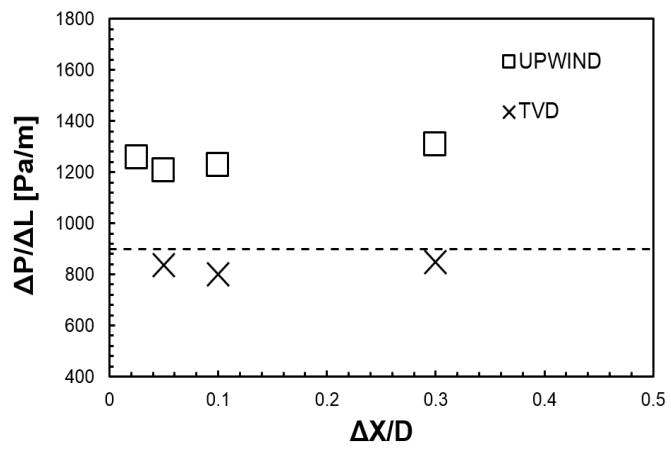

5.8(a): Gradiente de pressão

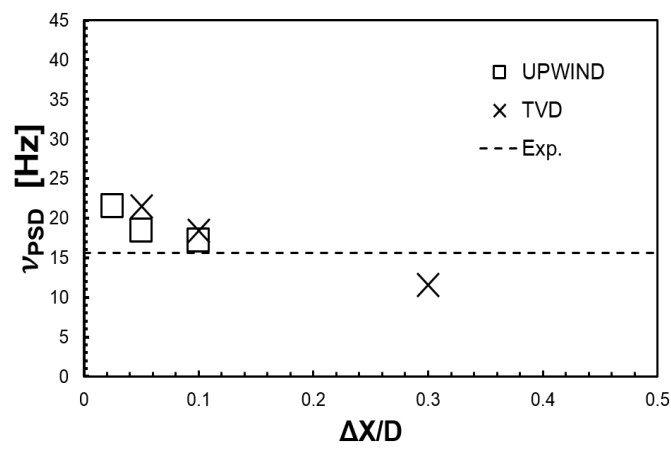

5.8(b): Frequência PSD

Figura 5.8: Influência do esquema de discretização espacial (1a. ordem upwind e 2a. ordem TVD) no gradiente de pressão e frequência PSD. Caso A. (Zhao et al., 2013).

Na previsão do gradiente de pressão, observa-se que o esquema TVD é superior ao esquema Upwind, pois obtêm-se solução independente da malha, para maiores valores do espaçamento. Para a Frequência PSD, na Fig. 5.8(b), a previsão obtida com os dois esquemas é bem próxima. Neste caso, o aumento na precisão da discretização espacial não foi efetivo, indicando a necessidade de aumentar a ordem da discretização temporal.

\section{4}

\section{Parâmetros Característicos do Escoamento Anular}

Visando avaliar o desempenho do Modelo de Dois Fluidos 1D para prever o escoamento no padrão anular, compara-se as principais grandezas caraterísticas deste tipo de escoamento com dados experimentais disponíveis, do conjunto de casos selecionados e indicados na Tabela 5.1. Primeiramente, resultados de pressão são apresentados, seguidos de dados relacionados à espessura do filme e da frequência de propagação das ondas interfaciais.

Para a obtenção das soluções apresentadas nesta seção, somente os Modelos 2 e 3 foram empregados. Para todos os casos, de acordo com o teste de malhas realizado, empregou-se uma malha com $\Delta x / D=0,1$. 
As simulações foram realizadas em um computador com processador Intel(R) Core(TM) i7-4790 CPU @ 3,60GHz (8 CPUs), 3,6 GHz e memoria RAM de 16, 384GB. O tempo médio de simulação para a configuração I (Zhao et al. (2013)) foi de $7 \mathrm{~h}$, enquanto que para as configurações II (Wolf et al. (2001) e III (Kaji (2008)) foram de 55 h e 67 h, respectivamente.

\section{4 .1 \\ Pressão}

Para ilustrar o comportamento do escoamento, apresenta-se na Fig.5.9, para o Caso A, o valor da pressão obtido numericamente em uma coordenada arbitrária, distante $x_{1}=1 \mathrm{~m}$ da entrada. Este resultado ilustra claramente o comportamento transiente do escoamento. Na mesma figura, o valor médio no tempo é apresentado. Pode-se observar que após aproximadamente $50 \mathrm{~s}$, um valor constante de pressão média é obtido.

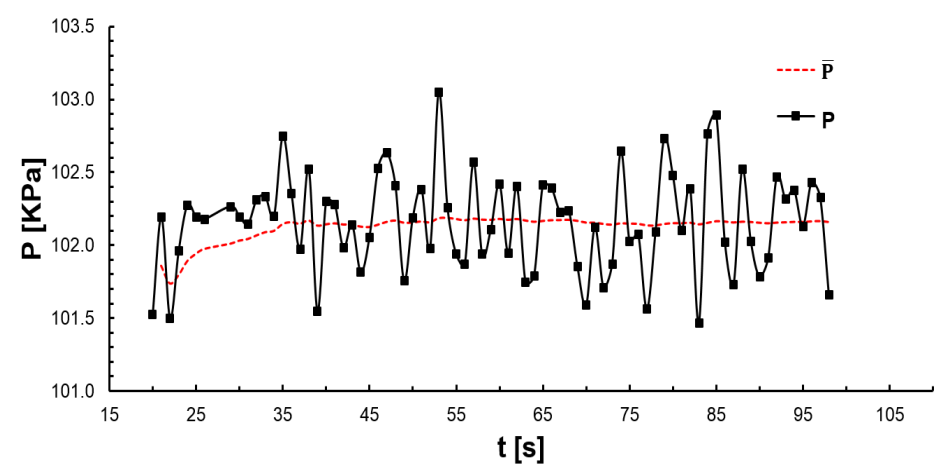

Figura 5.9: Comportamento da pressão no tempo. Caso A. Zhao et al. (2013)

A partir do comportamento da pressão ilustrado nas Figs. 5.9 e 5.10, para avaliar o gradiente de pressão e comparar com os dados experimentais, avaliouse a média temporal da pressão e selecionou-se uma coordenada afastada da entrada, de forma a garantir a obtenção de queda constante da pressão média temporal. Uma vez que a pressão foi mantida constante na saída, o gradiente de pressão, foi calculado através da diferença entre a pressão média no tempo reinante na coordenada $x_{1}$ e a pressão na saída. Para os casos de Zhao et al. (2013), Wolf et al. (2001) e Kaji (2008) os valores de $x_{1}$ foram de 0,5; 1 e 4, respectivamente.

As medições experimentais de Zhao et al. (2013) e Kaji (2008) foram realizadas medido-se o diferencial de pressão em tomadas localizadas a distâncias de 0,47 m e 4,24 m da entrada do líquido, respectivamente. Para Wolf et al. (2001) as medidas foram tomadas utilizando um transdutor diferencial 


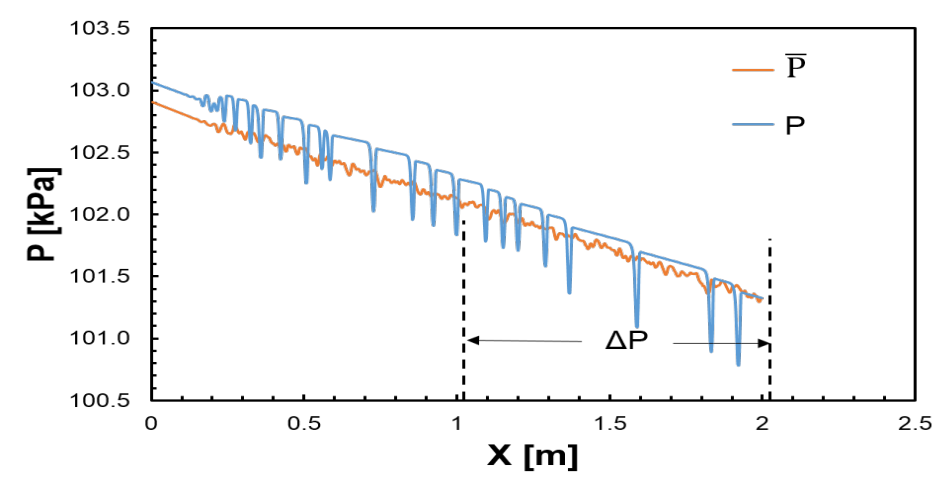

Figura 5.10: Comportamento da pressão na coordenada axial. Caso A. Zhao et al. (2013)

de pressão em distancias de 0,$67 ; 1,59 ; 3,2$ e 9,74 m à jusante da entrada do líquido.

A Fig. 5.11 apresenta a comparação do valor médio no tempo do gradiente de pressão com os dados experimentais, para todos os casos. A Figura 5.11(a) corresponde aos resultados obtidos com o Modelo 2 de pressão dinâmica e a Fig. 5.11(b) corresponde ao Modelo 3. Observa-se que o valor numérico é ligeiramente maior que o valor experimental na maioria dos casos e o erro relativo tende a crescer quanto maior é o gradiente de pressão. No entanto, para ambos os modelos de pressão dinâmica, as diferenças são inferiores a $20 \%$, o que pode ser considerado satisfatório.
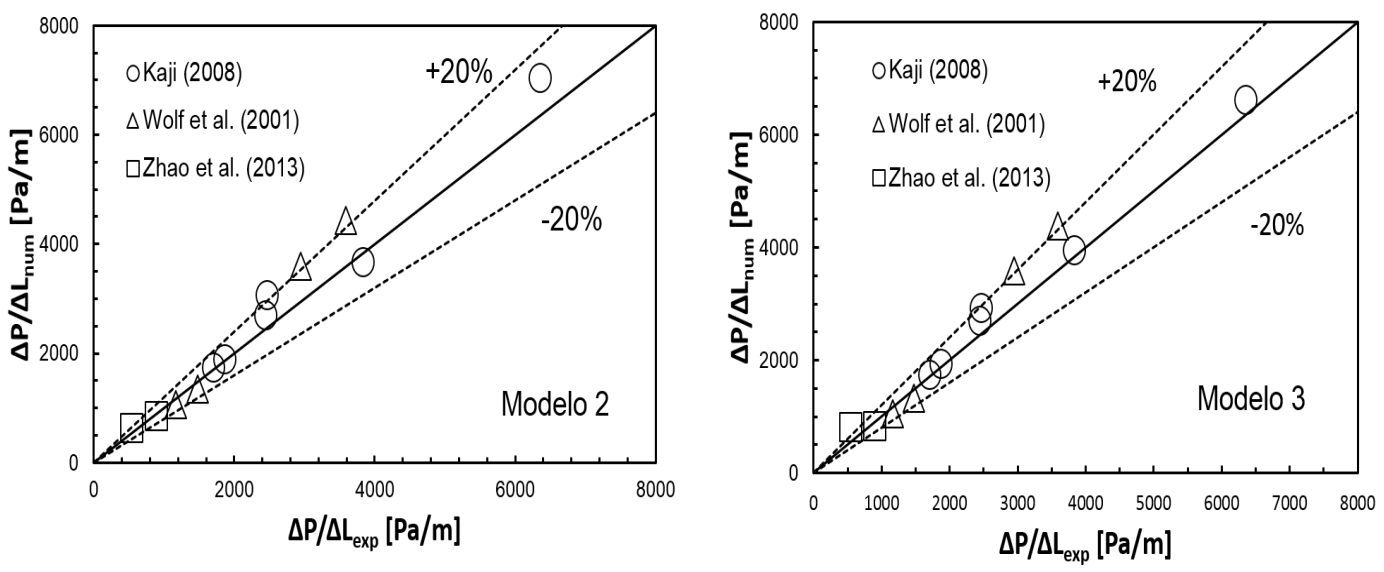

Figura 5.11: Comparação entre gradiente de pressão experimental e numérico

Na Fig. 5.12 os valores de gradiente de pressão da Fig. 5.11 são plotados em função da velocidade superficial do gás para diferentes Reynolds de líquido superficial $\left(\operatorname{Re}_{s L}\right)$ utilizando os Modelos 2 e 3 de pressão dinâmica. Para a configuração I (Zhao et al. (2013)), o número de Reynolds de líquido superficial é $\operatorname{Re}_{s L}=603$, sendo iguais a $\operatorname{Re}_{s L}=317$ e 635 para a configuração II (Wolf 
et al. (2001)). Já para a configuração III (Kaji (2008)), tem-se $\operatorname{Re}_{s L}=569$. Observa-se que o gradiente de pressão aumenta quando a velocidade superficial do gás aumenta, como é de se esperar. Observa-se ainda que o erro em relação ao valor experimental é maior para os casos com $U_{s G}>60 \mathrm{~m} / \mathrm{s}$.

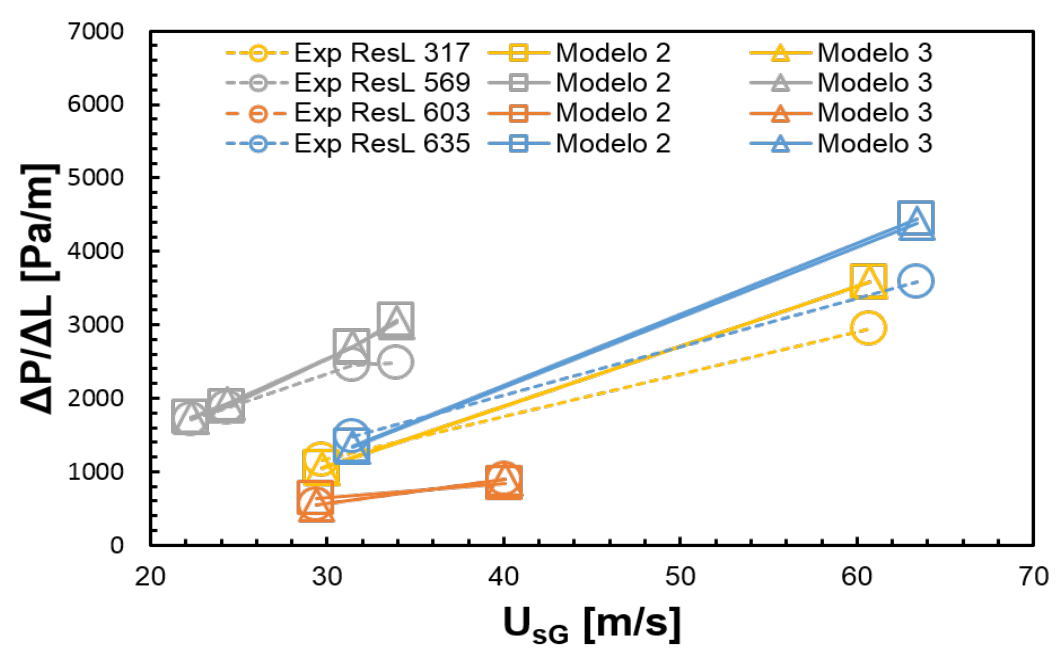

Figura 5.12: Gradiente de pressão em função da velocidade superficial do gás

\section{4 .2}

\section{Espessura do filme e frequência}

Como discutido anteriormente, espessura do filme e frequência das ondas são parâmetros importantes na caracterização do escoamento anular. Nesta seção o comportamento da interface gás-líquido é analisado, sendo avaliado o desempenho dos Modelos 2 e 3 para a pressão dinâmica, ao comparar a solução numérica com dados experimentais.

Uma caso representativo de cada conjunto de dados experimentais foi selecionado para ilustrar qualitativamente a evolução do filme de líquido axialmente e ao longo do tempo. Com relação à configuração I (Zhao et al., 2013), foi selecionado o Caso $\mathrm{A}\left(U_{s L}=0,0175 \mathrm{~m}\right.$ e $\left.U_{s G}=40,1 \mathrm{~m}\right)$. O par de velocidades superficiais da configuração II (Wolf et al., 2001) é igual a $U_{s L}=0,01 \mathrm{~m}$ e $U_{s G}=60,74 \mathrm{~m}$ e será denominado de Caso C. Para a configuração III (Kaji, 2008) selecionou-se o Caso B $\left(U_{s L}=0,03 \mathrm{~m} \mathrm{e}\right.$ $\left.U_{s G}=24,36 \mathrm{~m}\right)$.

Para cada caso, a evolução do filme de líquido obtida com os Modelos 2 e 3 é apresentada utilizando uma representação tridimensional da interface, nas Figs. 5.13 a 5.15. As figuras (a) correspondem ao Modelo 2 e as figuras (b) ao Modelo 3. Os gráficos apresentados correspondem à evolução do filme de líquido durante $5 \mathrm{~s}$ após um transiente inicial $(t>95 \mathrm{~s})$, onde o escoamento pode 
ser considerado como estatisticamente permanente. Analisando o conjunto de figuras, observa-se para todos os casos e com os dois modelos uma região de entrada onde ondulações não são encontradas. Esta região de desenvolvimento corresponde a região onde pequenas perturbações (não visíveis) na interface crescem até atingir uma condição estatisticamente estável. Como o tamanho da malha influencia no crescimento das pertubações, o tamanho desta região diminui com o refino da malha (com a redução da difusão numérica). Observase ainda que apesar da evolução da estrutura da interface obtida com os dois modelos ser semelhante, o Modelo 3 de pressão dinâmica induz a formação de ondas com amplitude maior do que o Modelo 2, para os Casos A e C, que possuem aproximadamente o mesmo diâmetro. No Caso B (diâmetro menor), o Modelo 2 apresentou ondas com maior amplitude.

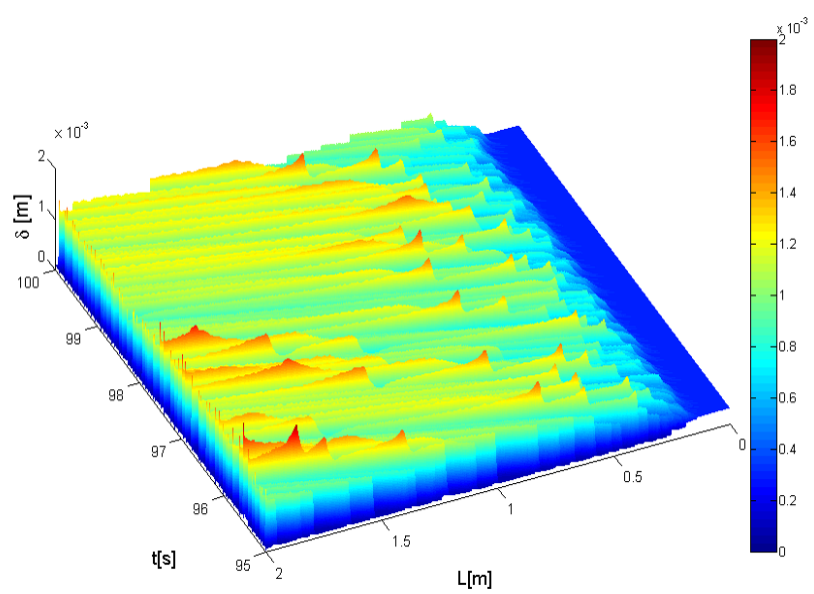

5.13(a): Modelo 2

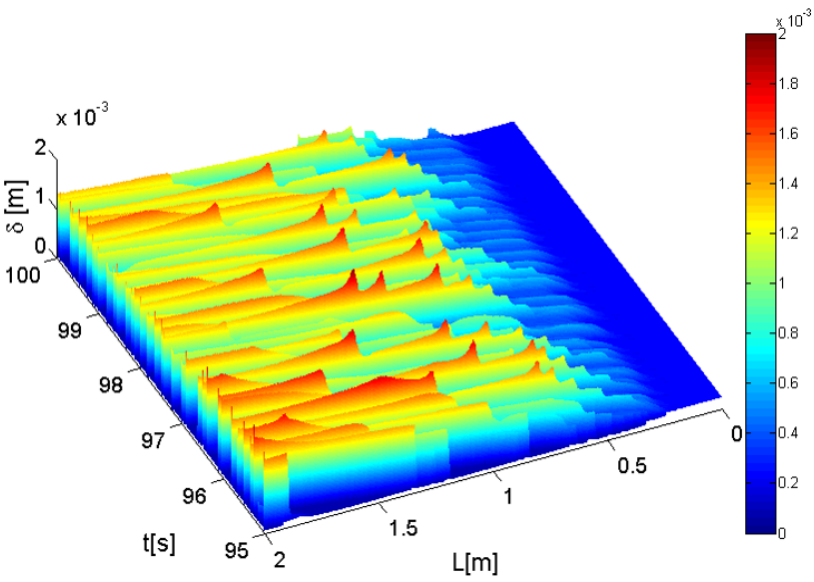

5.13(b): Modelo 3

Figura 5.13: Representação tridimensional da interface gás-líquido. Configuração I (Zhao et al. (2013)). Caso A.

Na Fig. 5.16 apresenta-se a comparação entre a espessura média no tempo 


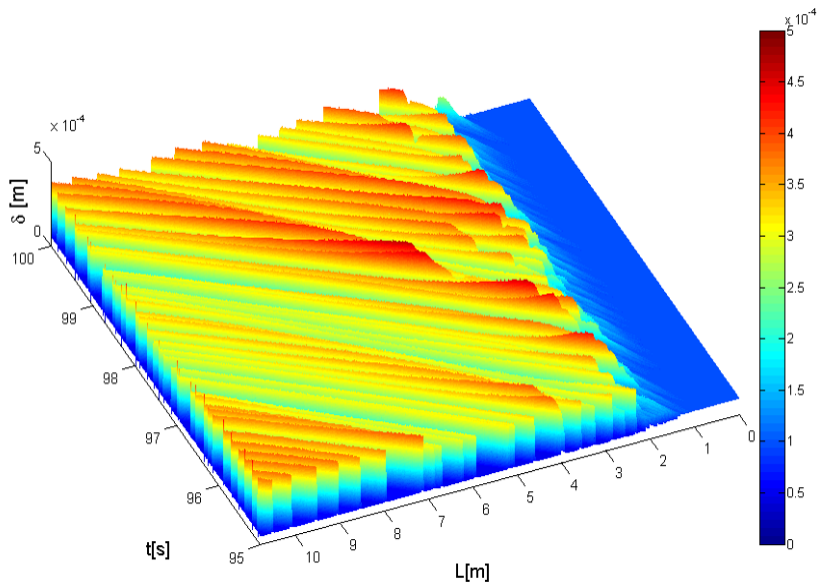

5.14(a): Modelo 2

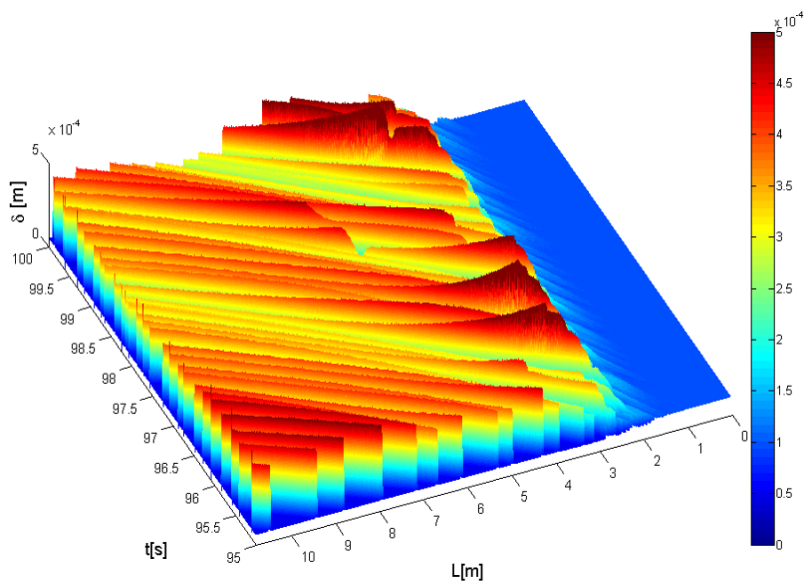

5.14(b): Modelo 3

Figura 5.14: Representação tridimensional da interface gás-líquido. Configuração II (Wolf et al. (2001)). Caso C.

e no espaço do filme de líquido $\left(\overline{\overline{h_{L}}}\right)$ obtida numericamente, com os Modelos 2 e 3 de pressão dinâmica, com os dados experimentais de Wolf et al. (2001), Kaji (2008) e Zhao et al. (2013). Wolf et al. e Zhao et al. utilizaram sondas de condutância posicionadas ao longo da seção de teste para medir a espessura do filme. Kaji não forneceu dados referentes à espessura do filme, tendo disponibilizando somente dados referentes a variação da fração de vazio $\left(\alpha_{G}\right)$ ao longo da tubulação. Dessa forma, para ser possível realizar a comparação, a espessura do filme foi determinada aqui, a partir dos dados experimentais de $\alpha_{G}$, utilizando a Eq. 2.14.

Analisando os dados da Fig. 5.16 referentes aos dois modelos, observa-se uma ótima concordância com os dados experimentais. Todos os dados referentes as configurações I e II (maior diâmetro) apresentam concordância dentro de 20\%. Uma discrepância maior, mas ainda razoável, pode ser observada entre 


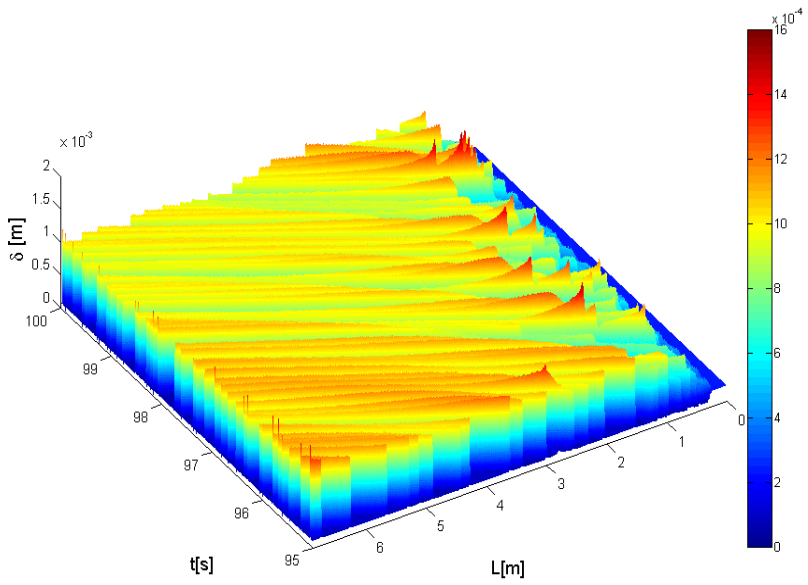

5.15(a): Modelo 2

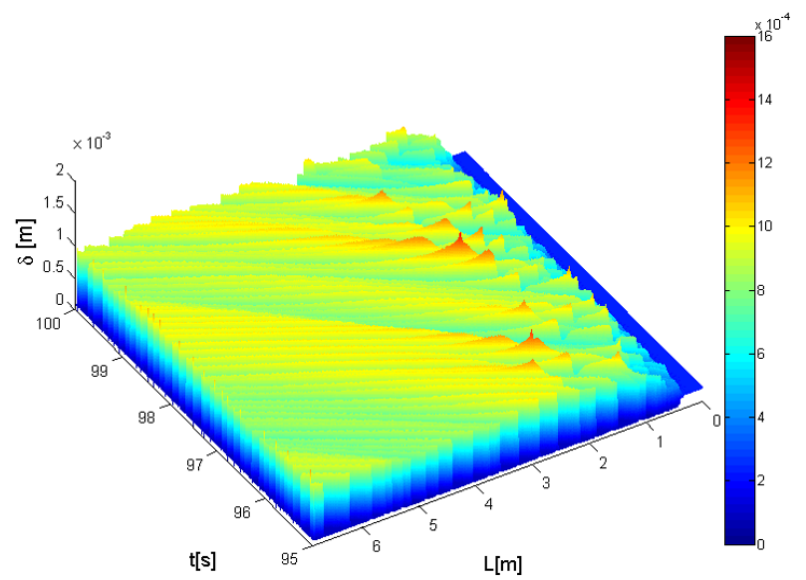

5.15(b): Modelo 3

Figura 5.15: Representação tridimensional da interface gás-líquido. Configuração III (Kaji (2008)). Caso B.

os dados dos casos da configuração III (menor diâmetro) e os dados estimados de $\overline{\overline{h_{L}}}$ de Kaji (2008).

Visando avaliar a influência das velocidades superficiais do gás e líquido na espessura do filme, os dados apresentados Fig. 5.16 são reagrupados em função do $R e_{s L}$ e plotados em função da velocidade superficial do gás na Fig. 5.17. A Tabela 5.3 ilustra as correspondências entre as velocidades superficiais e os números de Reynolds.

Observa-se na 5.17 que a espessura do filme diminui com o aumento da velocidade superficial do gás, e essa tendência foi capturada corretamente pelos dois modelos. Para velocidades superficiais do gás mais baixas, ocorre um maior espalhamento dos dados numéricos com relação aos dados experimentais, i.e., dependendo do número de Reynolds do líquido, os dados são sub- ou super-estimados. Para os casos de altas velocidades superficiais do gás, os 

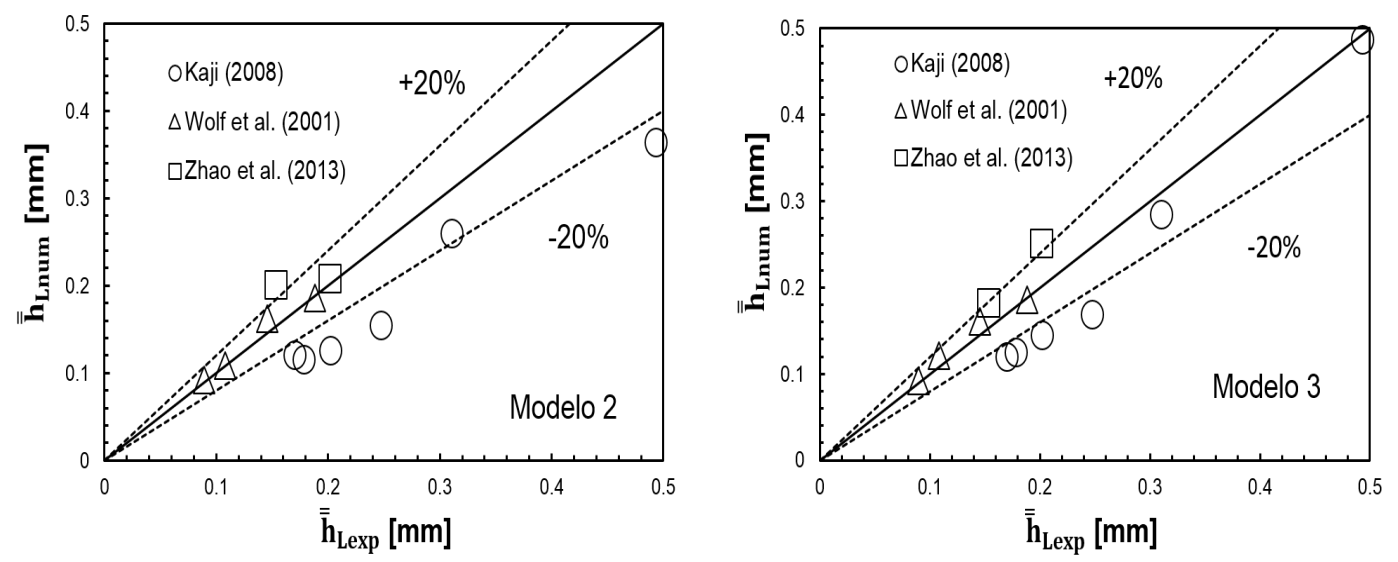

Figura 5.16: Comparação entre espessura média do filme experimental e numérica

Tabela 5.3: Reynolds Superficiais

\begin{tabular}{ccccc}
\hline Configuração & $U_{s G}[\mathrm{~m} / \mathrm{s}]$ & $U_{s L}[\mathrm{~m} / \mathrm{s}]$ & $R e_{s G}$ & $R e_{s L}$ \\
\hline I & 29,42 & 0,0175 & 68.420 & 603 \\
Zhao et al. $(2013)$ & 40,10 & 0,0175 & 93.300 & 603 \\
\hline II & 29,72 & 0,01 & 103.044 & 317 \\
Wolf et al. (2001) & 60,74 & 0,01 & 210.595 & 317 \\
& 31,43 & 0,02 & 108.973 & 635 \\
& 63,42 & 0,02 & 219.887 & 635 \\
\hline Kaji $(2008)$ & 22,30 & 0,03 & 41.493 & 569 \\
& 24,36 & 0,03 & 45.327 & 569 \\
& 31,42 & 0,03 & 58.463 & 569 \\
& 33,92 & 0,03 & 63.115 & 569 \\
& 24,49 & 0,10 & 45.568 & 1.897 \\
& 23,51 & 0,25 & 43.745 & 4.741 \\
\hline
\end{tabular}

dois modelos apresentam resultados coincidentes entre si e com os dados experimentais.

Conforme ilustrado nos mapas de padrão de escoamento das Figs. 5.1 e 5.2, com a diminuição da velocidade superficial do gás, mantendo aproximadamente constante a velocidade superficial do líquido, o padrão de escoamento tende a se tornar intermitente, instável, o que pode explicar o maior afastamento entre os dados numéricos e experimentais observados para as velocidades superficiais mais baixas do gás.

Segundo Berna et al. (2014), Zhao et al. (2013), entre outros autores, a espessura do filme e a queda de pressão podem ser afetadas significativamente pelos processos de entranhamento e deposição. Porém, a boa concordância obtida entre os resultados pode ser explicada levando em consideração, que os casos avaliados encontram-se em uma região onde estes fenômenos, que não estão sendo considerados, provavelmente não afetam as variáveis avaliadas de 


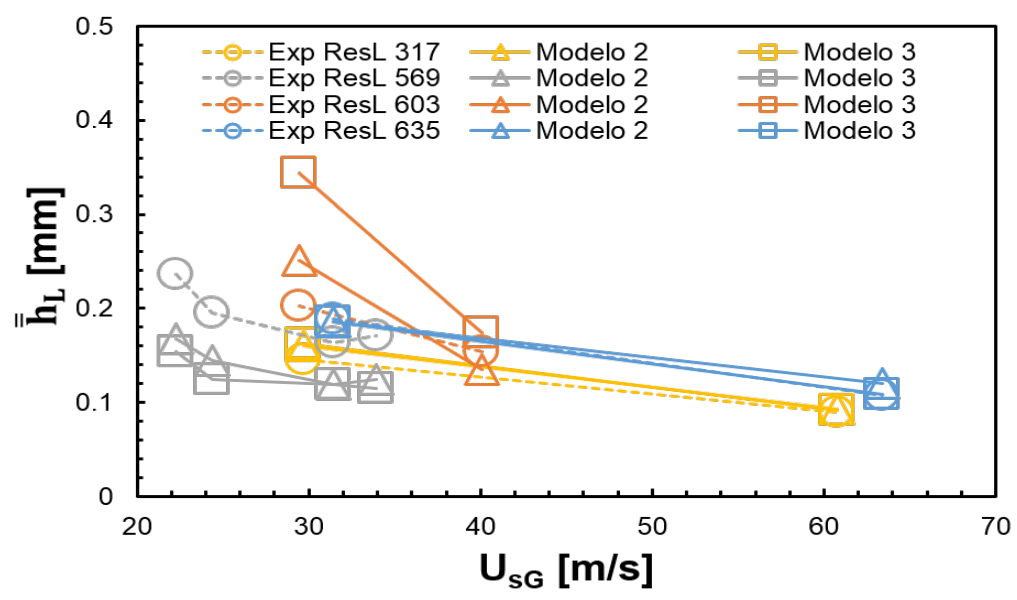

Figura 5.17: Comparação entre espessura média do filme experimental e numérica em função da velocidade superficial de gás, para diferentes $R e_{s L}$.

forma relevante, como observou-se nas Figs. 5.1 e 5.2.

A evolução temporal da espessura de filme de líquido local, $h_{L}$, foi medida por Zhao et al. (2013), para o Caso A, em diferentes coordenadas axiais $x_{1}=$ 0,62 m, $x_{2}=0,92 \mathrm{~m}$ e $x_{3}=2,00 \mathrm{~m}$. A Fig. 5.18 apresenta uma comparação entre os resultados das previsões numéricas obtidas com os Modelos 2 e 3 de pressão dinâmica e as medidas experimentais de Zhao et al. (2013). Na figura, os valores da espessura média no tempo $\overline{h_{L}}$ em cada coordenada também são apresentados. Observando os dados numéricos e experimentais, verifica-se a existência de uma fina camada de líquido com ondas interfaciais. As grandes ondas, conforme definição de Zhao et al. (2013)(ondas com amplitude 1,6 vezes maior que a espessura média, vide Seção 2.4, são claramente visíveis. Porém, a amplitude das ondas grandes previstas com os Modelos 2 e 3 são muito maiores do que as medidas experimentalmente, sendo aproximadamente 6 vezes maior do que espessura média do filme. Pode-se notar que os valores médios no tempo da espessura de filme $\overline{h_{L}}$ obtidos numericamente para este caso são mais elevados do que os valores experimentais, como reflexo das altas amplitudes das grandes ondas nos casos de Zhao et al. (2013) e Wolf et al. (2001).

As Figs. 5.19 e 5.20 mostram os resultados obtidos pelos Modelos 2 e 3 de pressão dinâmica para o caso de Wolf et al. (2001) de $U_{s G}=60,74 \mathrm{e}$ $U_{s L}=0,01 \mathrm{~m} / \mathrm{s}$ e de Kaji (2008) com $U_{s G}=24,36 \mathrm{~m} / \mathrm{s}$ e $U_{s L}=0,03 \mathrm{~m} / \mathrm{s}$ para diferentes posições na coordenada axial. Observa-se a existência da camada fina de líquido com ondas interfaciais de amplitude muito maior que a espessura do filme de líquido. Pode-se observar como a espessura média do filme diminui para coordenadas mais próximas à saída. Observa-se que os valores experimentais de espessura média do filme para os casos de Kaji (2008) (Configuração III) são 
mais elevados do que os obtidos numericamente, com comportamento oposto ao observado nos casos das Configurações I e II. Neste caso, como mencionado anteriormente, a espessura média do filme de líquido é calculado com base no valor experimental da fração volumétrica de líquido total, i.e., englobando o líquido presente no filme e líquido disperso como gotículas no núcleo de gás.

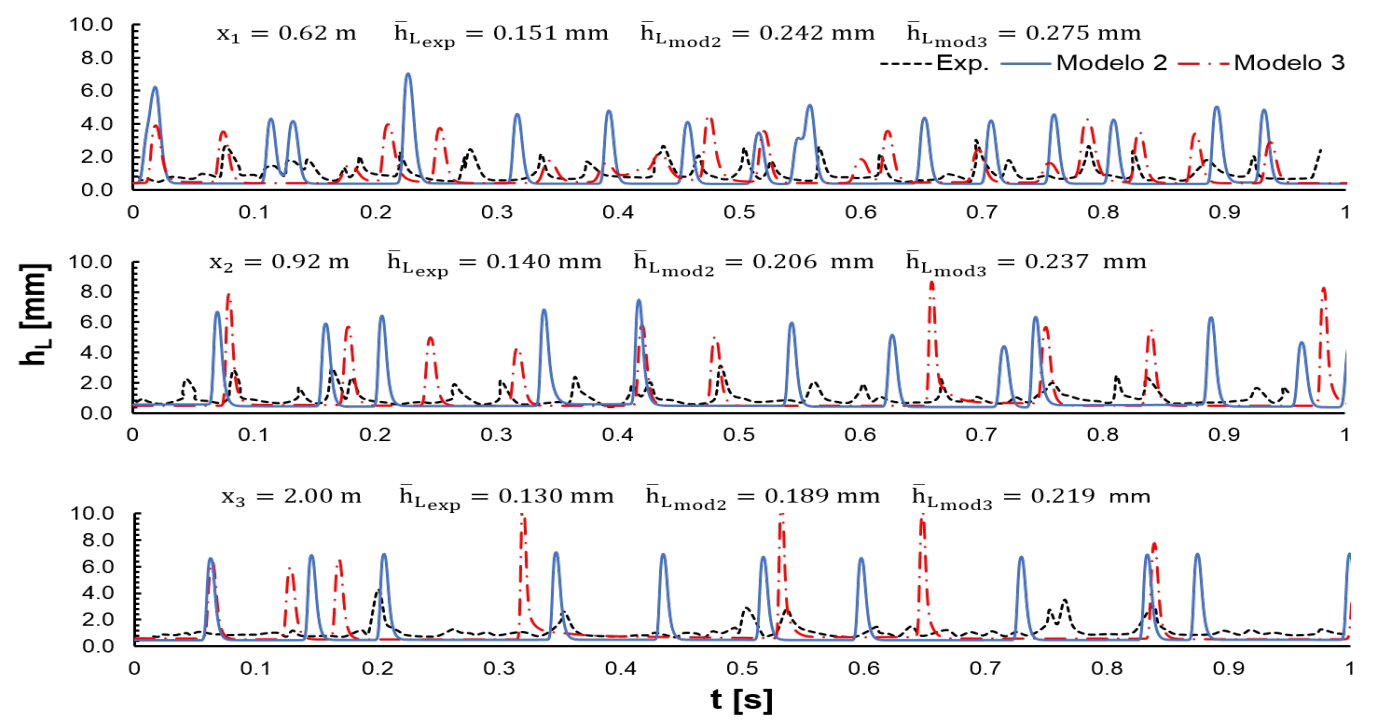

Figura 5.18: Evolução temporal da espessura de filme de líquido local adimensional, $h_{L}$ Configuração I. Caso A. (Zhao et al., 2013).

A variação ao longo da tubulação da média temporal da espessura do filme $\left(\overline{h_{L}}\right)$, correspondente ao Caso A (configuração I, $D_{i}=0,034 \mathrm{~m}$ ) é apresentada na Fig. 5.21(a), enquanto a Fig. 5.21(b) corresponde ao Caso B (configuração II, $D_{i}=0,019 \mathrm{~m}$ ). Os resultados obtidos com os 2 modelos de pressão dinâmica são comparados com os dados experimentais. Nota-se em ambos casos, o decaimento da espessura do filme ao longo da tubulação, e a mesma tendência foi prevista corretamente pelos dois modelos.

Conforme discutido por (Zhao et al., 2013), observa-se na Figs. 5.21(a) referente ao Caso A, que a espessura do filme é menor para distâncias axiais maiores a $25 \mathrm{D}$, permanecendo aproximadamente constante. No entanto, como já apresentado nas Figs. 5.6(b) e 5.7(b), enquanto a espessura do Caso A é super avaliada, o inverso pode ser observado para o Caso B (com menor velocidade superficial do gás). O perfil da espessura do filme na Fig. 5.18, Caso A, permite observar uma relação entre a amplitude das ondas grandes e a espessura de filme médio, indicando que a maior espessura do filme de líquido é devido contribuição excessiva das ondas grandes.

A ondulação na interface do filme apresenta ondas de pequena amplitude e ondas grandes, as quais viajam com frequências diferentes. A ondas grandes 


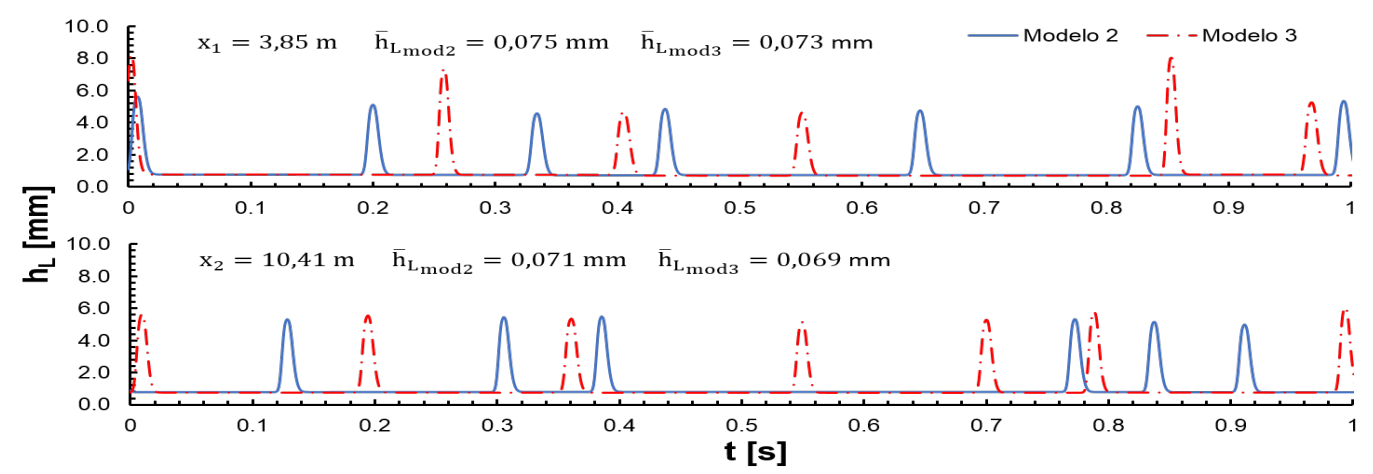

Figura 5.19: Evolução temporal da espessura de filme de líquido local adimensional, $h_{L}$ Configuração II. (Wolf et al., 2001).
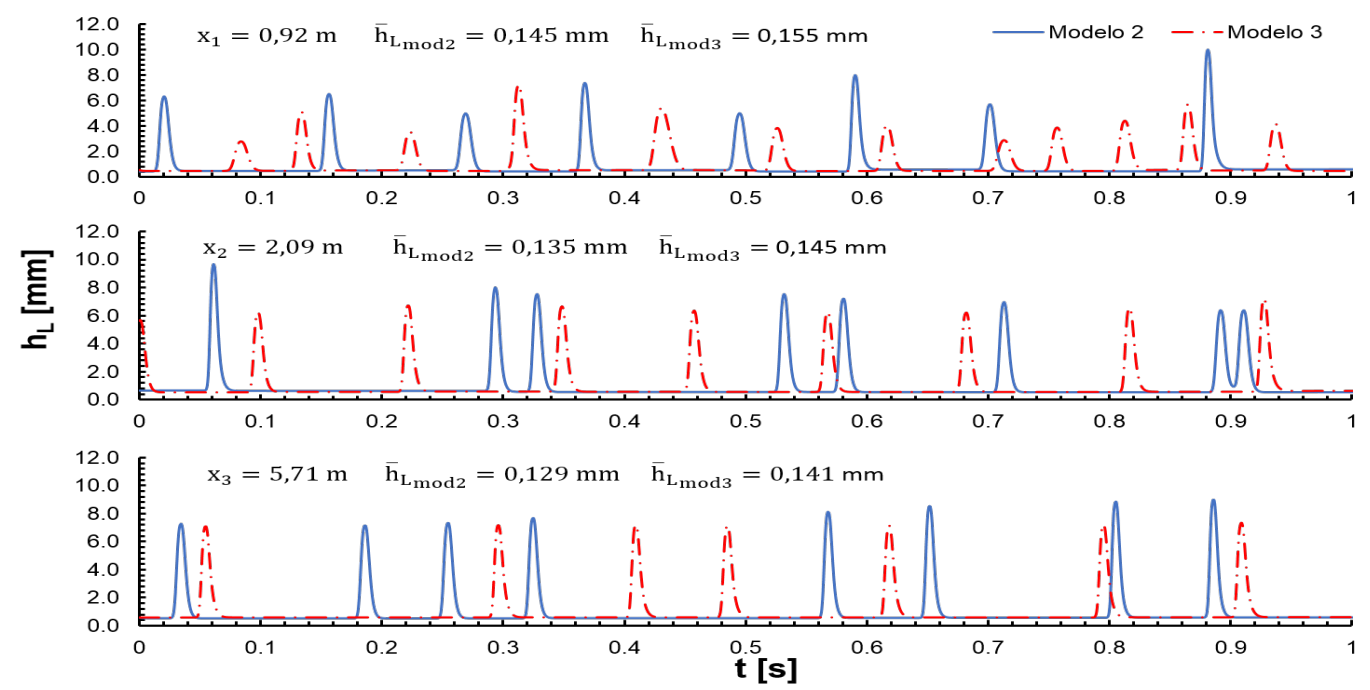

Figura 5.20: Evolução temporal da espessura de filme de líquido local adimensional, $h_{L}$ Configuração III. Caso B. (Kaji, 2008).

são claramente visíveis, conforme ilustrado na Fig. 5.18. Como foi relatado no Cap. 2, a frequência das ondas grandes $\left(\nu_{\mathrm{OG}}\right)$ é calculada contando as ondas em um intervalo de tempo. Por outro lado, a frequência da estrutura (frequência dominante), $\nu_{\mathrm{PSD}}$, é obtida pelo máximo valor do Power Spectral Density (PSD), , ou densidade espectral de potência do sinal, para diferentes posições.

A Fig. 5.22 apresenta a densidade espectral de potência do sinal, PSD, correspondente à configuração I (Caso A) nas mesmas três coordenadas axiais apresentadas na Fig. 5.18. Os dados numéricos obtidos com os Modelos 2 e 3 são comparados com os dados experimentais de Zhao et al. (2013). Analisando a figura, nota-se que enquanto os dados experimentais mostram que a amplitude do espectro de potência cai ao longo do duto, numericamente um aumento 


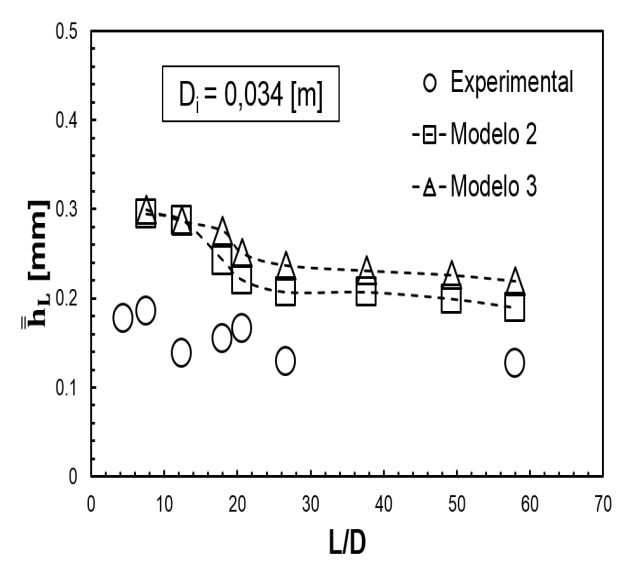

5.21(a): Caso A

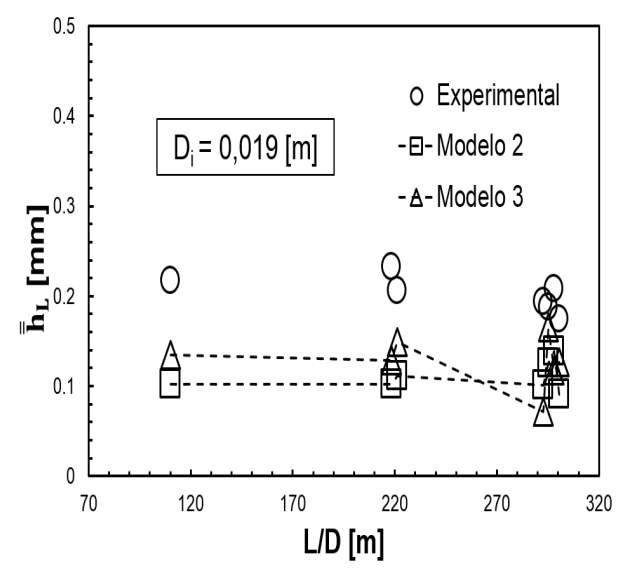

5.21(b): Caso B

Figura 5.21: Desenvolvimento da espessura do filme ao longo da direção axial é observado para ambos os modelos. Porém, a frequência dominante é pouco afetada. Segundo Zhao et al. (2013) coalescência leva a um incremento da amplitude das ondas, enquanto entranhamento pode levar a uma diminuição na amplitude, vide Fig. 5.22.
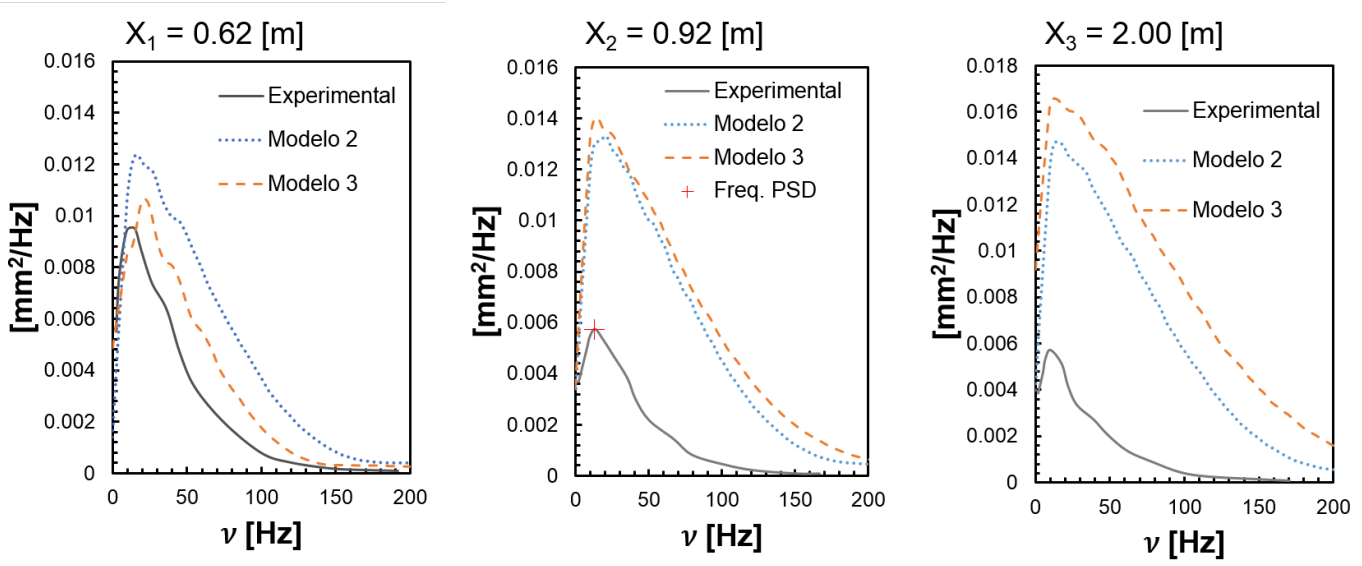

Figura 5.22: Power spectral densities (PSD) do sinal de espessura do filme para diferentes coordenadas axiais. Caso A.

Para melhor avaliar a variação axial da frequência das Ondas Grandes e a frequência da estrutura (PSD) apresenta-se na Fig. 5.23(a) a evolução axial das duas grandezas, para o Caso A. Os dados experimentais de Zhao et al. (2013) são comparados com os dados numéricos obtidos com os 2 modelos. Analisando as figuras, verifica-se que ambas as frequências decaem ao longo do duto. Observa-se uma diminuição significativa da PSD nos primeiros $20 D$ de tubulação até alcançar um valor estável, como foi previamente observado por Zhao et al. (2013). 
A diminuição tanto da frequência das Ondas Grandes como da frequência PSD ocorre (como sugerido por Zhao et al. (2013)) pela coalescência ou rompimento das ondas que leva à entrada de gotículas de líquido dentro do núcleo de gás. Pode-se afirmar que uma boa concordância foi obtida entre os dados numéricos e experimentais, especialmente, para o Modelo 2. Conforme mencionado no parágrafo anterior, constata-se que apesar do decaimento da amplitude do espectro de potência não ter sido capturado corretamente, boa previsão da frequência dominante foi obtida.

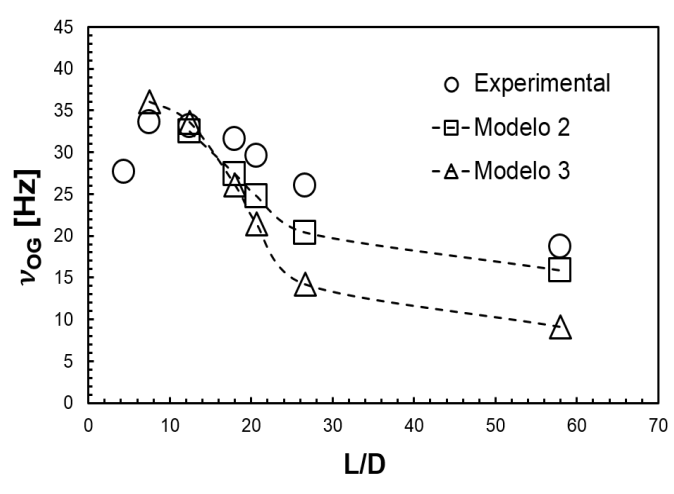

5.23(a): Frequência das Ondas Grandes

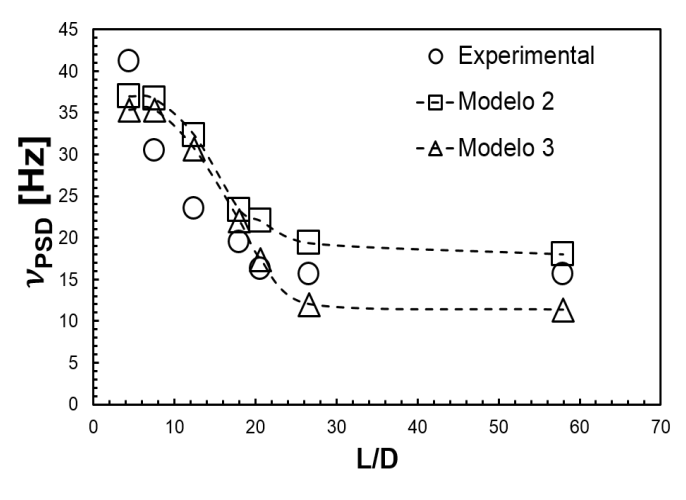

5.23(b): Frequência PSD

Figura 5.23: Desenvolvimento das frequências ao longo da direção axial. Caso A. (Zhao et al., 2013).

Os dados experimentais para a Frequência das Ondas Grandes obtidos pelos trabalhos de Zhao et al. (2013) e Wolf et al. (2001) são comparados na Fig. 5.24 aos resultados numéricos resultantes das previsões obtidas com os Modelos 2 e 3 de pressão dinâmica. Já a comparação da Frequência PSD (frequência das estruturas) com os dados dos trabalhos de Zhao et al. (2013) e Kaji (2008) é apresentada na Fig. 5.25 . Observa-se que boa concordância foi obtida com os 2 modelos para as duas frequências, com discrepâncias inferiores a $20 \%$ na maioria dos casos.

A influência das velocidades superficiais nas frequências de Ondas Grandes e frequências PSD são apresentadas na Fig. 5.26, onde a comparação dos dados experimentais com os resultados obtidos com os Modelos 2 e 3 é incluída. Ambos os modelos reproduziram a tendência de aumento das frequências com o aumento da velocidade superficial do gás. Não é possível afirmar claramente a superioridade de um dos modelos de pressão dinâmica na previsão das frequências. Assim como discutido anteriormente com relação a análise da dependência das velocidades superficiais na espessura média do filme de líquido $\overline{\overline{h_{L}}}$, Fig. 5.17, observa-se mais uma vez que, existe uma boa concordância entre os dados numéricos e experimentais, e não existe uma tendência com relação a concordância entre dados numéricos e experimentais com relação ao número 

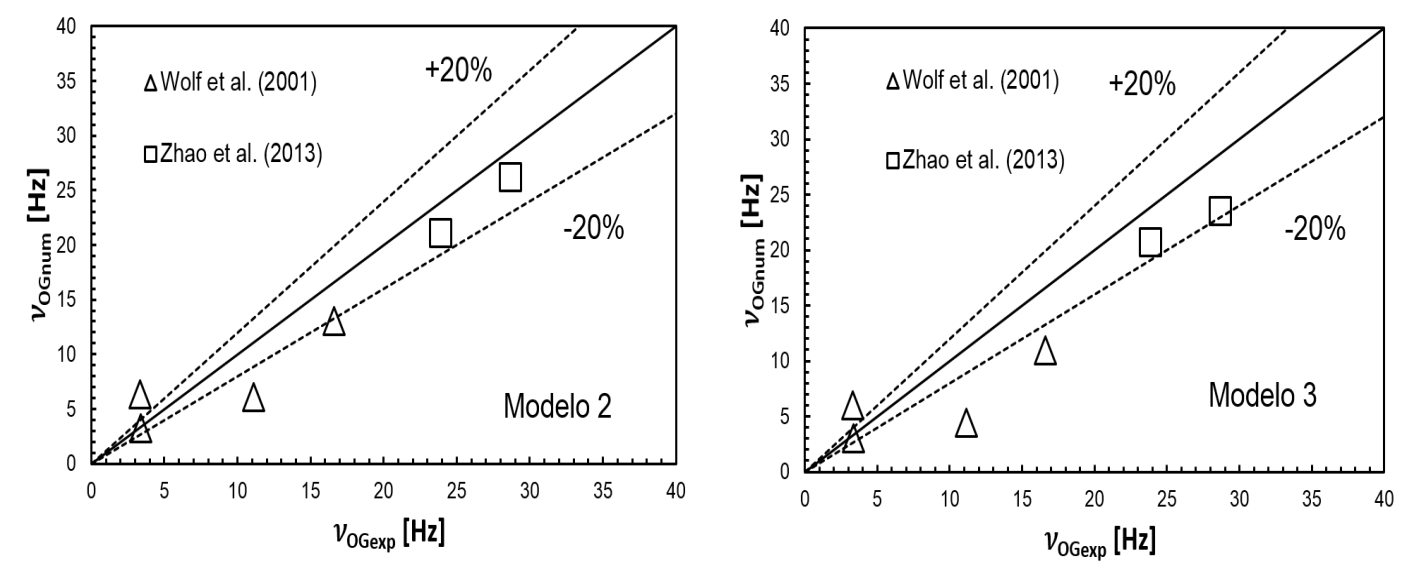

Figura 5.24: Comparação entre Frequência das Ondas Grandes experimental $\times$ numérica para os Modelos 2 e 3
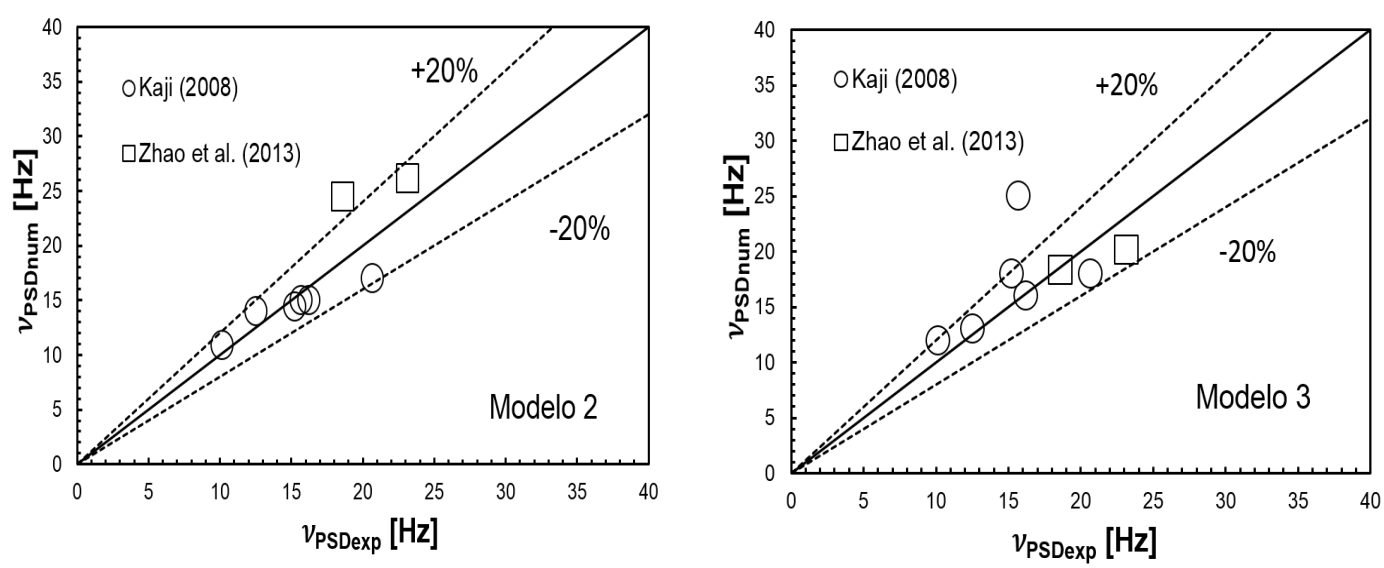

Figura 5.25: Comparação entre Frequência PSD experimental $\times$ numérica para os Modelos 2 e 3

de Reynolds superficial do líquido. Porém, observa-se (de forma inversa ao observado para $\overline{\overline{h_{L}}}$ ) uma deterioração nas predições nos casos de velocidades superficiais do gás maiores.

\subsection{3}

\section{Velocidade da estrutura}

Como discutido anteriormente, os trabalhos experimentais de Kaji (2008) e Wolf et al. (2001) medem a velocidade da estrutura mediante uma correlação cruzada entre dois sinais geradas por sondas separadas de uma determinada distância ao longo do duto. As comparações entre os dados experimentais e resultados numéricos obtidos com os Modelos 2 e 3 são apresentadas na Fig. 5.27. Assim como todos os outros resultados característicos do escoamento anular, a concordância numérico $\times$ experimental foi muito boa, com diferenças 


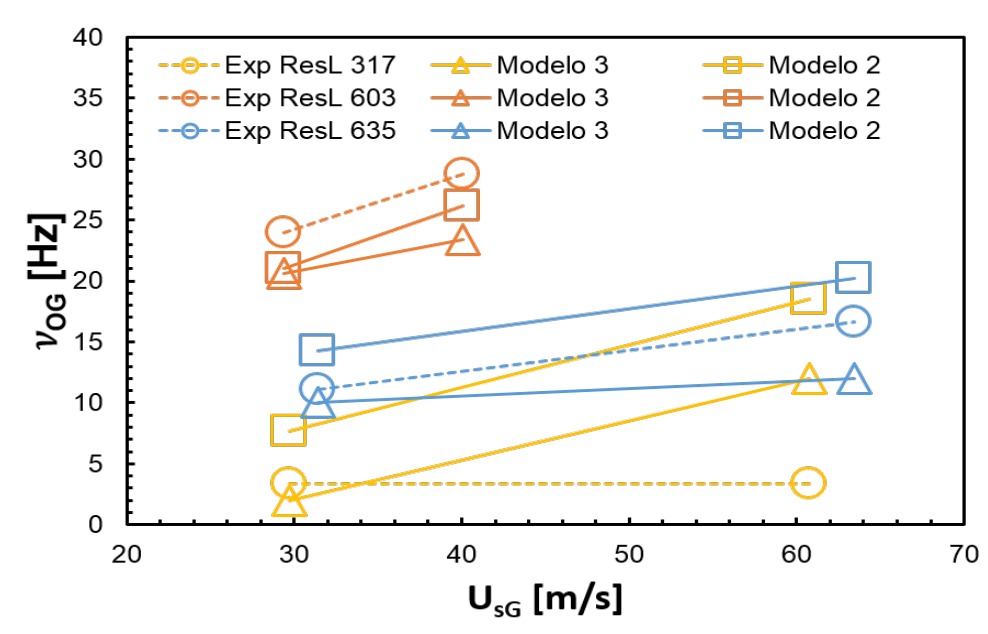

5.26(a): Frequência de Ondas Grandes

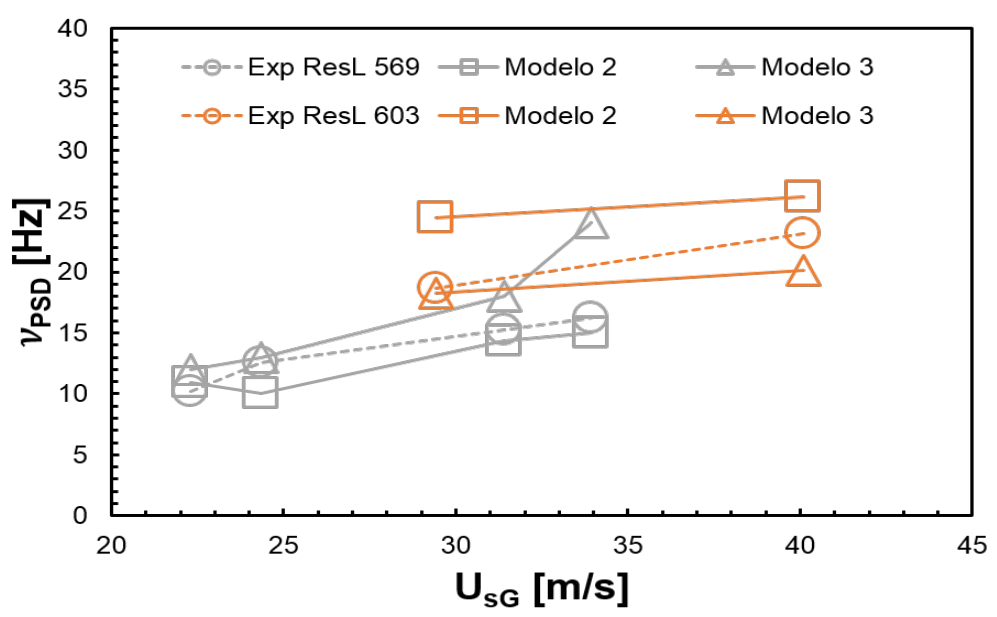

5.26(b): Frequência PSD

Figura 5.26: Comparação entre Frequência PSD experimental e numérica em função da velocidade superficial do gás

inferiores a $20 \%$.

A Fig. 5.28 apresenta a influência das velocidades superficiais na velocidade da estrutura, comparando os resultados numéricos com os dados experimentais. Excelente concordância foi obtida com os 2 modelos, mostrando que o aumento da velocidade superficial do gás induz um aumento da velocidade da estrutura, conforme esperado.

Finalmente, uma comparação entre a velocidade da estrutura experimental, a velocidade da onda calculada pela correlação de Berna et al. (2014) e as velocidades da estrutura calculadas pelos Modelos 2 e 3 é apresentada na Fig. 5.29. De acordo Berna et al. (2014) a correlação apresenta boa concordância com respeito dados experimentais. As velocidades obtidas pelos modelos também apresentam boa concordância com os dados experimentais, confirmando 

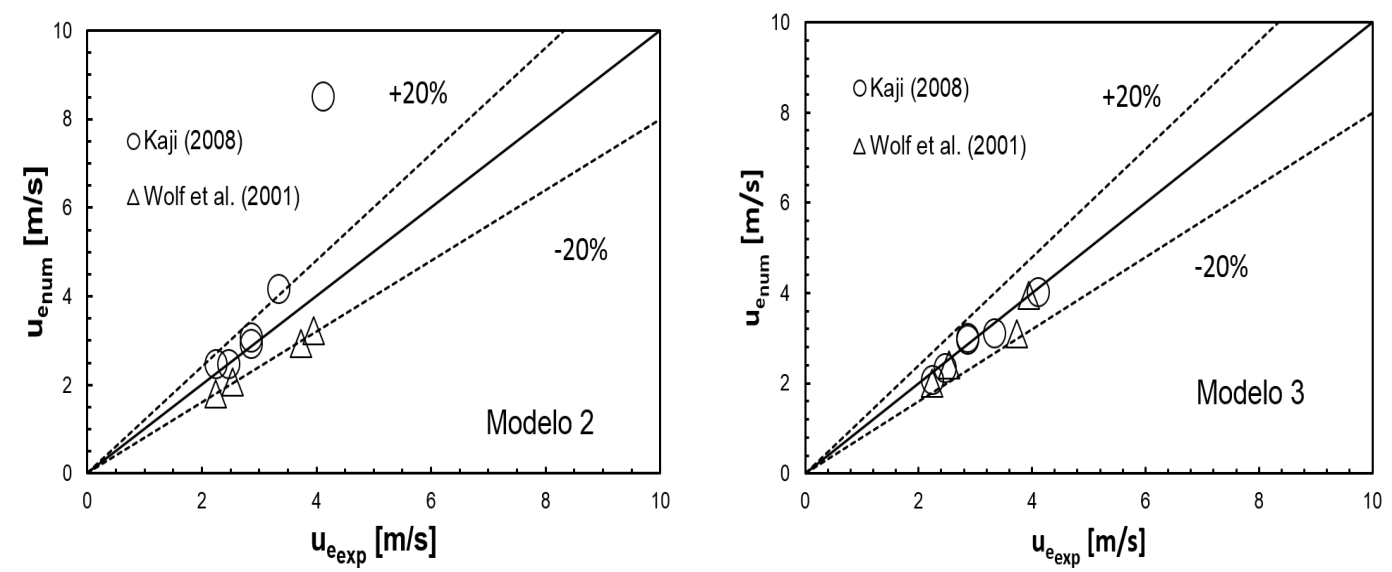

Figura 5.27: Comparação entre velocidade da estrutura experimental e numérica

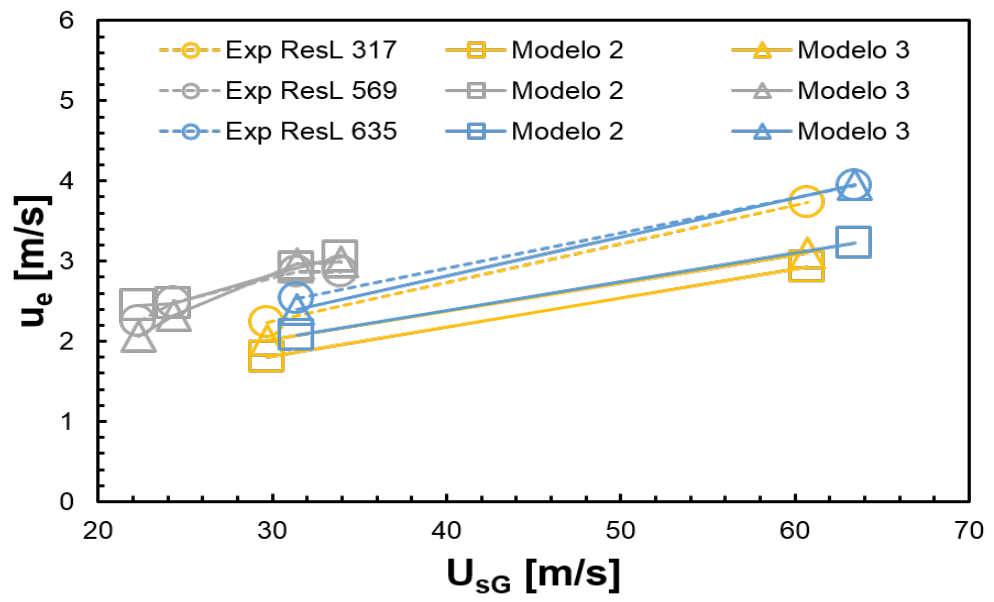

Figura 5.28: Velocidade da estrutura em função da velocidade superficial de gás

o bom desempenho da correlação. Na mesma figura foi incluída a estimativa do valor da velocidade da estrutura proposta por Fowler \& Lisseter (1992), a qual claramente apresenta um desempenho inferior a correlação de Berna et al. (2014).

\section{4 .4}

\section{Dados do escoamento anular}

As Tabelas 5.4 a 5.8 apresentam uma compilação dos resultados apresentados nas seções anteriores. 


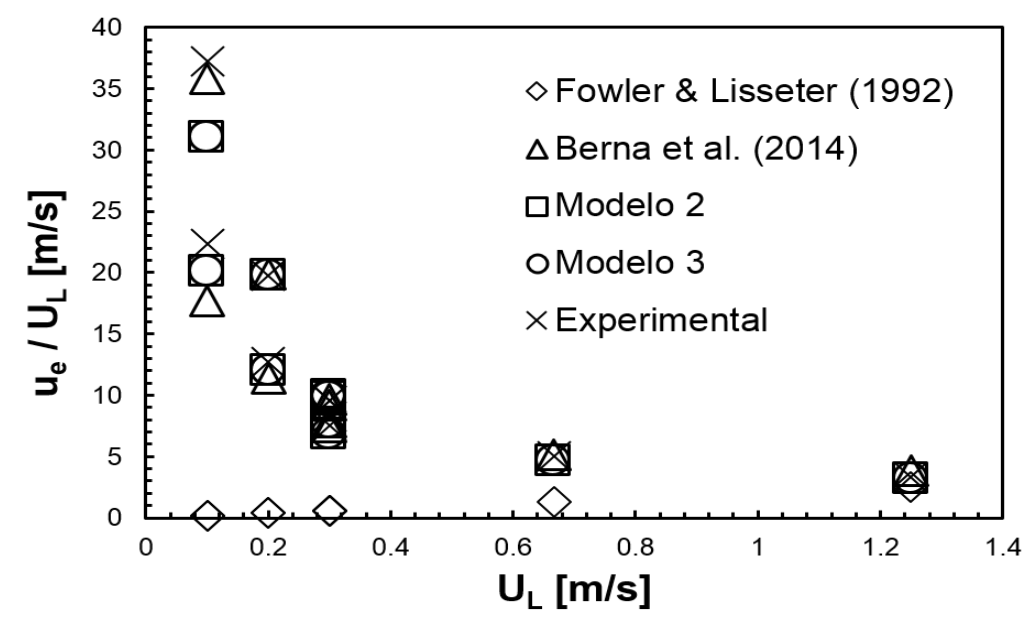

Figura 5.29: Velocidade de deslocamento das ondas em função da velocidade do filme de líquido

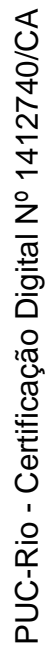

Tabela 5.4: Queda de Pressão

\begin{tabular}{cccccccc}
$\begin{array}{c}\text { Confi- } \\
\text { guração }\end{array}$ & $\begin{array}{c}U_{s G} \\
{[\mathrm{~m} / \mathrm{s}]}\end{array}$ & $\begin{array}{c}U_{s L} \\
{[\mathrm{~m} / \mathrm{s}]}\end{array}$ & $\begin{array}{c}\frac{\Delta P}{\Delta L} \\
{[\mathrm{~Pa} / \mathrm{m}]} \\
\text { exp. }\end{array}$ & $\begin{array}{c}\frac{\Delta P}{\Delta L} \\
{[\mathrm{~Pa} / \mathrm{m}]} \\
\text { Mod. 2 }\end{array}$ & $\begin{array}{c}\text { Erro } \\
\%\end{array}$ & $\begin{array}{c}\frac{\Delta P}{\Delta L} \\
{[\mathrm{~Pa} / \mathrm{m}]} \\
\text { Mod. 3 }\end{array}$ & $\begin{array}{c}\text { erro } \\
\%\end{array}$ \\
\hline $\begin{array}{c}\text { I I } \\
\text { Zhao } \text { et al. } \\
\text { (2013) }\end{array}$ & 29,42 & 0,0175 & 550 & 632 & 15,0 & 803 & 46,0 \\
\hline II & 29,72 & 0,0175 & 900 & 836 & 7,1 & 825 & 8,3 \\
Wolf et al. & 60,74 & 0,01 & 1.166 & 1.054 & 9,6 & 1.049 & 10,0 \\
(2001) & 31,43 & 0,02 & 1.479 & 1.352 & 8,6 & 1.333 & 9,9 \\
& 63,42 & 0,02 & 3.587 & 4.434 & 23,6 & 4.386 & 22,3 \\
\hline III & 22,30 & 0,03 & 1.712 & 1.735 & 1,3 & 1.734 & 1,3 \\
Kaji et al. & 24,36 & 0,03 & 1.875 & 1.880 & 0,3 & 1.927 & 2,8 \\
(2008) & 31,42 & 0,03 & 2.451 & 2.690 & 9,8 & 2.699 & 10,1 \\
& 33,92 & 0,03 & 2.475 & 3.059 & 23,6 & 2.919 & 17,9 \\
& 24,49 & 0,10 & 3.844 & 3.664 & 4,7 & 3.949 & 2,7 \\
& 23,51 & 0,25 & 6.358 & 7.028 & 10,5 & 6.601 & 3,8 \\
\hline
\end{tabular}


Tabela 5.5: Filme de líquido

\begin{tabular}{|c|c|c|c|c|c|c|c|}
\hline $\begin{array}{l}\text { Confi- } \\
\text { guração }\end{array}$ & $\begin{array}{c}U_{s G} \\
{[\mathrm{~m} / \mathrm{s}]}\end{array}$ & $\begin{array}{c}U_{s L} \\
{[\mathrm{~m} / \mathrm{s}]}\end{array}$ & $\begin{array}{c}\overline{\overline{h_{L}}} \\
{[\mathrm{~mm}]} \\
\text { exp. }\end{array}$ & $\begin{array}{c}\overline{\overline{h_{L}}} \\
{[\mathrm{~mm}]} \\
\text { Mod. 2 }\end{array}$ & $\begin{array}{c}\text { Erro } \\
\%\end{array}$ & $\begin{array}{c}\overline{\overline{h_{L}}} \\
{[\mathrm{~mm}]} \\
\text { Mod. } 3\end{array}$ & $\begin{array}{c}\text { erro } \\
\%\end{array}$ \\
\hline I & 29,42 & 0,0175 & 0,202 & 0,207 & 2,6 & 0,251 & 24,2 \\
\hline $\begin{array}{c}\text { Zhao et al. } \\
\text { (2013) }\end{array}$ & 40,10 & 0,0175 & 0,154 & 0,204 & 2,8 & 0,233 & 51,4 \\
\hline II & 29,72 & 0,01 & 0,146 & 0,162 & 11,4 & 0,160 & 10,1 \\
\hline \multirow{3}{*}{$\begin{array}{c}\text { Wolf et al. } \\
\quad(2001)\end{array}$} & 60,74 & 0,01 & 0,089 & 0,092 & 2,8 & 0,092 & 3,3 \\
\hline & 31,43 & 0,02 & 0,188 & 0,186 & 1,3 & 0,186 & 1,3 \\
\hline & 63,42 & 0,02 & 0,108 & 0,109 & 0,8 & 0,121 & 11,7 \\
\hline III & 22,30 & 0,03 & 0,248 & 0,154 & 37,9 & 0,168 & 32,3 \\
\hline \multirow{5}{*}{$\begin{array}{l}\text { Kaji et al. } \\
\quad(2008)\end{array}$} & 24,36 & 0,03 & 0,203 & 0,111 & 45,1 & 0,129 & 36,5 \\
\hline & 31,42 & 0,03 & 0,171 & 0,120 & 29,8 & 0,119 & 30,3 \\
\hline & 33,92 & 0,03 & 0,179 & 0,115 & 35,6 & 0,124 & 30,4 \\
\hline & 24,49 & 0,10 & 0,311 & 0,259 & 16,8 & 0,284 & 8,6 \\
\hline & 23,51 & 0,25 & 0,494 & 0,363 & 26,5 & 0,486 & 1,5 \\
\hline
\end{tabular}

Tabela 5.6: Dados de Frequência das Ondas Grandes

\begin{tabular}{cccccccc}
\hline $\begin{array}{c}\text { Confi- } \\
\text { guração }\end{array}$ & $\begin{array}{c}U_{s G} \\
{[\mathrm{~m} / \mathrm{s}]}\end{array}$ & $\begin{array}{c}U_{s L} \\
{[\mathrm{~m} / \mathrm{s}]}\end{array}$ & $\begin{array}{c}\nu_{O G} \\
{[\mathrm{~Hz}]} \\
\text { exp. }\end{array}$ & $\begin{array}{c}\nu_{O G} \\
{[\mathrm{~Hz}]} \\
\text { Mod. } 2\end{array}$ & $\begin{array}{c}\text { Erro } \\
\%\end{array}$ & $\begin{array}{c}\nu_{O G} \\
{[\mathrm{~Hz}]} \\
\text { Mod. } 3\end{array}$ & $\begin{array}{c}\text { erro } \\
\%\end{array}$ \\
\hline I & 29,42 & 0,0175 & 23,9 & 21,0 & 12,1 & 20,6 & 13,9 \\
$\begin{array}{c}\text { Zhao } \text { et al. } \\
\text { (2013) }\end{array}$ & 40,10 & 0,0175 & 28,7 & 26,1 & 9,0 & 23,4 & 18,6 \\
\hline II & 29,72 & 0,01 & 3,4 & 3,2 & 5,2 & 3,0 & 10,6 \\
Wolf et al. & 60,74 & 0,01 & 3,3 & 6,3 & 89,5 & 6,0 & 80,4 \\
(2001) & 31,43 & 0,02 & 11,1 & 6,1 & 45,4 & 4,4 & 60,2 \\
& 63,42 & 0,02 & 16,6 & 13,1 & 21,3 & 11,0 & 33,9 \\
\hline
\end{tabular}

Tabela 5.7: Dados de Frequência PSD

\begin{tabular}{cccccccc}
\hline $\begin{array}{c}\text { Confi- } \\
\text { guração }\end{array}$ & $\begin{array}{c}U_{s G} \\
{[\mathrm{~m} / \mathrm{s}]}\end{array}$ & $\begin{array}{c}U_{s L} \\
{[\mathrm{~m} / \mathrm{s}]}\end{array}$ & $\begin{array}{c}\nu_{P S D} \\
{[\mathrm{~Hz}]} \\
\text { exp. }\end{array}$ & $\begin{array}{c}\nu_{P S D} \\
{[\mathrm{~Hz}]} \\
\text { Mod. } 2\end{array}$ & $\begin{array}{c}\text { Erro } \\
\%\end{array}$ & $\begin{array}{c}\nu_{P S D} \\
{[\mathrm{~Hz}]} \\
\text { Mod. 3 }\end{array}$ & $\begin{array}{c}\text { erro } \\
\%\end{array}$ \\
\hline I & 29,42 & 0,0175 & 18,6 & 24,4 & 31,3 & 18,3 & 1,8 \\
$\begin{array}{c}\text { Zhao et al. } \\
\text { (2013) }\end{array}$ & 40,10 & 0,0175 & 23,2 & 26,1 & 12,8 & 18,5 & 20,3 \\
\hline III & 22,30 & 0,03 & 10,2 & 10,9 & 7,2 & 12,0 & 17,9 \\
Kaji et al. & 24,36 & 0,03 & 12,6 & 14,0 & 11,4 & 13,0 & 3,5 \\
(2008) & 31,42 & 0,03 & 15,3 & 14,4 & 5,9 & 18,0 & 17,9 \\
& 33,92 & 0,03 & 16,2 & 15,0 & 7,5 & 16,0 & 1,3 \\
& 24,49 & 0,10 & 20,7 & 17,0 & 17,8 & 18,0 & 12,9 \\
& 23,51 & 0,25 & 15,7 & 15,0 & 4,5 & 25,0 & 59,0 \\
\hline
\end{tabular}


Tabela 5.8: Dados de Velocidade da Estrutura

Confi- $U_{s G} \quad U_{s L} \quad u_{e} \quad u_{e} \quad$ Erro $u_{e}$ erro $\begin{array}{llllllll}\text { guração } & {[\mathrm{m} / \mathrm{s}]} & {[\mathrm{m} / \mathrm{s}]} & {[\mathrm{m} / \mathrm{s}]} & {[\mathrm{m} / \mathrm{s}]} & \% & {[\mathrm{~m} / \mathrm{s}]} & \%\end{array}$

\begin{tabular}{cccccccc} 
& & & exp. & Mod. 2 & \multicolumn{3}{c}{ Mod. 3 } \\
\hline II & 29,72 & 0,01 & 2,2 & 1,8 & 19,6 & 2,0 & 10,2
\end{tabular}

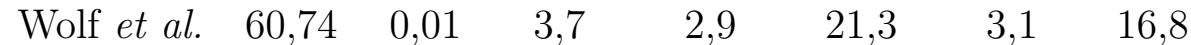

$\begin{array}{llllllll}(2001) & 31,43 & 0,02 & 2,5 & 2,1 & 18,2 & 2,4 & 5,4\end{array}$

\begin{tabular}{cccccccc} 
& 63,42 & 0,02 & 3,9 & 3,2 & 18,3 & 4,0 & 0,1 \\
\hline III & 22,30 & 0,03 & 2,3 & 2,5 & 8,9 & 2,1 & 8,4
\end{tabular}

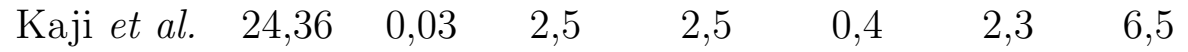

$\begin{array}{llllllll}(2008) & 31,42 & 0,03 & 2,9 & 2,9 & 1,7 & 3,0 & 3,1\end{array}$

$\begin{array}{lllllll}33,92 & 0,03 & 2,9 & 3,1 & 6,3 & 3,0 & 4,2\end{array}$

$\begin{array}{lllllll}24,49 & 0,10 & 3,4 & 4,2 & 23,9 & 3,1 & 7,5\end{array}$

$\begin{array}{lllllll}23,51 & 0,25 & 4,1 & 8,5 & 106,3 & 4,0 & 2,7\end{array}$




\section{6}

\section{Comentários Finais}

Visando analisar escoamentos verticais ascendentes no padrão anular, o Modelo de Dois Fluidos 1D foi selecionado. Uma análise de hiperbolicidade do sistema de equações foi realizada. Confirmou-se que a introdução do parâmetro de fluxo contribui para tornar o sistema de equações bem-posto. Mostrou-se que a introdução de uma pressão dinâmica pode tornar o sistema de equações bem-posto, e consequentemente independente da malha, sem a introdução do parâmetro de fluxo. Dois modelos disponíveis na literatura foram selecionados para serem investigados. O modelo proposto por Fowler \& Lisseter (1992)denominado de Modelo 1 e o modelo proposto por Bestion (1990) (Modelo 2).

No modelo proposto por Fowler \& Lisseter (1992), a pressão dinâmica só atua na equação de conservação de quantidade de movimento do líquido, sendo baseada na diferença entre a velocidade do líquido e a velocidade das ondas interfaciais. Fowler \& Lisseter (1992) propõe um modelo simplificado para avaliar a velocidade da onda. Neste trabalho, foi proposto uma modificação no modelo Fowler \& Lisseter (1992), com a introdução de uma correlação mais realista para avaliar a velocidade das ondas, de acordo com recomendação de Berna et al. (2014). O modelo proposto foi denominado de Modelo 3. No modelo proposto por Bestion (1990), a pressão dinâmica é proporcional a diferença entre a velocidade do gás e do líquido, atuando nas duas equações de conservação de quantidade de movimento.

Mostrou-se que a contribuição da pressão dinâmica do Modelo 1 apesar de ser capaz de tornar o sistema bem posto, a região no mapa de padrões, onde o sistema é bem posto, é muito pequena. Com a melhor avaliação da velocidade da onda do Modelo 2, uma ampliação significativa na região em que o sistema é bem-posto é obtida. O Modelo 3 é sempre bem posto, com a escolha adequada do parâmetro de proporcionalidade entre a pressão dinâmica e a diferença de velocidades.

Para avaliar o desempenho dos modelos de pressão dinâmica na previsão de escoamentos verticais ascendentes, introduziu-se o referido termo em um código numérico desenvolvido pelo grupo de Dinâmica dos Fluidos Computacional do Departamento de Engenharia Mecânica da PUC-Rio. O código foi desenvolvido para a simulação de escoamentos bifásicos com ou sem troca 
de calor ao longo de tubulações, utilizando o Modelo de Dois Fluidos unidimensional, o qual foi vastamente testado e validado. Adicionalmente, visando aumentar a precisão dos resultados obtidos, introduziu-se no código existente um esquema de segunda ordem na discretização do termo de variação espacial das equações de conservação, baseado na metodologia TVD. Testes de validação da metodologia TVD foram realizados, onde contatou-se o aumento na precisão obtida.

O primeiro passo na análise de desempenho dos modelos de pressão dinâmica consistiu em realizar um teste de malha, pois uma das características de um sistema mal-posto é a constante dependência na malha. Com o teste realizado, constatou-se que o efeito do modelo de pressão dinâmica proposto por Fowler \& Lisseter (1992) (Modelo 1) não é significativo para estabilizar o Modelo de Dois Fluidos. Os resultados não apresentaram independência da malha, indicando que o sistema é mal posto. Por outro lado, o Modelo 2 proposto por Bestion (1990) e o Modelo 3 apresentado neste trabalho, apresentaram resultados independentes da malha para as grandezas características do escoamento anular (gradiente de pressão, espessura do filme, frequências de ondas grandes e PSD e velocidade da estrutura). Adicionalmente, obteve-se boa concordância com os valores experimentais. Uma vez que o Modelo 1 não se mostrou efetivo, este foi descartado de avaliações subsequentes.

O desempenho dos Modelos 2 e 3 de pressão dinâmica na previsão de escoamentos verticais ascendentes foi realizada através da comparação com dados experimentais de Zhao et al. (2013), Wolf et al. (2001) e Kaji (2008), permitindo avaliar o desempenho da metodologia para uma ampla faixa de velocidades, assim como para diferentes diâmetros das tubulações.

Mostrou-se que a modelagem conseguiu prever de foma adequada o escoamento no padrão anular, conseguindo representar a formação de ondas interfaciais. Apesar dos bons resultados obtidos, verificou-se que os Modelos 2 e 3 super-estimam a amplitude das grandes ondas. A presente modelagem não incorpora modelos de entranhamento e deposição de gotas, como consequência, na ausência de desprendimento de gotas. Como possível consequência, são maiores do que deveriam, e acabam afetando a avaliação da espessura média do filme de líquido. Outro parâmetro que pode afetar a espessura do filme é o fator de atrito interfacial. Diversas expressões foram propostas na literatura e apenas uma foi utilizada aqui, conforme sugerido por Inácio (2012) e Alves et al. (2012).

Apesar da limitação da modelagem mencionada no parágrafo anterior, pode-se afirmar que excelentes resultados foram obtidos com os dois modelos, os quais apresentaram as corretas tendências com relação a variação das 
velocidades superficiais de gás e líquido. Obteve-se ainda, para ambos os modelos, diferenças inferiores a $20 \%$ para todas as grandezas características do escoamento no padrão anular, o que é bastante aceitável para modelagens $1 \mathrm{D}$.

\section{1}

\section{Sugestão para Trabalhos Futuros}

Como primeira sugestão de trabalhos futuros, recomenda-se avaliar o impacto na precisão da metodologia com a introdução de um esquema de segunda ordem no tempo para avaliar o termo transiente.

A influência na previsão do escoamento dos fatores de atrito deve ser realizada, em especial com relação ao fator de atrito interfacial, conforme realizado por Alves et al. (2012).

No presente estudo, o salto de pressão na interface foi desprezado. Dessa forma, recomenda-se avaliar seu impacto na modelagem, em especial para o caso de escoamento no padrão anular, o qual possui duas curvaturas, na seção transversal e axial.

Como sugestão de trabalhos futuros, recomenda-se incluir relações para o entranhamento e deposição de gotículas da fase líquida no núcleo de gás, o qual auxiliaria numa melhor estimativa numérica da espessura do filme.

Recomenda-se investigar outras combinações de velocidades superficiais, outras configurações de tubulações, assim como outras combinações de fluidos, realizando sempre que possível comparações com dados experimentais.

Sugere-se ainda um estudo detalhado da presença da pressão dinâmica em tubulações horizontais e levemente inclinadas para escoamento anular, assim como em padrões de escoamento diferente ao regime anular. 


\section{7}

\section{Referências Bibliográficas}

ALVES, M. V. C.. 2014. Modelagem numérica do escoamento transiente churn-anular em tubulações verticais e sua aplicação na simulação de carga de líquido em poços de gás. Ph.D. thesis, Universidade Federal de Santa Catarina.

ALVES, M. V. C.; BARBOSA JR, J. ; FALCONE, G.. 2012. Modeling the transient behavior of churn-annular flow in a vertical pipe. 3rd Brazilian Conference on Boiling, Condensation and Multiphase flow, vol. 400.

BAKER, O.. 1954. Design of pipe lines for simultaneous oil and gas flow. Oil Gas J., 26.

BANERJEE, S.; CHAN, A.. 1980. Separated flow models-I. Analysis of the averaged and local instantaneous formulations. International Journal of Multiphase Flow, 6(1), 1-24.

BARNEA, D.. 1987. A unified model for predicting flow-pattern transitions for the whole range of pipe inclinations. International Journal of Multiphase Flow, 13(1), 1-12.

BELT, R.; VAN'T WESTENDE, J.; PRASSER, H. ; PORTELA, L.. 2010. Time and spatially resolved measurements of interfacial waves in vertical annular flow. International Journal of Multiphase Flow, 36(7), 570-587.

BENDAT, J. S.. 1971. Analysis and Measurement Procedures. RANDOM DATA, 407.

BENDIKSEN, K. H.; MAINES, D.; MOE, R.; NULAND, S. ; OTHERS. 1991. The dynamic two-fluid model OLGA: Theory and application. SPE production engineering, 6(02), 171-180.

BERNA, C.; ESCRIVÁ, A.; MUÑOZ-COBO, J. ; HERRANZ, L.. 2014. Review of droplet entrainment in annular flow: Interfacial waves and onset of entrainment. Progress in Nuclear Energy, 74, 14-43.

BESTION, D.. 1990. The physical closure laws in the CATHARE code. Nuclear Engineering and Design, 124(3), 229-245. 
BONIZZI, M.; ISSA, R.. 2003. On the simulation of three-phase slug flow in nearly horizontal pipes using the multi-fluid model. International journal of multiphase flow, 29(11), 1719-1747.

BONIZZI, M.. 2003. Transient one-dimensional modelling of multiphase slug flows. Ph.D. thesis, Imperial College London (University of London).

CARNEIRO, J. N. E.. 2006. Simulação Numérica de Escoamentos Bifásicos No Regime de Golfadas em Tubulações Horizontais e Levemente Inclinadas. Dissertação de Mestrado, PUC-RJ.

COURANT, R.; LAX, P.. 1949. On nonlinear partial differential equations with two independent variables. Communications on Pure and Applied Mathematics, 2(2-3), 255-273.

EMAMZADEH, M.; ISSA, R. I.. 2013. A model for predicting the transition between stratified and annular flow in horizontal pipes. Multiphase Science and Technology, 25(1).

FARIAS, P.; MARTINS, F.; SAMPAIO, L.; SERFATY, R. ; AZEVEDO, L.. 2012. Liquid film characterization in horizontal, annular, two-phase, gasliquid flow using time-resolved laser-induced fluorescence. Experiments in fluids, 52(3), 633-645.

FORE, L. B.; DUKLER, A. E.. 1995. Droplet deposition and momentum transfer in annular flow. AIChE Journal, 41(9), 2040-2046.

FORE, L.; BEUS, S. ; BAUER, R.. 2000. Interfacial friction in gas-liquid annular flow: analogies to full and transition roughness. International journal of multiphase flow, 26(11), 1755-1769.

FOWLER, A.; LISSETER, P.. 1992. Flooding and flow reversal in annular two-phase flows. SIAM Journal on Applied Mathematics, 52(1), 15-33.

GALLENI, F.; ISSA, R. I.. 2015. Linear stability analysis of the discretized one-dimensional two-fluid model equations for slug capturing in vertical flow. Multiphase Science and Technology, 27(2-4), 215-227.

GHAJAR, A. J.; TANG, C. C.. 2010. Void fraction and flow patterns of twophase gas-liquid flow in various pipe inclinations. HEFAT 2010.

HAN, P.; GUO, L.. 2015. Numerical simulation of terrain-induced severe slugging coupled by hydrodynamic slugs in a pipeline-riser system. International Journal of Heat and Fluid Flow, 56, 355-366. 
HOLMÅs, H.; SIRA, T.; NORDSVEEN, M.; LANGTANGEN, H. ; SCHULKES, R.. 2008. Analysis of a $1 D$ incompressible two-fluid model including artificial diffusion. IMA journal of applied mathematics, 73(4), 651-667.

INÁCIO, J. D. R. G.. 2012. Simulação do Regime Intermitente em Tubulações Verticais Utilizando o Modelo de Dois Fluidos com Diferentes Relações de Fechamento. Dissertação de Mestrado, PUC-RJ.

ISHII, M.; GROLMES, M.. 1975. Inception criteria for droplet entrainment in two-phase concurrent film flow. AIChE Journal, 21(2), 308-318.

ISHII, M.; MISHIMA, K.. 1984. Two-fluid model and hydrodynamic constitutive relations. Nuclear Engineering and design, 82(2), 107-126.

ISHII, M.. 1975. Thermo-fluid dynamic theory of two-phase flow. NASA STI/Recon Technical Report A, 75, 29657.

ISHII, M.; HIBIKI, T.. 2011. Thermo-fluid dynamics of two-phase flow. Springer Science.

ISSA, R.; MONTINI, M.. 2010. The effect of surface tension and diffusion on one-dimensional modelling of slug flow. International Conference on Multiphase Flow.

ISSA, R. I.; GALLENI, F.. 2015. Mechanistic simulation of slug flowin vertical pipes using the one-dimensional two-fluid model. Multiphase Science and Technology, 27(2-4), 229-245.

ISSA, R.; KEMPF, M.. 2003. Simulation of slug flow in horizontal and nearly horizontal pipes with the two-fluid model. International journal of multiphase flow, 29(1), 69-95.

JAYANTI, S.; HEWITT, G. F. ; WHITE, S.. 1990. Time-dependent behaviour of the liquid film in horizontal annular flow. International journal of multiphase flow, 16(6), 1097-1116.

KAJI, R.. 2008. Characteristics of two-phase flow structures and transitions in vertical upflow. Ph.D. thesis, University of Nottingham.

MANDHANE, J.; GREGORY, G. ; AZIZ, K.. 1974. A flow pattern map for gas-liquid flow in horizontal pipes. International Journal of Multiphase Flow, 1(4), 537-553.

MATLAB. 2012. version 7.14.0 (R2012a). Natick, Massachusetts: The MathWorks Inc. 
MCCASLIN, J.; DESJARDINS, O.. 2014. Numerical investigation of gravitational effects in horizontal annular liquid-gas flow. International Journal of Multiphase Flow, 67, 88-105.

MONTINI, M.. 2011. Closure relations of the one-dimensional two-fluid model for the simulation of slug flows. Ph.D. thesis, Imperial College London.

NIECKELE, A. O.; CARNEIRO, J. N. E.; CHUCUYA, R. C. ; AZEVEDO, J. H. P.. 2013. Initiation and Statistical Evolution of Horizontal Slug Flow With a Two-Fluid Model. Journal of Fluids Engineering, 135(12), 121302.

NYDAL, O.; BANERJEE, S.. 1996. Dynamic slug tracking simulations for gas-liquid flow in pipelines. Chemical Engineering Communications, 141(1), 13-39.

ORTEGA, A. J.; NIECKELE, A. O.. 2005. Simulation of horizontal two-phase slug flows using the two-fluid model with a conservative and non-conservative formulation. Anais do COBEM 2005, 18th International Congress of Mechanical Engineering.

OWEN, D.; HEWITT, G.. 1987. An improved annular two-phase flow model. Proceedings of the 3rd International Conference on Multiphase Flow, the Hague, the Netherlands.

PARAS, S.; KARABELAS, A.. 1991. Properties of the liquid layer in horizontal annular flow. International journal of multiphase flow, 17(4), 439-454.

PASqualetTE, M. D. A.; CARneiro, J. N. E.; JOHANSEN, S. T. ; NIECKELE, A. O.. 2015. Numerical simulation of horizontal viscous oil-gas flows in the stratified and slug regimes with the two-fluid model. Proceedings of IV Journeys in Multiphase Flows (JEM 2015).

PATANKAR, S.. 1980. Numerical heat transfer and fluid flow. CRC Press.

PETROBRAS. $2016 . \quad$ Plataformas petrolíferas. https://diariodopresal.wordpress.com/petroleo-e-gas/ ( disponivel Agosto 22 de 2016).

PROSPERETTI, A.; TRYGGVASON, G.. 2007. Computational methods for multiphase flow. Cambridge university press.

ROACHE, P. J.. 1998. (21) Verification and Validation in Computational Science and Engineering. Hermosa Publishers. 
SCHUBRING, D.; SHEDD, T.. 2008. Wave behavior in horizontal annular air-water flow. International Journal of Multiphase Flow, 34(7), 636-646.

SEKOGUCHI, K.; TAKEISHI, M.. 1989. Interfacial structures in upward huge wave flow and annular flow regimes. International journal of multiphase flow, 15(3), 295-305.

SILVA, I. S. F. D.; NIECKELE, A. O.. 2016. Numerical Simulation of Annular Flow in Horizontal Pipes using the Two Fluid Model. Proceedings of 9th International Conference on Multiphase Flow.

SIMÕES, E. F.; CARNEIRO, J. N. E. ; NIECKELE, A. O.. 2014. Numerical prediction of non-boiling heat transfer in horizontal stratified and slug flow by the Two-Fluid Model. International Journal of Heat and Fluid Flow, 47, $135-145$.

SONG, J. H.; ISHII, M.. 2001. On the stability of a one-dimensional two-fluid model. Nuclear engineering and design, 204(1), 101-115.

SWEBY, P. K.. 1984. High resolution schemes using flux limiters for hyperbolic conservation laws. SIAM journal on numerical analysis, 21(5), 995-1011.

TAITEL, Y.; DUKLER, A.. 1976. A model for predicting flow regime transitions in horizontal and near horizontal gas-liquid flow. AIChE Journal, 22(1), $47-55$.

VAN ALBADA, G.; VAN LEER, B. ; ROBERTS JR, W.. 1997. A comparative study of computational methods in cosmic gas dynamics. Pages 95-103 of: Upwind and High-Resolution Schemes. Springer.

VAN LEER, B.. 1974. Towards the ultimate conservative difference scheme. II. Monotonicity and conservation combined in a second-order scheme. Journal of computational physics, 14(4), 361-370.

VERSTEEG, H. K.; MALALASEKERA, W.. 2007. An introduction to computational fluid dynamics: the finite volume method. Pearson Education.

WALLIS, G. B.. 1969. One-dimensional two-phase flow. McGraw-Hill.

WALTRICH, P. J.; FALCONE, G. ; BARBOSA, J. R.. 2013. Axial development of annular, churn and slug flows in a long vertical tube. International Journal of Multiphase Flow, 57, 38-48.

WHALLEY, P.; HEWITT, G. F.. 1978. The correlation of liquid entrainment fraction and entrainment rate in annular two-phase flow. UKAEA Atomic Energy Research Establishment. 
WOLF, A.; JAYANTI, S. ; HEWITT, G.. 2001. Flow development in vertical annular flow. Chemical Engineering Science, 56(10), 3221-3235.

ZHAO, Y.; MARKIDES, C. N.; MATAR, O. K. ; HEWITT, G. F.. 2013. Disturbance wave development in two-phase gas-liquid upwards vertical annular flow. International Journal of Multiphase Flow, 55, 111-129.

ZUBER, N.; FINDLAY, J.. 1965. Average volumetric concentration in twophase flow systems. Journal of heat transfer, 87(4), 453-468. 